\title{
Design and Experimental Results for the S814 Airfoil
}

Dan M. Somers

Airfoils, Incorporated

State College, Pennsylvania

NREL technical monitor: James Tangler

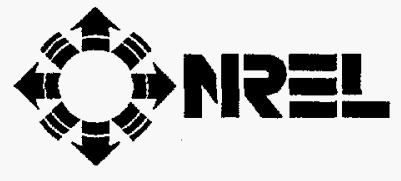

National Renewable Energy Laboratory 1617 Cole Boulevard

Golden, Colorado 80401-3393

A national laboratory of the U.S. Department of Energy Managed by Midwest Research Institute for the U.S. Department of Energy under contract No. DE-AC36-83CH10093

Work performed under task number WE711110

January 1997 


\section{NOTICE}

This report was prepared as an account of work sponsored by an agency of the United States government. Neither the United States government nor any agency thereof, nor any of their employees, makes any warranty, express or implied, or assumes any legal liability or responsibility for the accuracy, completeness, or usefulness of any information, apparatus, product, or process disclosed, or represents that its use would not infringe privately owned rights. Reference herein to any specific commercial product, process, or service by trade name, trademark, manufacturer, or otherwise does not necessarily constitute or imply its endorsement, recommendation, or favoring by the United States govemment or any agency thereof. The views and opinions of authors expressed herein do not necessarily state or reflect those of the United States government or any agency thereof.

Available to DOE and DOE contractors from:

Office of Scientific and Technical Information (OSTI)

P.O. Box 62

Oak Ridge, TN 37831

Prices available by calling (423) 576-8401

Available to the public from:

National Technical Information Service (NTIS)

U.S. Department of Commerce

5285 Port Royal Road

Springfield, VA 22161

(703) 487-4650 


\section{DISCLAMMER}

Portions of this document may be illegible in electronic image products. Images are produced from the best available original document. 


\section{Forward}

Validation of the Eppler Airfoil Design and Analysis Code has been a goal of several NREL-sponsored, two-dimensional investigations in the low-turbulence wind tunnel of the Delft University of Technology Low Speed Laboratory, The Netherlands. Initial validation of the code with respect to wind-turbine airfoils was based on data acquired for low maximum-lift-coefficient airfoils of the thin- and thick-airfoil families. The first of these tests was conducted in 1985 upon completion of the design effort for a thin-airfoil family for stall-regulated rotors. The primary airfoil of this family, the 13.5-percent-thick $\$ 805$, was tested and the results showed that the Eppler Code predicted all the section characteristics well except the profile drag coefficient. The drag coefficient was under predicted as a result of underestimating the significance of the laminar separation bubbles, through which the laminar flow transitioned to turbulent flow. The design of the subsequent thick-airfoil family included an adjustment to the design methodology that accounted for this bias error. In 1986, this adjustment was verified in a wind-tunnel test of the 21-percent-thick S809, the primary airfoil of this thick-airfoil family. Through these tests, the Eppler Code was "validated" so future airfoils, of moderate thickness, can be designed with greater confidence. For wind-turbine blades, moderate-thickness airfoils are typically used for the outboard portion of the blade.

The objective of the present wind-tunnel investigation is to verify the predictions of the Eppler Code for a very thick airfoil having a high maximum lift coefficient designed to be largely insensitive to leading-edge roughness effects. The 24-percent-thick S814 airfoil was designed with these characteristics to accommodate aerodynamic and structural considerations for the root region of a wind-turbine blade. In addition, the maximum lift-to-drag ratio was designed to occur at a high lift coefficient. To accomplish the objective, a two-dimensional, wind-tunnel test of the S814 airfoil was conducted in 1994 in the lowturbulence wind tunnel of the Delft University of Technology. Through this test, the Eppler Airfoil Design and Analysis Code was found to significantly over predict the maximum lift coefficient of this airfoil and demonstrated the need for further validation of the Eppler Code so future airfoils, of large thickness and maximum lift coefficient can be designed with greater confidence.

\footnotetext{
$\frac{\text { Lames } \searrow \text { Tangler }}{\text { James L. Tangler }}$

Wind Technology Division

National Renewable Energy Laboratory

1617 Cole Blvd.

Golden, Colorado 80401 USA

Internet Address: tanglerj@tcplink.nrel.gov

Phone 303-384-6934

FAX 303-384-6901
} 


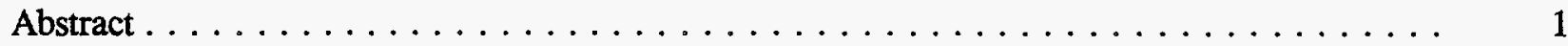

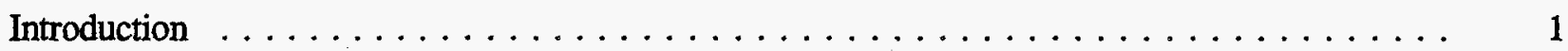

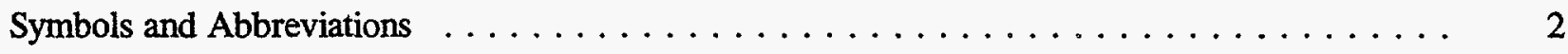

Airfoil Design $\ldots \ldots \ldots \ldots \ldots \ldots \ldots \ldots \ldots \ldots \ldots \ldots \ldots \ldots \ldots \ldots \ldots \ldots$

Experimental Procedure $\ldots \ldots \ldots \ldots \ldots \ldots \ldots \ldots \ldots \ldots \ldots \ldots \ldots \ldots \ldots \ldots \ldots$

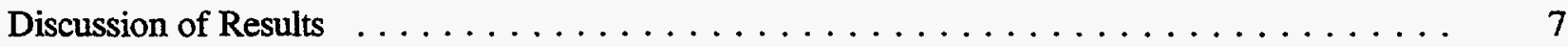

Concluding Remarks $\quad \ldots \ldots \ldots \ldots \ldots \ldots \ldots \ldots \ldots \ldots \ldots \ldots \ldots \ldots \ldots$

Acknowledgments $\ldots \ldots \ldots \ldots \ldots \ldots \ldots \ldots \ldots \ldots \ldots \ldots \ldots \ldots \ldots \ldots \ldots \ldots$

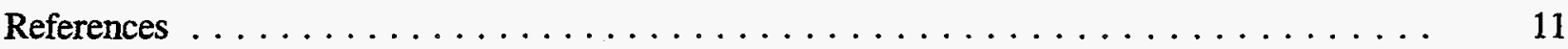

Table 1. Airfoil Design Specifications $\ldots \ldots \ldots \ldots \ldots \ldots \ldots \ldots \ldots \ldots \ldots \ldots \ldots \ldots$

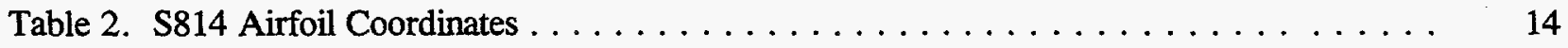

Table 3. Model Orifice Locations . . . . . . . . . . . . . . . . . . . . . 15

Table 4. Roughness Location and Size . . . . . . . . . . . . . . . . 17 
1. Inviscid, incompressible pressure distributions $\ldots \ldots \ldots \ldots \ldots \ldots \ldots \ldots$

2. S814 airfoil shape . . . . . . . . . . . . . . . . . . . . . . 19

3. Delft University of Technology $1.80-\times 1.25-\mathrm{m}$ low-speed wind tunnel . . . . . . . . . 20

4. Model and wake rakes mounted in test section (dimensions in $\mathrm{mm}$ ) . . . . . . . . 21

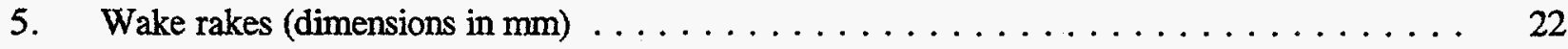

6. Wake-rake, static-pressure and total-pressure tubes (dimensions in $\mathrm{mm}$ ) . . . . . . 23

7. Pressure distributions for $\mathrm{R}=1.5 \times 10^{6}$ and $\mathrm{M}=0.10$ with transition free . . . . . 24

8. Upper-surface flow visualization at $c_{l}=0.4$ for $\mathrm{R}=1.5 \times 10^{6}$ and $\mathrm{M}=0.10 \ldots 34$

9. Lower-surface flow visualization at $c_{b}=0.4$ for $\mathrm{R}=1.5 \times 10^{6}$ and $\mathrm{M}=0.10 \ldots 35$

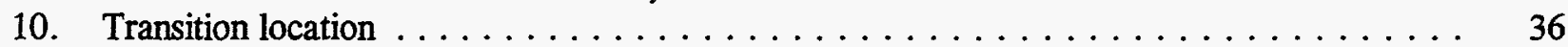

11. Spanwise drag coefficients for $\mathrm{R}=1.5 \times 10^{6}$ and $\mathrm{M}=0.10$ with transition free $\ldots \ldots 41$

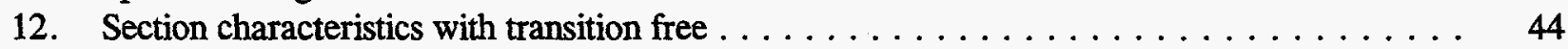

13. Effect of fixing transition on section characteristics. . . . . . . . . . . . . 50

14. Effect of roughness of reference 27 on section characteristics $\ldots \ldots \ldots \ldots \ldots \ldots \ldots$

15. Effect of roughness on maximum lift coefficient $\ldots \ldots \ldots \ldots \ldots \ldots \ldots \ldots$

16. Comparison of theoretical and experimental pressure distributions . . . . . . . . . . 60

17. Comparison of theoretical and experimental section characteristics with transition

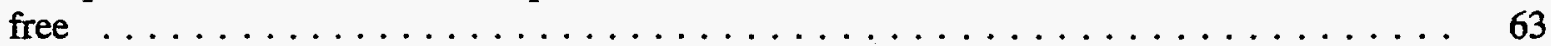

18. Comparison of theoretical and experimental section characteristics with transition

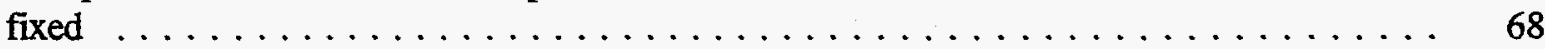

19. Comparison of experimental section characteristics of $\$ 814$ and NACA 4424 airfoils for $\mathrm{R}=3.0 \times 10^{6}$ with transition free $\ldots \ldots \ldots \ldots \ldots \ldots \ldots \ldots$

20. Comparison of experimental section characteristics of S814 and NACA 23024 airfoils for $\mathrm{R}=3.0 \times 10^{6}$ with transition free $\ldots \ldots \ldots \ldots \ldots \ldots \ldots$ 


\title{
Design and Experimental Results for the S814 Airfoil
}

\author{
Dan M. Somers $\dagger$ \\ June 1994
}

\begin{abstract}
A 24-percent-thick airfoil, the $\$ 814$, for the root region of a horizontal-axis wind-turbine blade has been designed and analyzed theoretically and verified experimentally in the low-turbulence wind tunnel of the Delft University of Technology Low Speed Laboratory, The Netherlands. The two primary objectives of high maximum lift, insensitive to roughness, and low profile drag have been achieved. The constraints on the pitching moment and the airfoil thickness have been satisfied. Comparisons of the theoretical and experimental results show good agreement with the exception of maximum lift which is overpredicted. Comparisons with other airfoils illustrate the higher maximum lift and the lower profile drag of the S814 airfoil, thus confirming the achievement of the objectives.
\end{abstract}

\section{Introduction}

The majority of the airfoils in use on horizontal-axis wind turbines today were originally developed for aircraft. The design requirements for these airfoils, primarily National Advisory Committee for Aeronautics (NACA) and National Aeronautics and Space Administration (NASA) airfoils (refs. 1-6), are significantly different from those for wind-turbine airfoils (ref. 7). Accordingly, several families of airfoils have been designed specifically for stall-regulated, horizontal-axis wind-turbine applications (refs. 8-13).

The airfoil designed under the present study, the $S 814$ (ref.10), is intended for the root region of a horizontal-axis wind-turbine blade. Unlike the $S 811$ (ref. 9), an earlier root airfoil that sacrifices insensitivity to leading-edge roughness in favor of a higher, transition-free, maximum lift coefficient, the S814 airfoil should produce a maximum lift coefficient that is insensitive to roughness. Thus, the S814 airfoil, together with the $\mathbf{S 8 1 5}$ airfoil (ref. 10), is intended to replace the S811 airfoil.

To complement the design effort, the S814 airfoil was selected for experimental verification because it represents a particularly challenging test case for the theoretical method (refs. 14 and 15) due to its large thickness, high maximum lift coefficient, and low Reynolds number. In 1994, an investigation was conducted in the low-turbulence wind tunnel (ref. 16) of the Delft University of Technology Low Speed Laboratory, The Netherlands, to obtain the basic, low-speed, two-dimensional aerodynamic characteristics of this airfoil. The results have been compared with predictions from the method of references 14 and 15 and also with data from another low-turbulence wind tunnel for other airfoils.

The specific tasks performed under this study are described in Solar Energy Research Institute (SERI) Subcontract Number AF-1-11154-1 and National Renewable Energy Laboratory (NREL) Subcontract Number AAH-3-13322-01. The initial specifications for the airfoil are outlined in the SERI subcontract. These specifications were later refined during conversations with James L. Tangler of SERI, now NREL.

† President, Airfoils, Incorporated, State College, Pennsylvania 


\section{Symbols and Abbreviations}

Values are given in both SI and U.S. Customary Units. Measurements and calculations were made in SI Units.

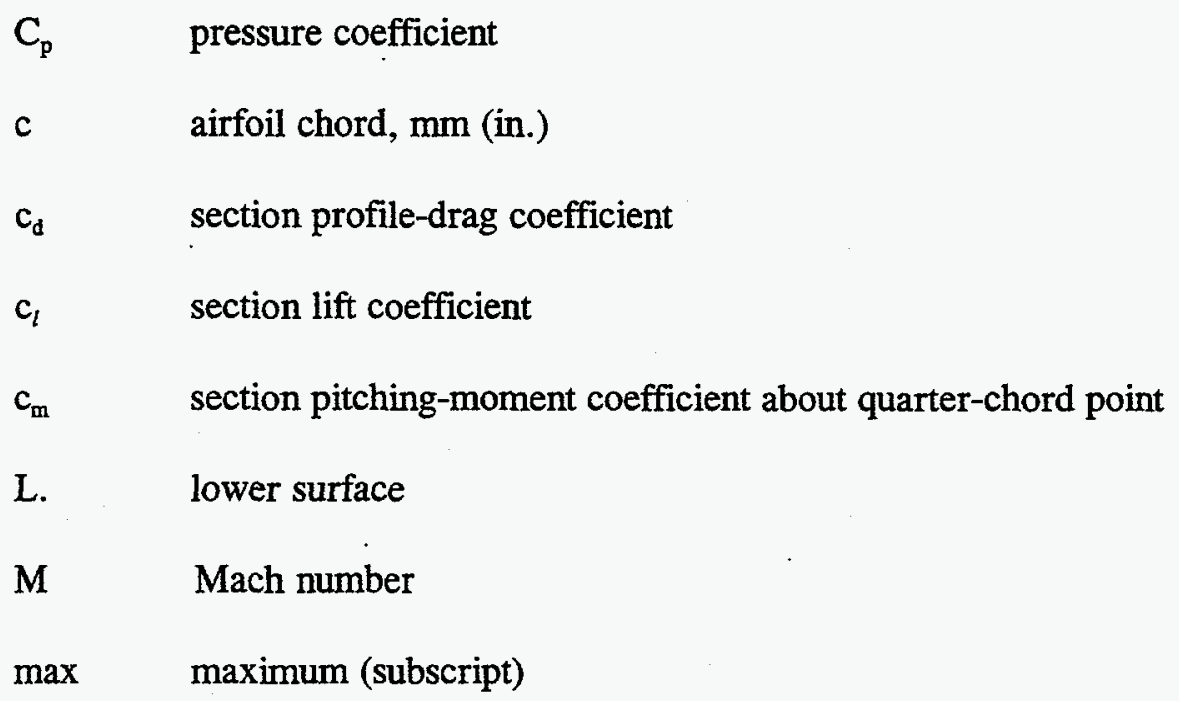




\section{Airfoil Design}

\section{Objectives and Constraints}

The design specifications for the airfoil are contained in table 1 . Two primary objectives are evident. The first objective is to achieve a maximum lift coefficient of at least 1.30 for a Reynolds number of $1.5 \times 10^{6}$, which corresponds to the 0.40 blade radial station. A requirement related to this objective is that the maximum lift coefficient not decrease with transition fixed near the leading edge on both surfaces. The second objective is to obtain low profile-drag coefficients over the range of lift coefficients from 0.6 to 1.2 for the same Reynolds number.

Two major constraints were placed on the design of this airfoil. First, the zero-lift pitching-moment coefficient must be no more negative than -0.15 . Second, the airfoil thickness must be 24-percent chord.

\section{Philosophy}

Given the above objectives and constraints, certain characteristics of the design are apparent. The following sketch illustrates a drag polar that meets the goals for this design.

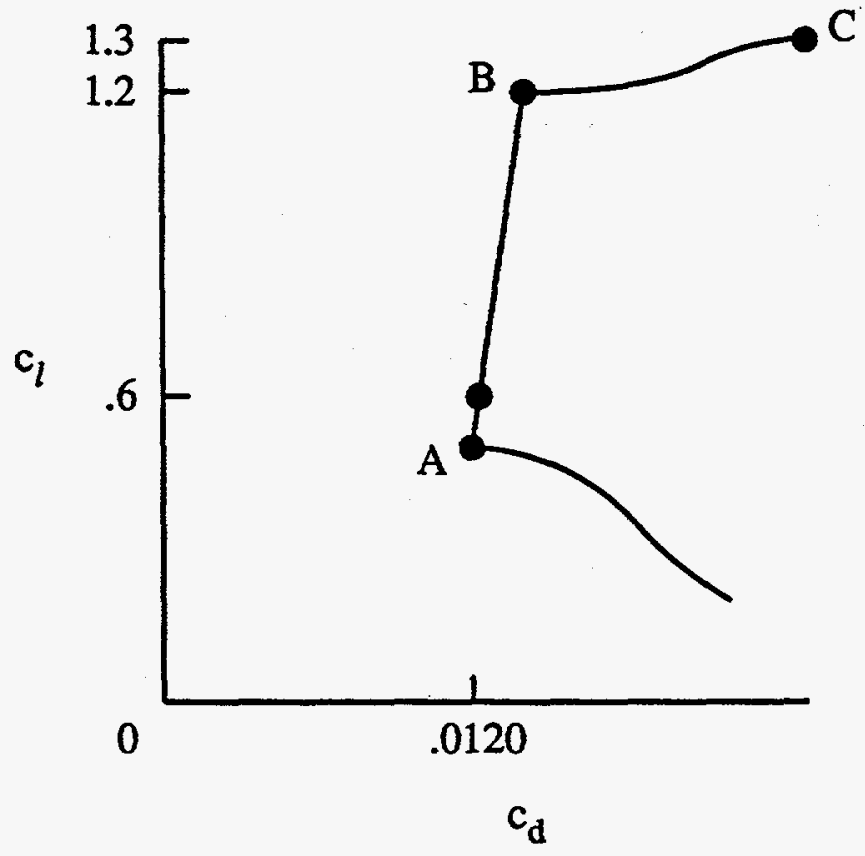

Sketch 1

The desired airfoil shape can be traced to the pressure distributions that occur at the various points in sketch 1. Point $A$ is the lower limit of the low-drag, lift-coefficient range. The lift coefficient at point $A$ is 0.1 lower than the objective specified in table 1 . The difference is intended as a margin against such contingencies as manufacturing tolerances, operational deviations, three-dimensional effects, and inaccuracies in the theoretical method. A similar margin is also desirable at the upper limit of the low-drag range, point $B$, although this margin is constrained by the proximity of the upper limit to the maximum lift coefficient. The drag at point $B$ is not as low as at point $A$, unlike the polars of many laminar-flow airfoils where the drag within the laminar bucket is nearly constant. This characteristic is related to the elimination 
of significant (drag-producing) laminar separation bubbles on the upper surface. (See ref. 17.) It is acceptable because the ratio of the profile drag to the total drag of the wind-turbine blade decreases with increasing lift coefficient. The drag increases very rapidly outside the low-drag range because the boundary-layer transition point moves quickly toward the leading edge with increasing (or decreasing) lift coefficient. This feature results in a leading edge that produces a suction peak at higher lift coefficients, which ensures that transition on the upper surface will occur very near the leading edge. Thus, the maximum lift coefficient, point $C$, occurs with turbulent flow along the entire upper surface and, therefore, should be insensitive to roughness at the leading edge.

Because the large airfoil thickness allows a wider low-drag range than specified, the lower limit of the low-drag range should be well below point $\mathrm{A}$.

From the preceding discussion, the pressure distributions along the polar can be deduced. The pressure distribution at point $\mathrm{A}$ should look something like sketch 2.

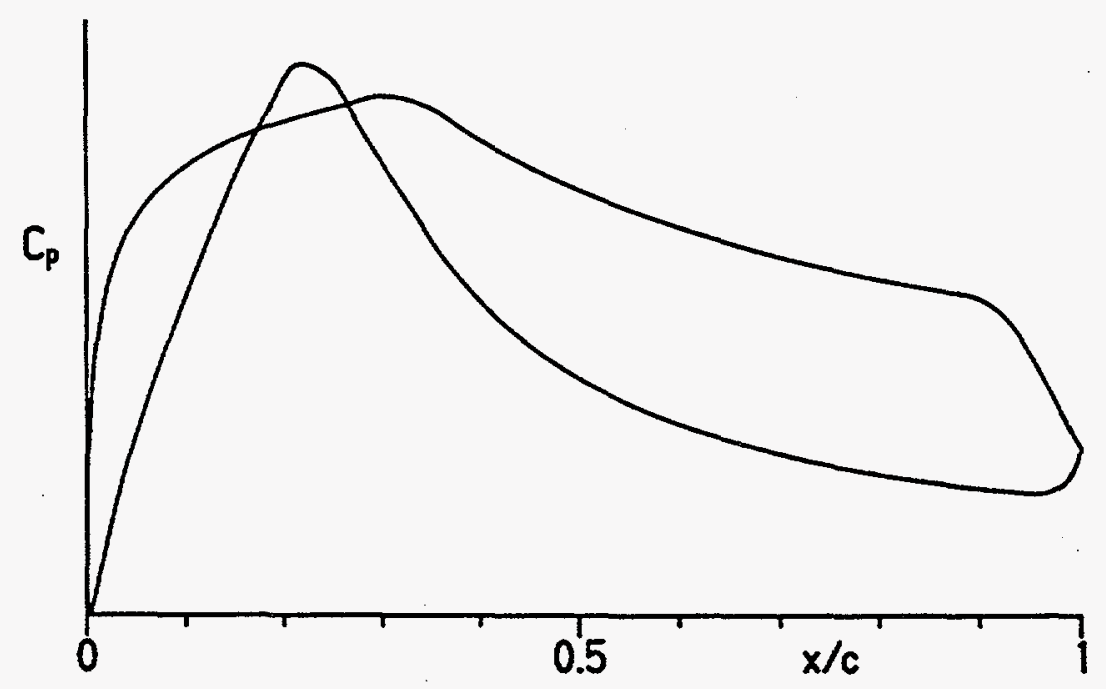

Sketch 2

To achieve low drag, a favorable pressure gradient is desirable along the upper surface to about 30-percent chord. Aft of this point, a short region having a shallow, adverse pressure gradient ("transition ramp") promotes the efficient transition from laminar to turbulent flow (ref. 18). The transition ramp is followed by a concave pressure recovery. The specific pressure recovery employed represents a compromise between maximum lift, drag, and stall characteristics. The steep adverse pressure gradient aft of about 90-percent chord is a "separation ramp," originally proposed by F. X. Wortmann, which confines turbulent separation to a small region near the trailing edge. By constraining the movement of the separation point at high angles of attack, high lift coefficients can be achieved with little drag penalty. This feature has the added benefit of promoting docile stall characteristics. (See ref. 19.)

A favorable pressure gradient is desirable along the lower surface to about 20-percent chord to achieve low drag. The pressure gradients along the forward portion of the lower surface increase the amount of camber in the leading-edge region while maintaining low drag at the lower lift coefficients. The forward camber serves to balance, with respect to the pitching-moment constraint, the aft camber, both of which contribute to the achievement of a high maximum lift coefficient. This region is followed by a curved transition ramp 
(ref. 17) that is longer than the ramp on the upper surface. The transition ramp is followed by a concave pressure recovery that produces lower drag and has less tendency to separate than the corresponding linear or convex pressure recovery (ref. 18). The pressure recovery must begin relatively far forward to alleviate separation at lower lift coefficients, especially with transition fixed near the leading edge.

The amounts of pressure recovery on the upper and lower surfaces are determined by the airfoil-thickness and pitching-moment constraints.

At point $B$, the pressure distribution should look like sketch 3.

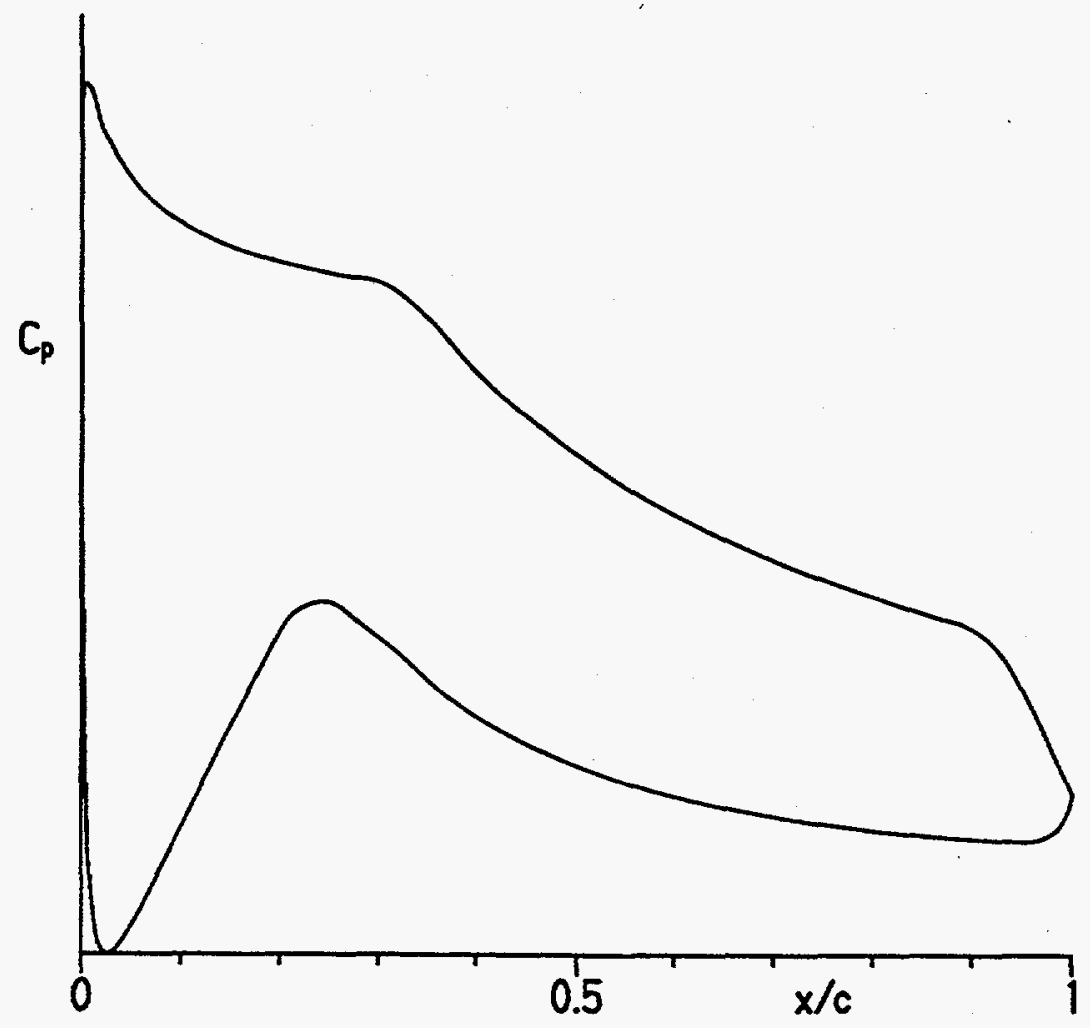

Sketch 3

No suction spike exists at the leading edge. Instead, the peak occurs just aft of the leading edge. Transition is essentially imminent over the entire forward portion of the upper surface. This feature allows a wider low-drag range to be achieved and higher lift coefficients to be reached without significant separation. It also causes the transition point to move very quickly toward the leading edge with increasing lift coefficient, which leads to the roughness insensitivity of the maximum lift coefficient.

\section{Execution}

Given the pressure distributions previously discussed, the design of the airfoil is reduced to the inverse problem of transforming the pressure distributions into an airfoil shape. The Eppler Airfoil Design and Analysis Code (refs. 14 and 15) was used because of its unique capability for multipoint design and because of confidence gained during the design, analysis, and experimental verification of several other airfoils. (See refs. 20-22.) 
The airfoil is designated the S814. The inviscid, incompressible pressure distributions computed by the method of references 14 and 15 for lift coefficients of 0.6 and 1.2 are shown in figure 1 . The airfoil shape is shown in figure 2 and the coordinates are contained in table 2 . The airfoil thickness is 24-percent chord.

\title{
Experimental Procedure
}

\author{
Wind Tunnel
}

The low-turbulence wind tunnel (ref. 16) of the Delft University of Technology Low Speed Laboratory, The Netherlands, is a closed-throat, single-return, atmospheric tunnel (fig. 3). The octagonal test section is $1800 \mathrm{~mm}$ (70.9 in.) wide by $1250 \mathrm{~mm}$ (49.2 in.) high (fig. 4). Electrically actuated turntables provide positioning and attachment for the two-dimensional model. The turntables are flush with the top and bottom tunnel walls and rotate with the model. The axis of rotation coincided with the quarter chord of the model which was mounted vertically between the turntables. The gaps between the model and the turntables were sealed. The turbulence level in the test section varies from 0.02 percent at $10 \mathrm{~m} / \mathrm{s}(30 \mathrm{ft} / \mathrm{s})$ to 0.04 percent at $60 \mathrm{~m} / \mathrm{s}(200 \mathrm{ft} / \mathrm{s})$.

\section{Model}

The composite, wind-tunnel model was constructed by Glasfaser-Flugzeug-Service GmbH, Grabenstetten, Federal Republic of Germany, using aluminum molds milled by the Delft University of Technology. The model consisted of a pseudo spar, two end ribs, and an upper and a lower shell. It had a chord of $650 \mathrm{~mm}$ ( $25.6 \mathrm{in}$.) and a span of $1248 \mathrm{~mm}$ (49.1 in.). Upper- and lower-surface orifices were located to one side of the midspan at the staggered positions listed in table 3 . All the orifices were $0.40 \mathrm{~mm}(0.016 \mathrm{in}$. $)$ in diameter with their axes perpendicular to the surface. Heating elements for the infrared flow-visualization technique were bonded into the upper and lower shells. The surface of the model consisted of polyester gelcoat that had been sanded and polished to ensure an aerodynamically smooth finish. The measured model contour was within $0.07 \mathrm{~mm}$ ( $0.003 \mathrm{in}$.) of the prescribed shape.

\section{Wake Rake}

A total-pressure and a static-pressure wake rake (fig. 5) were mounted on a strut between the tunnel sidewalls (fig. 4). The strut could be positioned spanwise and streamwise in the test section. Movement of the strut along its axis provided positioning of the wake rakes normal to the sidewalls. The rakes employed 67 total-pressure and 21 static-pressure tubes, $1.5 \mathrm{~mm}(0.06 \mathrm{in}$.) in diameter (fig. 6). Each static-pressure tube had four orifices located $90^{\circ}$ apart, 5 tube diameters from the elliptical tip of the tube. The sharp-edged tips of the total-pressure tubes were located 0.55 chord downstream of the trailing edge of the model.

\section{Instrumentation}

Measurements of the basic tunnel pressures, the pressures on the model, and the wake-rake pressures were made by a multitube manometer which was read automatically using fiber-optic photoelectric cells. Data were obtained and recorded by an electronic data-acquisition system. 
Methods

The pressures measured on the model were reduced to standard pressure coefficients and numerically integrated to obtain section normal-force coefficients and section pitching-moment coefficients about the quarter-chord point. Section profile-drag coefficients were computed from the wake-rake total and static pressures by the method of reference 23 .

Standard, low-speed, wind-tunnel boundary corrections (ref. 24) have been applied to the data. The following procedure was used. The uncorrected force, moment, and pressure coefficients were referred to the apparent dynamic pressure as measured tunnel empty at the model position. The lift, profile-drag, pitching-moment, and pressure coefficients and the angle of attack were then corrected by the method of reference 24. Finally, as a check, the corrected pressure distribution was numerically integrated to obtain the corrected normal-force (and pitching-moment) coefficient which, together with the corrected profiledrag coefficient and angle of attack, yields the corrected lift coefficient (and chord-force coefficient).

At angles of attack beyond stall, the total-pressure coefficients measured in the middle of the wake became negative. When this occurred, the drag was obtained using the method of reference 25 . At even greater angles of attack, the wake became wider than the wake rake, at which point, the drag was obtained from a cosine-squared extrapolation of the measured wake pressure distribution.

\section{Tests}

The model was tested at Reynolds numbers based on the airfoil chord from $0.7 \times 10^{6}$ to $3.0 \times 10^{6}$ with transition free (smooth) and with transition fixed by roughness at 2-percent chord on the upper surface and 10-percent chord on the lower surface. The grit roughness was sized using the method of reference 26 and sparsely distributed along 3-mm (0.1-in.) wide strips applied to the model with lacquer. (See table 4.) The model was also tested with a roughness developed for field testing of wind-turbine blades (ref. 27), which consisted of granular roughness, varying in size from $0.38 \mathrm{~mm}(0.015 \mathrm{in}$.) to $0.64 \mathrm{~mm}(0.025 \mathrm{in}$.), sparsely distributed onto $51-\mathrm{mm}(2.0$-in.) wide, $0.05-\mathrm{mm}(0.002$-in.) thick, double-sided adhesive tape. The centerline of the tape was aligned with 2-percent chord on the upper surface and 10-percent chord on the lower surface.

Starting from $0^{\circ}$, the angle of attack was increased and then decreased to determine hysteresis. The same procedure was followed for negative angles of attack.

For several test runs, the model surfaces were coated with oil to determine the location, as well as the nature, of the boundary-layer transition from laminar to turbulent flow (ref. 28). Transition was also located using infrared flow visualization (ref. 29).

\section{Discussion of Results \\ Experimental Results \\ Pressure Distributions}

The pressure distributions at various angles of attack for a Reynolds number of $1.5 \times 10^{6}$ and a Mach number of 0.10 with transition free are shown in figure 7. At an angle of attack of $-0.05^{\circ}$ (fig. 7(a)), a laminar separation bubble is evident on the upper surface around 45-percent chord and on the lower surface around 30-percent chord. As the angle of attack is increased, the bubble on the upper surface moves slowly forward and decreases in length whereas the bubble on the lower surface moves slowly aft and 
increases slightly in length. At an angle of attack of $7.19^{\circ}$ (fig. 7(b)), which corresponds to the upper limit of the low-drag range, the bubble on the upper surface has almost disappeared. As the angle of attack is increased further, turbulent, trailing-edge separation occurs on the upper surface. The amount of separation increases slowly with increasing angle of attack. The maximum lift coefficient occurs at an angle of attack just beyond $10.26^{\circ}$ (fig. 7(b)). As the angle of attack is increased further, the separation point moves rapidly forward to about 40-percent chord (fig. 7(c)) and then slowly migrates further forward (fig. 7(d)).

As the angle of attack is decreased from $-0.05^{\circ}$ (fig. 7(e)), the laminar separation bubble on the lower surface moves slowly forward and decreases slightly in length whereas the bubble on the upper surface moves slowly aft and increases in length and then disappears. At an angle of attack of $-10.38^{\circ}$ (fig. 7 (f)), the laminar flow on the upper surface extends almost to the trailing edge as indicated by the reoccurrence of the laminar separation bubble at about 95 -percent chord. At an angle of attack of $-13.43^{\circ}$ (fig. $7(\mathrm{~g})$ ), three-dimensional separation probably occurs in the concave region on the lower surface as evidenced by the convex nature of the pressure distribution over that region. As the angle of attack is decreased further, the turbulent-separation point on the lower surface moves rapidly forward to about 20-percent chord (fig.7(h)), where it remains (figs. 7(i) and 7(j)).

\section{Transition Location}

The upper- and lower-surface, boundary-layer flow visualizations at a lift coefficient of $0.4\left(\alpha=0^{\circ}\right)$ for a Reynolds number of $1.5 \times 10^{6}$ and a Mach number of 0.10 are shown in figures 8 and 9 , respectively. The mechanism of the transition from laminar to turbulent flow on both surfaces is a laminar separation bubble as shown in the oil-flow photographs (figs. 8(a) and 9(a)). Note that the model orifices generally have only a small influence on the transition location downstream of their staggered positions and not at the orifices themselves (fig. 8(b)).

The variation of transition location with lift coefficient, as determined by infrared flow visualization, is shown in figure 10. It should be noted that laminar separation cannot be detected using this technique. Thus, for lift coefficients that exhibit laminar separation bubbles, the transition location measured corresponds to the turbulent-reattachment point. Because the lower-surface transition location varies little with Reynolds number, data were obtained for Reynolds numbers of $0.7 \times 10^{6}, 1.5 \times 10^{6}$, and $3.0 \times 10^{6}$ only. Thus, the lower-surface transition locations shown for Reynolds numbers of $1.0 \times 10^{6}$ and $2.0 \times 10^{6}$ (figs. $10(\mathrm{~b})$ and $10(\mathrm{~d})$ ) are interpolated.

\section{Section Characteristics}

Spanwise drag measurements.- The variation of profile-drag coefficient with total-pressure wake-rake span station for a Reynolds number of $1.5 \times 10^{6}$ and a Mach number of 0.10 with transition free is shown in figure 11. The three angles of attack shown, $-8^{\circ}, 0^{\circ}$, and $7^{\circ}$, correspond approximately to the lower limit, the middle, and the upper limit of the low-drag range, respectively. The greatest deviations from the mean occur in the vicinity of the stations that correspond to the orifices in the model $(-1.7$ to $8.2 \mathrm{~cm}(-0.7$ to 3.2 in.)). Large deviations are apparent only at the limits of the low-drag range (figs. 11(a) and 11(c)). A total-pressure wake-rake position of $23.0 \mathrm{~cm}(9.1 \mathrm{in}$.), which is $4.4 \mathrm{~cm}(1.7 \mathrm{in}$.) above the tunnel centerline, was selected for all succeeding measurements because it resulted in a drag coefficient representative of the mean value at each of the three angles of attack.

Reynolds number effects.- The section characteristics with transition free are shown in figure 12 . For the design Reynolds number of $1.5 \times 10^{6}$ (fig. 12(c)), the maximum lift coefficient is 1.32 , which exceeds the design objective by 2 percent. No hysteresis occurs. Low drag coefficients are exhibited over the range 
of lift coefficients from about -0.6 to about 1.2. Thus, the lower limit of the low-drag range is well below the design objective and the upper limit meets the design objective. The drag coefficient at the specified lower limit of the low-drag range $\left(c_{l}=0.6\right)$ is 0.0097 , which is 19 percent below the design objective. The zero-lift pitching-moment coefficient is -0.137 , which is 9 percent less negative than the design constraint.

In general, the lift-curve slope, the maximum lift coefficient, and the zero-lift pitching-moment coefficient increase in magnitude with increasing Reynolds number; the upper limit of the low-drag range and the drag coefficients decrease. The zero-lift angle of attack, $-3.5^{\circ}$, is essentially unaffected by Reynolds number. The stall characteristics become less docile with increasing Reynolds number.

Additional measurements (not shown) indicate that the application of turbulators (ref. 22) to eliminate the laminar separation bubbles on the upper and lower surfaces does not lower the drag coefficients, even for the lowest Reynolds number of $0.7 \times 10^{6}$. These results confirm the achievement of the design goal to eliminate significant (drag-producing) laminar separation bubbles through the incorporation of transition ramps in the pressure distributions.

Effect of roughness.- The effect of fixing transition on the section characteristics is shown in figure 13. The zero-lift angle of attack, the lift-curve slope, and the pitching-moment coefficients decrease in magnitude with transition fixed. These results are primarily a consequence of the boundary-layer displacement effect which decambers the airfoil, the displacement thickness being greater for the transitionfixed condition than for the transition-free condition. In addition, the lift-curve slope decreases with transition fixed because the roughness induces earlier trailing-edge separation. The maximum lift coefficient for the design Reynolds number of $1.5 \times 10^{6}$ (fig. 13(c)) is 1.22 , a reduction of 8 percent from that for the transition-free condition. Thus, one of the most important design requirements has essentially been achieved. The drag coefficients are, of course, adversely affected by the roughness. For many conditions, the Reynolds number, based on local velocity and boundary-layer momentum thickness, at the roughness location is too low to support turbulent flow. Accordingly, to force transition, the roughness must be so large that it increases the momentum thickness, which abnormally decreases the magnitudes of the lift and pitching-moment coefficients and increases the drag coefficients. Conversely, at almost all negative lift coefficients, the roughness on the upper surface was apparently too small to force transition resulting in inappropriately low drag coefficients.

The effect of the roughness of reference 27 on the section characteristics is shown in figure 14 . The effects are more severe than those of fixing transition. The maximum lift coefficient for the design Reynolds number of $1.5 \times 10^{6}$ (fig. 14(b)) is 1.01 , a reduction of 23 percent from that for the transition-free condition. It should be remembered that the effects of roughness are related to the ratio of the roughness height to the airfoil chord. Therefore, the effects of this roughness may be exaggerated because the chord of the wind-tunnel model is smaller than the chord of the wind-turbine blade at the corresponding blade radial station.

The effect of roughness on the maximum lift coefficient is summarized in figure 15 . In general, the effect of fixing transition decreases with increasing Reynolds number whereas the effect of the roughness of reference 27 is essentially constant.

\section{Comparison of Theoretical and Experimental Results}

\section{Pressure Distributions}

The comparison of theoretical and experimental pressure distributions is shown in figure 16 . The theoretical pressure distributions are inviscid and incompressible whereas the experimental pressure 
distributions were obtained for a Reynolds number of $1.5 \times 10^{6}$ and a Mach number of 0.10 with transition free. Although the magnitudes of the pressure coefficients at a lift coefficient of 0.64 (fig. 16(a)), roughly the specified lower limit of the low-drag range, do not match exactly, the pressure gradients agree well except where laminar separation bubbles are present and along the separation ramp forward of the trailing edge. The bubbles are not modeled in the pressure distributions predicted by the method of references 14 and 15. At a lift coefficient of 1.20 (fig. 16(b)), the upper limit of the low-drag range, the decambering viscous effects are more apparent and the disparities include small differences in the pressure gradients as well as larger differences in the magnitudes of the pressure coefficients. At the maximum lift coefficient (fig. 16(c)), the agreement is poor primarily because the effect of the upper-surface, trailing-edge separation on the pressure distribution is not modeled in the theory.

\section{Transition Location}

The predicted and measured transition locations are compared in figure 17. The theory consistently predicts transition forward of the locations measured in the wind tunnel. This result is obtained because the method of references 14 and 15 "defines" the transition location as the end of the laminar boundary layer whether due to natural transition or laminar separation. In the wind tunnel, transition was confirmed only by the observation of attached turbulent flow. Thus, the majority of the disparity between the predicted and measured transition locations is due to the difference between the laminar-separation and turbulent-reattachment points. Accordingly, the agreement between theory and experiment is better for conditions that produce shorter laminar separation bubbles (higher lift coefficients for the upper surface and lower lift coefficients for the lower surface and/or higher Reynolds numbers).

\section{Section Characteristics}

The comparison of theoretical and experimental section characteristics with transition free is shown in figure 17. In general, the magnitudes of the zero-lift angle of attack, the upper limit of the low-drag range, and the pitching-moment coefficients are overpredicted. The lift-curve slope is slightly underpredicted. The maximum lift coefficient is significantly overpredicted. The drag coefficients are predicted relatively accurately.

The comparison of theoretical and experimental section characteristics with transition fixed is shown in figure 18. The magnitudes of the zero-lift angle of attack and the pitching-moment coefficients are again overpredicted. The lift-curve slope is predicted quite accurately. The maximum lift coefficient is again significantly overpredicted. The agreement between the predicted and measured drag coefficients is poor, at least in part, because of the abnormal roughness effect previously discussed.

\section{Comparisons with Other Airfoils}

The comparisons of the experimental section characteristics of the S814 airfoil and the NACA 4424 and 23024 airfoils (ref. 4) for a Reynolds number of $3.0 \times 10^{6}$ with transition free are shown in figures 19 and 20 , respectively. The $\$ 814$ airfoil achieves a higher maximum lift coefficient and exhibits lower drag coefficients than do the NACA airfoils. The $\$ 814$ airfoil also produces more negative pitching-moment coefficients than do the NACA airfoils. These comparisons confirm the achievement of the design objectives. 


\section{Concluding Remarks}

A 24-percent-thick airfoil, the S814, for the root region of a horizontal-axis wind-turbine blade has been designed and analyzed theoretically and verified experimentally in the low-turbulence wind tunnel of the Delft University of Technology Low Speed Laboratory, The Netherlands. The two primary objectives of a high maximum lift coefficient, insensitive to leading-edge roughness, and low profile-drag coefficients have been achieved. The constraints on the zero-lift pitching-moment coefficient and the airfoil thickness have been satisfied. Comparisons of the theoretical and experimental results show good agreement with the exception of the maximum lift coefficient which is overpredicted. Comparisons with other airfoils illustrate the higher maximum lift coefficient and the lower profile-drag coefficients, thus confirming the achievement of the primary objectives.

\section{Acknowledgments}

The assistance of the staff of the Delft University of Technology Low Speed Laboratory is gratefully acknowledged. In particular, the meticulousness of Loek M. M. Boermans is sincerely appreciated. Also, the diligence of Eric Wolfert Voet is recognized as is the perseverance of James L. Tangler of NREL.

\section{References}

1. Jacobs, Eastman N.; Ward, Kenneth E.; and Pinkerton, Robert M.: The Characteristics of 78 Related Airfoil Sections from Tests in the Variable-Density Wind Tunnel. NACA Rep. 460, 1933.

2. Jacobs, Eastman N.; and Pinkerton, Robert M.: Tests in the Variable-Density Wind Tunnel of Related Airfoils Having the Maximum Camber Unusually far Forward. NACA Rep. 537, 1935.

3. Jacobs, Eastman N.; Pinkerton, Robert M.; and Greenberg, Harry: Tests of Related Forward-Camber Airfoils in the Variable-Density Wind Tunnel. NACA Rep. 610, 1937.

4. Abbott, Ira H.; Von Doenhoff, Albert E.; and Stivers, Louis S., Jr.: Summary of Airfoil Data. NACA Rep. 824, 1945. (Supersedes NACA WR L-560.)

5. Abbott, Ira H.; and Von Doenhoff, Albert E.: Theory of Wing Sections. Dover Publ., Inc., c.1959.

6. McGhee, Robert J.; Beasley, William D.; and Whitcomb, Richard T.: NASA Low- and MediumSpeed Airfoil Development. NASA TM-78709, 1979.

7. Tangler, J. L.; and Somers, D. M.: Status of the Special-Purpose Airfoil Families. SERI/TP-2173264, Dec. 1987.

8. Somers, Dan M.: The $\$ 801$ through S808 Airfoils. Airfoils, Inc., 1987. [Proprietary to NREL]

9. Somers, Dan M.: The S809 through S813 Airfoils. Airfoils, Inc., 1988. [Proprietary to NREL]

10. Somers, Dan M.: The S814 and S815 Airfoils. Airfoils, Inc., 1992. [Proprietary to NREL]

11. Somers, Dan M.: The S816, S817, and S818 Airfoils. Airfoils, Inc., 1992. [Proprietary to NREL]

12. Somers, Dan M.: The $\$ 819$, S820, and S821 Airfoils. Airfoils, Inc., 1993. [Proprietary to NREL] 
13. Somers, Dan M.: The S822 and S823 Airfoils. Airfoils, Inc., 1993. [Proprietary to NREL]

14. Eppler, Richard: Airfoil Design and Data. Springer-Verlag (Berlin), 1990.

15. Eppler, R.: Airfoil Program System. User's Guide. R. Eppler, c.1993.

16. van Ingen, J. L.; Boermans, L. M. M.; and Blom, J. J. H.: Low-Speed Airfoil Section Research at Delft University of Technology. ICAS-80-10.1, Munich, Oct. 1980.

17. Eppler, Richard; and Somers, Dan M.: Airfoil Design for Reynolds Numbers Between 50,000 and 500,000 . Proceedings of the Conference on Low Reynolds Number Airfoil Aerodynamics, UNDASCP-77B123, Univ. of Notre Dame, June 1985, pp. 1-14.

18. Wortmann, F. X.: Experimental Investigations on New Laminar Profiles for Gliders and Helicopters. TIL/T.4906, British Minist. Aviat., Mar. 1960. (Translated from Z. Flugwissenschaften, Bd. 5, Heft 8, Aug. 1957, S. 228-243.)

19. Maughmer, Mark D.; and Somers, Dan M.: Design and Experimental Results for a High-Altitude, Long-Endurance Airfoil. J. Aircr., vol. 26, no. 2, Feb. 1989, pp. 148-153.

20. Somers, Dan M.: Subsonic Natural-Laminar-Flow Airfoils. Natural Laminar Flow and Laminar Flow Control, R. W. Barnwell and M. Y. Hussaini, eds., Springer-Verlag New York, Inc., 1992, pp. 143-176.

21. Somers, Dan M.: Design and Experimental Results for the S805 Airfoil. Airfoils, Inc., 1988. [Proprietary to NREL]

22. Somers, Dan M.: Design and Experimental Results for the S809 Airfoil. Airfoils, Inc., 1989. [Proprietary to NREL]

23. The Cambridge University Aeronautics Laboratory: The Measurement of Profile Drag by the PitotTraverse Method. R. \& M. No. 1688, British A.R.C., 1937.

24. Allen, H. Julian; and Vincenti, Walter G.: Wall Interference in a Two-Dimensional-Flow Wind Tunnel, With Consideration of the Effect of Compressibility. NACA Rep. 782, 1944. (Supersedes NACA WR A-63.)

25. Pfenninger, Werner: Vergleich der Impulsmethode mit der Wägung bei Profilwiderstandsmessungen. Mitteilungen aus dem Institut für Aerodynamik an der Eidgenössischen Technischen Hochschule Zürich, Nr. 8, 1943.

26. Braslow, Albert L.; and Knox, Eugene C.: Simplified Method for Determination of Critical Height of Distributed Roughness Particles for Boundary-Layer Transition at Mach Numbers From 0 to 5. NACA TN 4363, 1958.

27. Tangler, J.; Smith, B.; Jager, D.; and Olsen, T.: Atmospheric Performance of the Special-Purpose SERI Thin-Airfoil Family: Final Results. SERI/TP-257-3939, Sept. 1990.

28. Loving, Donald L.; and Katzoff, S.: The Fluorescent-Oil Film Method and Other Techniques for Boundary-Layer Flow Visualization. NASA MEMO 3-17-59L, 1959. 
29. Quast, Armin: Detection of Transition by Infrared Image Technique. ICIASF'87 Record, 1987, pp. 125-133.

Table 1. Airfoil Design Specifications

\begin{tabular}{l|c}
\hline \multicolumn{1}{c|}{ Parameter } & Objective/Constraint \\
\hline \hline Reynolds number & $1.5 \times 10^{6}$ \\
\hline Maximum lift coefficient & $\geq 1.30$ \\
\hline Low-drag, lift-coefficient range: & 0.6 \\
Lower limit & 1.2 \\
Upper limit & $\leq 0.0120$ \\
\hline Minimum profile-drag coefficient & $\geq-0.15$ \\
\hline Zero-lift pitching-moment coefficient & $0.24 \mathrm{c}$ \\
\hline Thickness & \\
\hline \hline
\end{tabular}


Table 2. S814 Airfoil Coordinates

\begin{tabular}{|c|c|c|c|}
\hline \multicolumn{2}{|c|}{ Upper Surface } & \multicolumn{2}{|c|}{ Lower Surface } \\
\hline $\mathrm{x} / \mathrm{c}$ & $z / c$ & $\mathrm{x} / \mathrm{c}$ & $z / c$ \\
\hline 0.00116 & 0.00703 & 0.00048 & -0.00470 \\
\hline .00830 & .01892 & .00607 & -.01746 \\
\hline .02064 & .03130 & .01644 & -.03159 \\
\hline .03771 & .04378 & .03097 & -.04646 \\
\hline .05918 & .05608 & .04923 & -.06162 \\
\hline .08475 & .06791 & .07077 & -.07662 \\
\hline .11409 & .07903 & .09515 & -.09096 \\
\hline .14685 & .08921 & .12193 & -.10412 \\
\hline .18266 & .09821 & .15072 & -.11545 \\
\hline .22111 & .10580 & .18122 & -.12425 \\
\hline .26177 & .11175 & .21322 & -.12971 \\
\hline .30418 & .11564 & .24712 & -.13079 \\
\hline .34829 & .11696 & .28389 & -.12736 \\
\hline .39439 & .11573 & .32394 & -.11990 \\
\hline .44237 & .11251 & .36753 & -.10887 \\
\hline .49169 & .10775 & .41483 & -.09511 \\
\hline .54177 & .10173 & .46552 & -.07962 \\
\hline .59199 & .09473 & .51909 & -.06328 \\
\hline .64174 & .08698 & .57485 & -.04703 \\
\hline .69037 & .07873 & .63189 & -.03173 \\
\hline .73723 & .07016 & .68912 & -.01818 \\
\hline .78169 & .06146 & .74529 & -.00701 \\
\hline .82312 & .05276 & .79901 & .00134 \\
\hline .86095 & .04417 & .84887 & .00671 \\
\hline .89460 & .03567 & .89348 & .00917 \\
\hline .92380 & .02706 & .93154 & .00910 \\
\hline .94879 & .01848 & .96197 & .00701 \\
\hline .96963 & .01071 & .98364 & .00377 \\
\hline .98582 & .00470 & .99606 & .00102 \\
\hline .99632 & .00112 & 1.00000 & .00000 \\
\hline 1.00000 & .00000 & & \\
\hline
\end{tabular}


Table 3. Model Orifice Locations

\begin{tabular}{|c|c|c|c|}
\hline \multicolumn{2}{|c|}{ Upper Surface } & \multicolumn{2}{|c|}{ Lower Surface } \\
\hline $\mathrm{x} / \mathrm{c}$ & $\mathrm{y}, \mathrm{mm}$ (in.) & $\mathrm{x} / \mathrm{c}$ & $\mathrm{y}, \mathrm{mm}$ (in.) \\
\hline 0.000 & $104.6(4.12)$ & 0.002 & $202.7(7.98)$ \\
\hline .002 & $104.5(4.11)$ & .004 & $202.4(7.97)$ \\
\hline .003 & $105.9(4.17)$ & .006 & $201.6(7.94)$ \\
\hline .006 & $106.3(4.19)$ & .008 & $201.5(7.93)$ \\
\hline .007 & $107.4(4.23)$ & .012 & $200.3(7.89)$ \\
\hline .011 & $107.9(4.25)$ & .016 & $199.0(7.83)$ \\
\hline .015 & $108.8(4.28)$ & .020 & $198.4(7.81)$ \\
\hline .019 & $109.9(4.32)$ & .026 & $197.3(7.77)$ \\
\hline .025 & $111.0(4.37)$ & .032 & $196.0(7.72)$ \\
\hline .031 & $112.3(4.42)$ & .038 & $195.2(7.68)$ \\
\hline .040 & $113.7(4.48)$ & .048 & $193.7(7.63)$ \\
\hline .048 & $114.9(4.52)$ & .062 & $190.4(7.50)$ \\
\hline .061 & $117.1(4.61)$ & .079 & $188.8(7.43)$ \\
\hline .077 & $119.8(4.72)$ & .101 & $184.6(7.27)$ \\
\hline .101 & $123.3(4.85)$ & .151 & $176.8(6.96)$ \\
\hline .150 & $131.7(5.18)$ & .182 & $171.3(6.74)$ \\
\hline .199 & $139.5(5.49)$ & .202 & $168.3(6.62)$ \\
\hline .251 & $148.3(5.84)$ & .211 & $166.8(6.56)$ \\
\hline .279 & $152.6(6.01)$ & .221 & $164.8(6.49)$ \\
\hline .300 & $156.7(6.17)$ & .231 & $164.4(6.47)$ \\
\hline .311 & $158.3(6.23)$ & .242 & $161.5(6.36)$ \\
\hline .320 & $161.7(6.37)$ & .252 & $159.5(6.28)$ \\
\hline .330 & $161.6(6.36)$ & .262 & $157.7(6.21)$ \\
\hline .340 & $163.4(6.43)$ & .273 & $155.9(6.14)$ \\
\hline .351 & $165.3(6.51)$ & .282 & $154.6(6.09)$ \\
\hline .360 & $166.6(6.56)$ & .292 & $152.8(6.01)$ \\
\hline .370 & $168.6(6.64)$ & .304 & $150.7(5.93)$ \\
\hline .380 & $170.3(6.70)$ & .312 & $149.7(5.89)$ \\
\hline .390 & $171.8(6.77)$ & .323 & $147.7(5.81)$ \\
\hline .401 & $173.8(6.84)$ & .331 & $145.9(5.74)$ \\
\hline .410 & $175.5(6.91)$ & .343 & $143.9(5.66)$ \\
\hline .420 & $177.5(6.99)$ & .352 & $142.4(5.61)$ \\
\hline
\end{tabular}


Table 3. Model Orifice Locations (concluded)

\begin{tabular}{|c|c|c|c|}
\hline \multicolumn{2}{|c|}{ Upper Surface } & \multicolumn{2}{|c|}{ Lower Surface } \\
\hline $\mathrm{x} / \mathrm{c}$ & $y, \mathrm{~mm}$ (in.) & $\mathrm{x} / \mathrm{c}$ & $\mathrm{y}, \mathrm{mm}$ (in.) \\
\hline .431 & $179.0(7.05)$ & .362 & $141.0(5.55)$ \\
\hline .439 & $180.4(7.10)$ & .371 & $139.0(5.47)$ \\
\hline .450 & $182.1(7.17)$ & .382 & $137.4(5.41)$ \\
\hline .460 & $183.9(7.24)$ & .392 & $135.4(5.33)$ \\
\hline .469 & $185.4(7.30)$ & .402 & $133.7(5.26)$ \\
\hline .480 & $187.5(7.38)$ & .413 & $131.8(5.19)$ \\
\hline .491 & $188.8(7.43)$ & .421 & $130.7(5.15)$ \\
\hline .500 & $190.3(7.49)$ & .432 & $128.7(5.07)$ \\
\hline .510 & $192.5(7.58)$ & .441 & $127.1(5.00)$ \\
\hline .519 & $194.2(7.64)$ & .452 & $125.2(4.93)$ \\
\hline .530 & $195.8(7.71)$ & .461 & $123.6(4.87)$ \\
\hline .538 & $197.9(7.79)$ & .471 & $122.0(4.80)$ \\
\hline .550 & $199.8(7.87)$ & .483 & $120.1(4.73)$ \\
\hline .570 & $198.2(7.80)$ & .492 & $118.2(4.65)$ \\
\hline .601 & $194.9(7.67)$ & .501 & $115.6(4.55)$ \\
\hline .650 & $189.8(7.47)$ & .523 & $113.0(4.45)$ \\
\hline .700 & $184.5(7.26)$ & .550 & $108.2(4.26)$ \\
\hline .749 & $179.3(7.06)$ & .601 & $112.3(4.42)$ \\
\hline .801 & $174.2(6.86)$ & .650 & $117.5(4.63)$ \\
\hline .850 & $168.8(6.65)$ & .702 & $124.1(4.88)$ \\
\hline .880 & $165.5(6.51)$ & .749 & $128.1(5.04)$ \\
\hline .901 & $163.4(6.43)$ & .799 & $133.3(5.25)$ \\
\hline .921 & $161.0(6.34)$ & .851 & $138.9(5.47)$ \\
\hline .941 & $158.9(6.26)$ & .878 & $141.5(5.57)$ \\
\hline .961 & $156.6(6.17)$ & .899 & $143.7(5.66)$ \\
\hline .979 & $154.6(6.09)$ & .921 & $146.1(5.75)$ \\
\hline \multirow[t]{3}{*}{.999} & $152.3(6.00)$ & .939 & $148.0(5.83)$ \\
\hline & & .962 & $150.2(5.91)$ \\
\hline & & .983 & $143.7(5.66)$ \\
\hline
\end{tabular}

[c $=650 \mathrm{~mm}(25.6 \mathrm{in})$. 
Table 4. Roughness Location and Size

\begin{tabular}{c|c|c|c|c|c|c}
\hline \multicolumn{1}{c}{} & \multicolumn{3}{c|}{ Upper Surface } & \multicolumn{3}{c}{ Lower Surface } \\
\cline { 2 - 8 } $\begin{array}{c}\text { Reynolds } \\
\text { Number }\end{array}$ & $\mathrm{x} / \mathrm{c}$ & $\begin{array}{c}\text { Grit } \\
\text { Number }\end{array}$ & $\begin{array}{c}\text { Nominal } \\
\text { Size, mm (in.) }\end{array}$ & $\begin{array}{c}\text { Grit } \\
\text { x/c }\end{array}$ & $\begin{array}{c}\text { Nominal } \\
\text { Number }\end{array}$ & Size, mm (in.) \\
\hline \hline $0.7 \times 10^{6}$ & 0.02 & 46 & $0.419(0.0165)$ & 0.10 & 30 & $0.711(0.0280)$ \\
\hline $1.0 \times 10^{6}$ & .02 & 60 & $.297(.0117)$ & .10 & 30 & $.711(.0280)$ \\
\hline $1.5 \times 10^{6}$ & .02 & 90 & $.178(.0070)$ & .10 & 46 & $.419(.0165)$ \\
\hline $2.0 \times 10^{6}$ & .02 & 120 & $.124(.0049)$ & .10 & 54 & $.351(.0138)$ \\
\hline $3.0 \times 10^{6}$ & .02 & 120 & $.124(.0049)$ & .10 & 54 & $.351(.0138)$ \\
\hline \hline
\end{tabular}




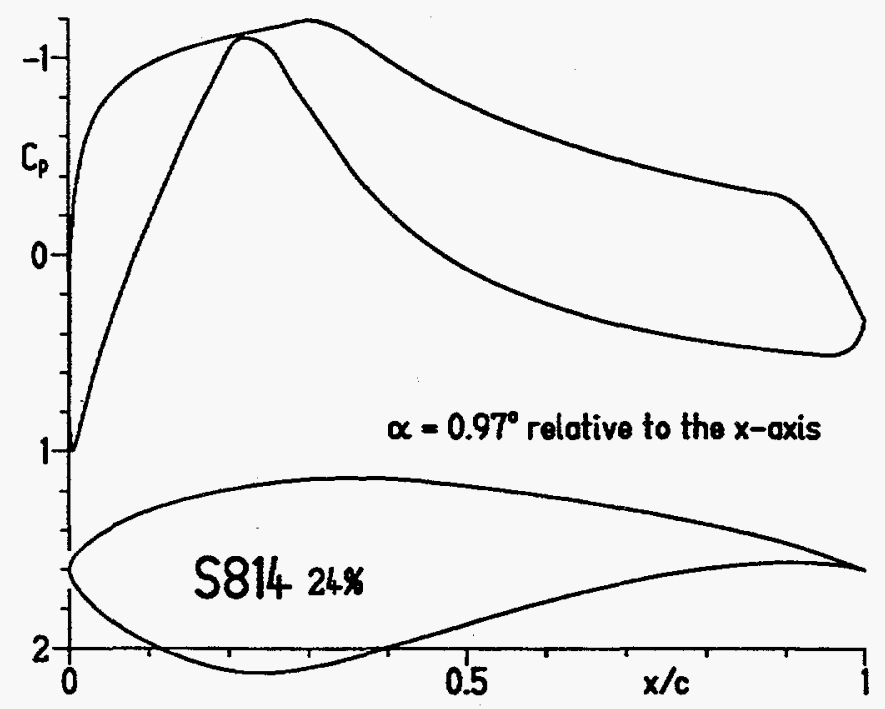

(a) $c_{l}=0.6$.

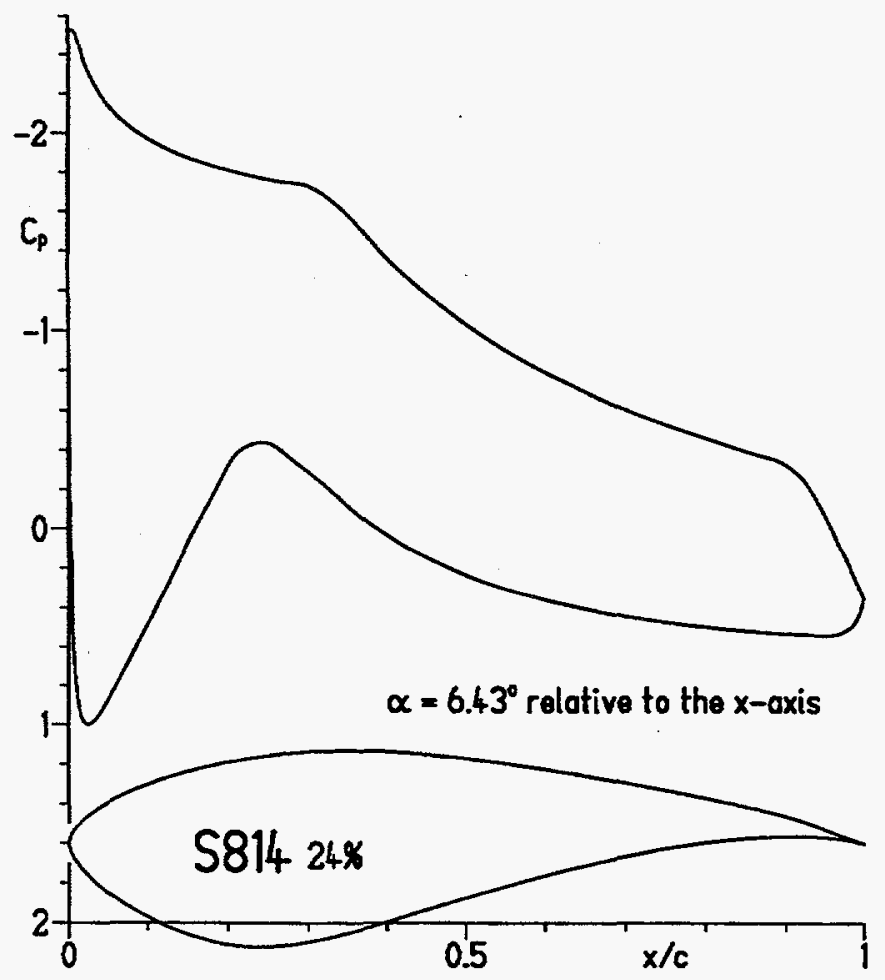

(b) $\mathrm{c}_{l}=1.2$

Figure 1.- Inviscid, incompressible pressure distributions. 


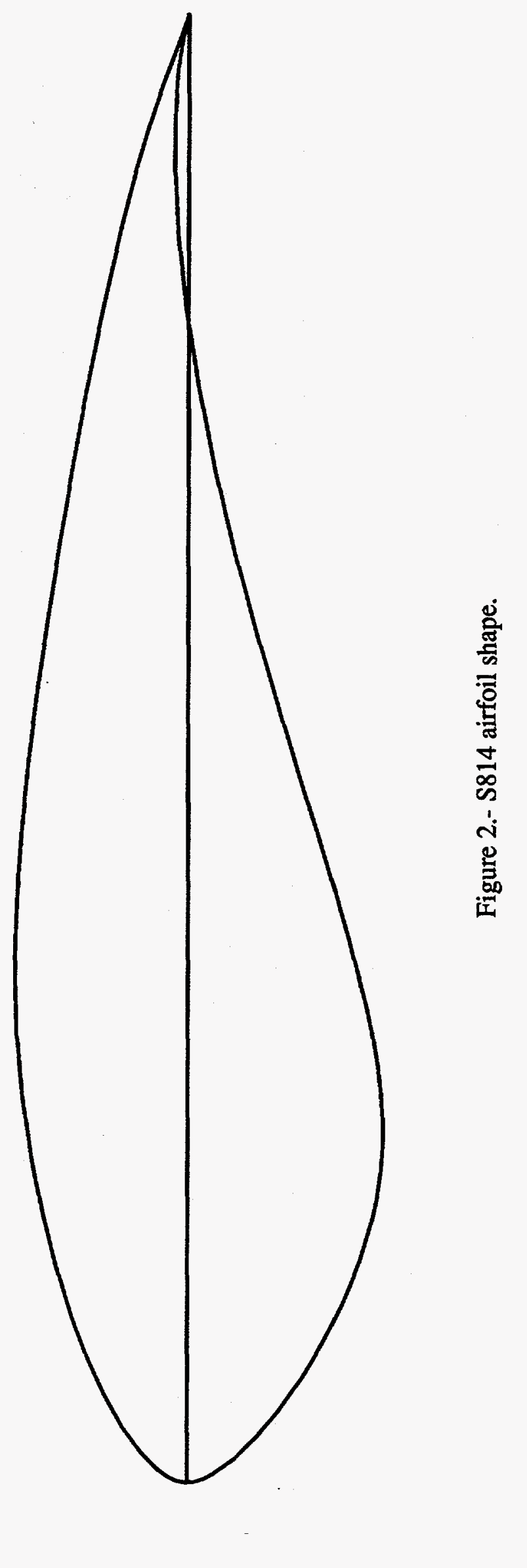




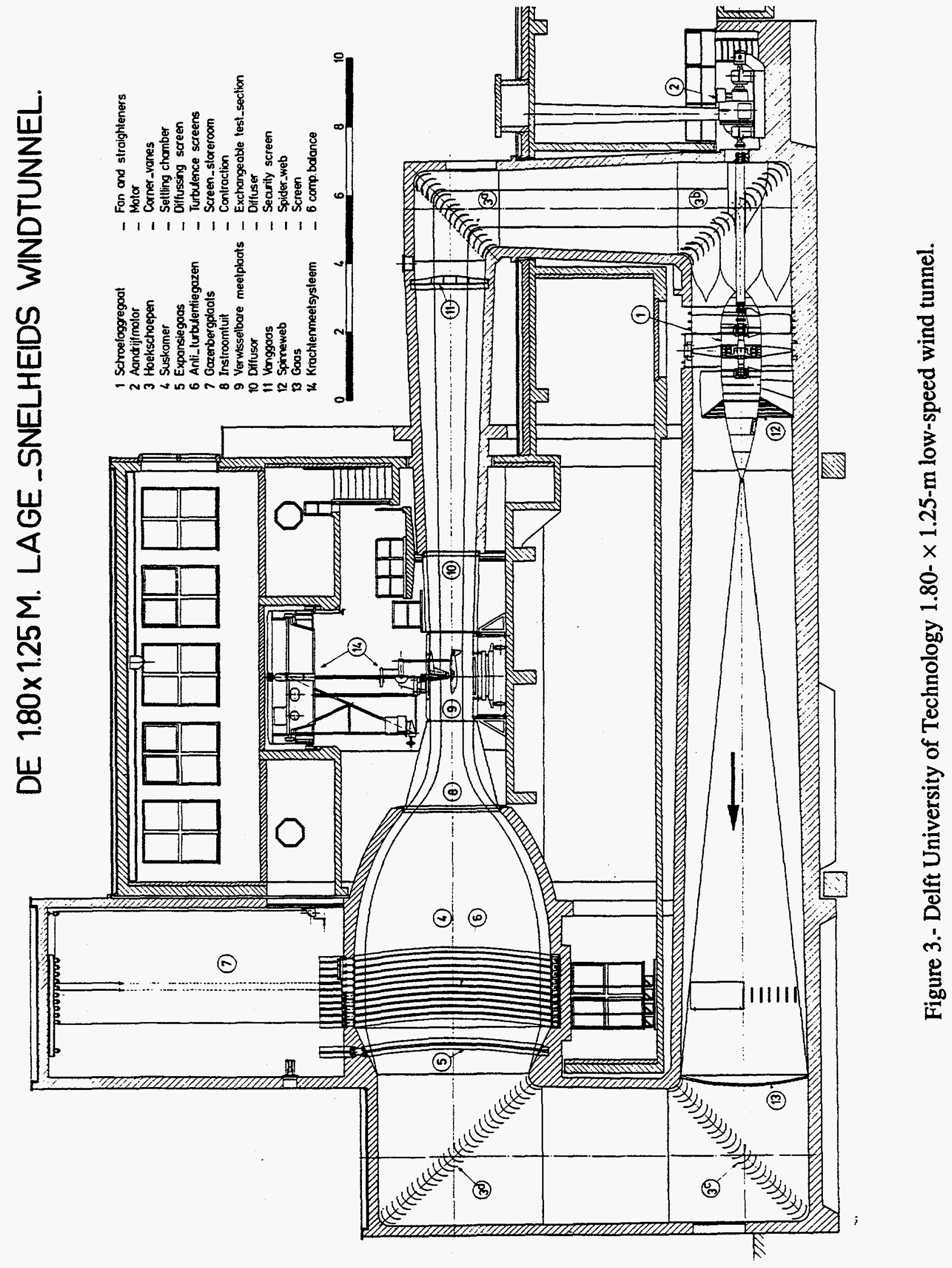




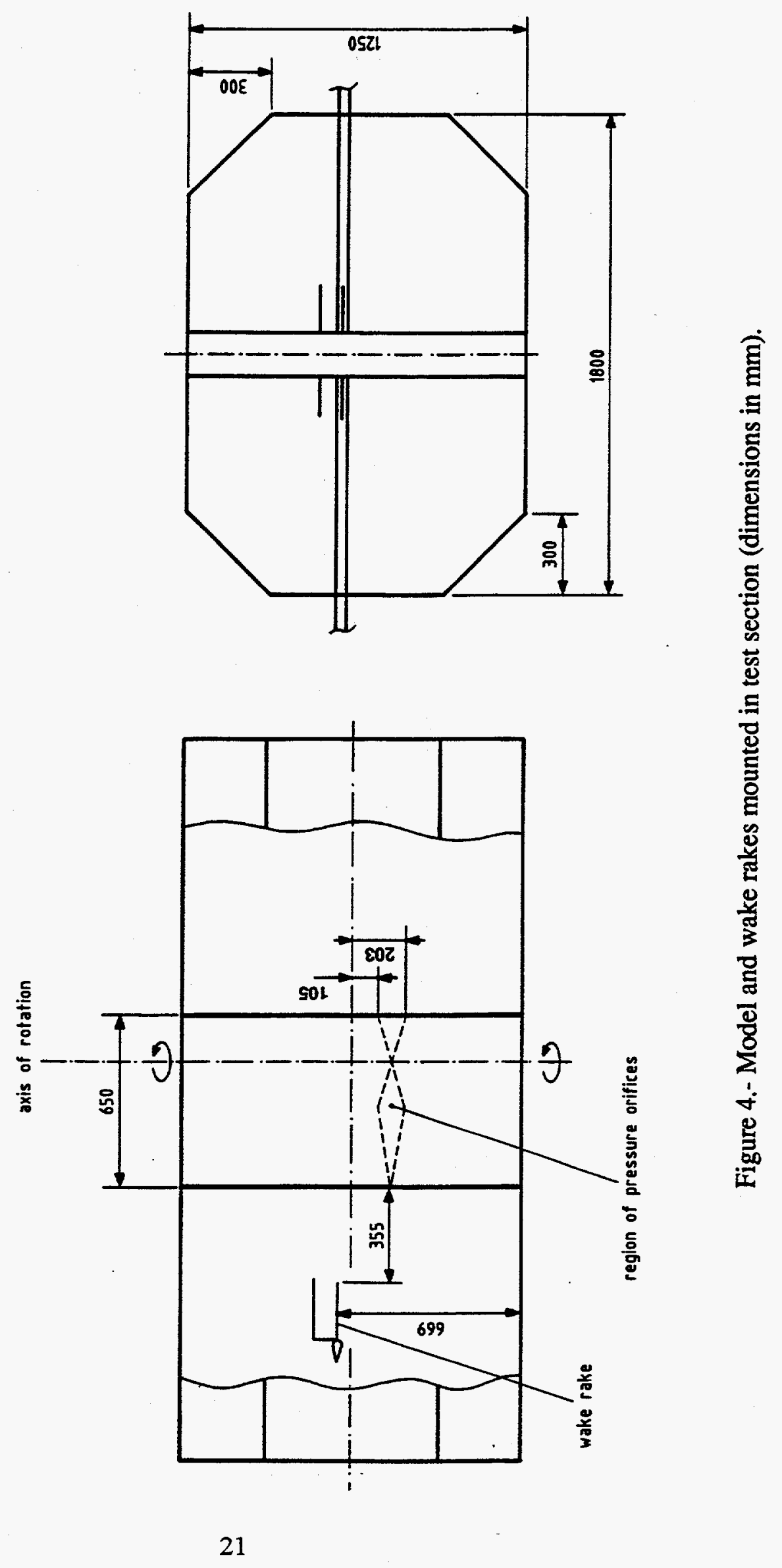




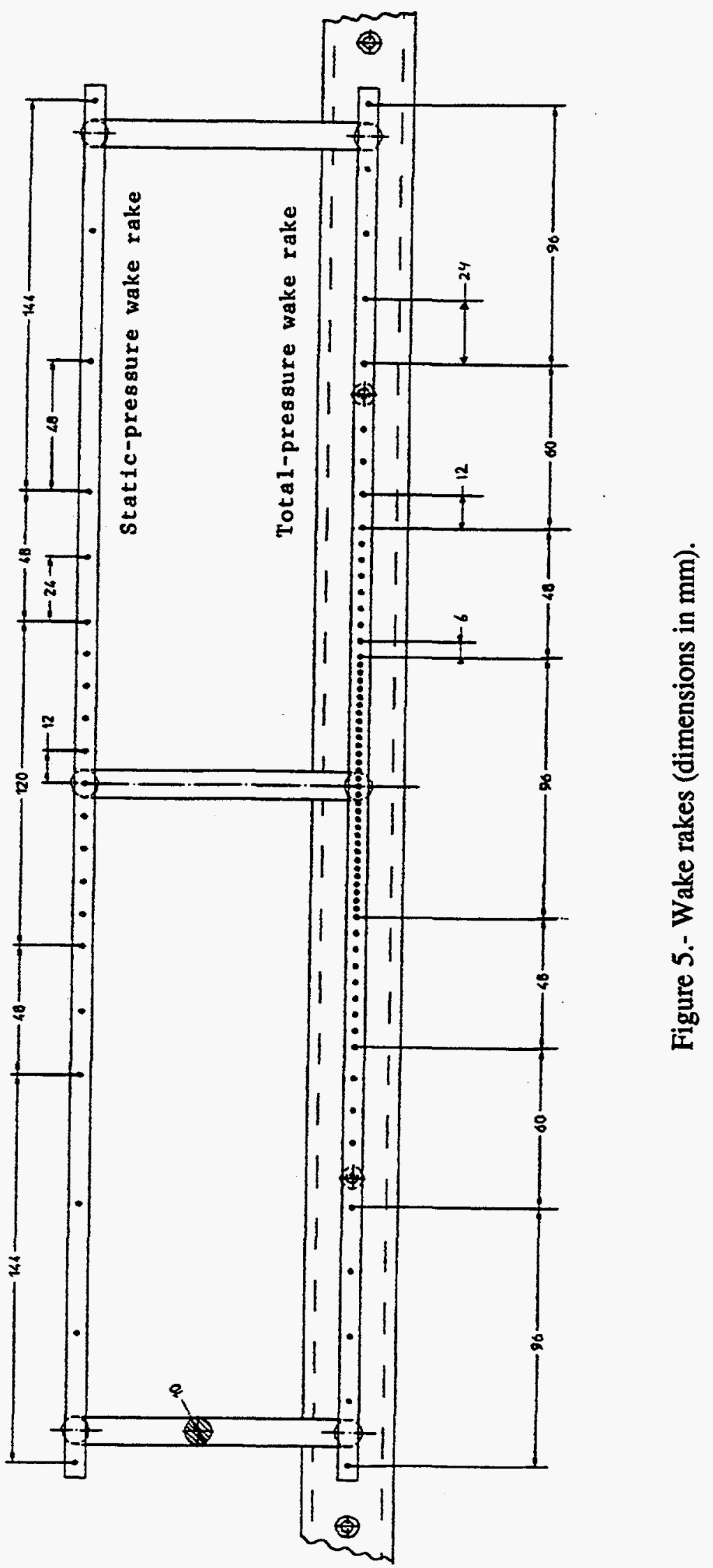




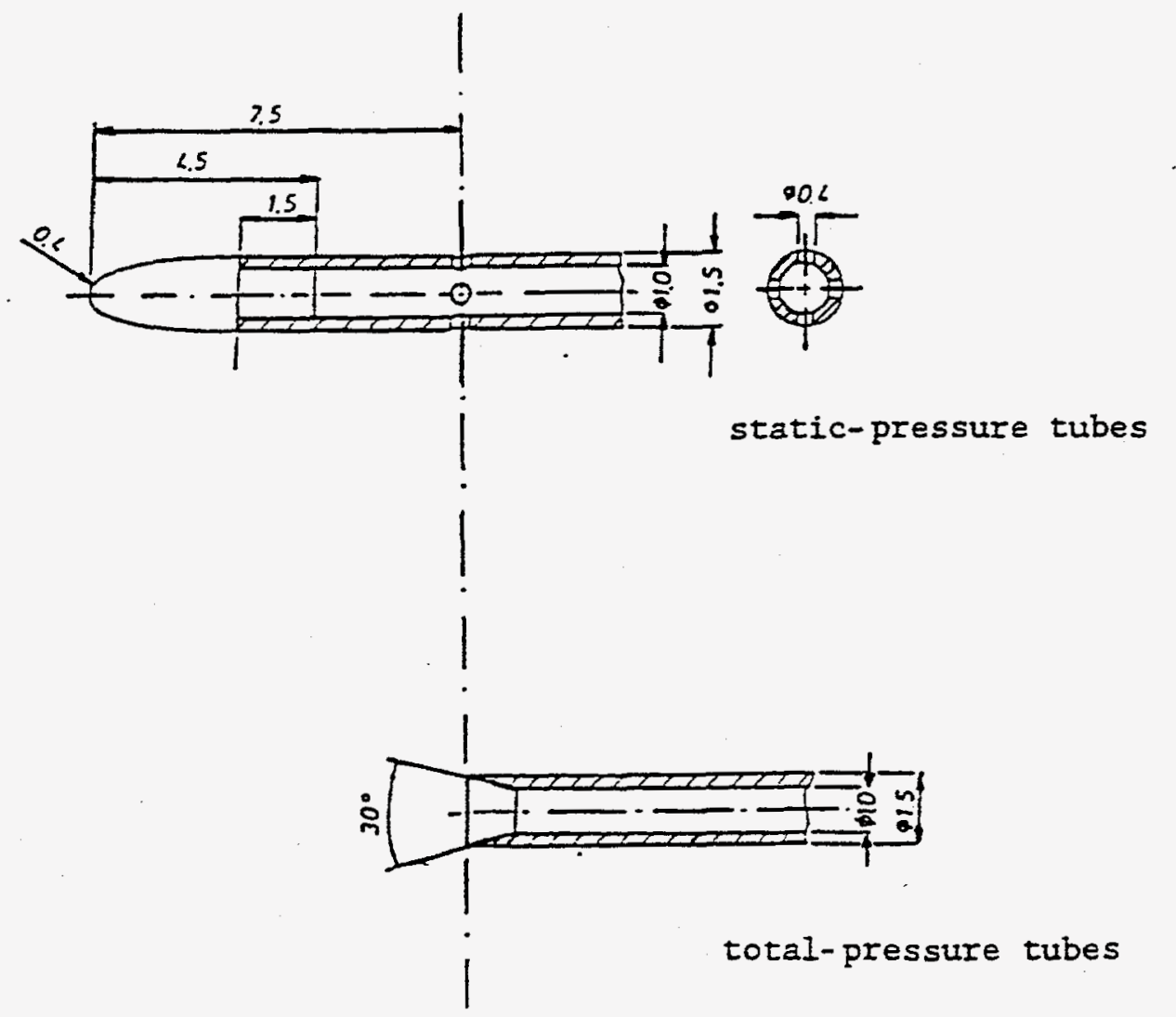

Figure 6.- Wake-rake, static-pressure and total-pressure tubes (dimensions in mm). 



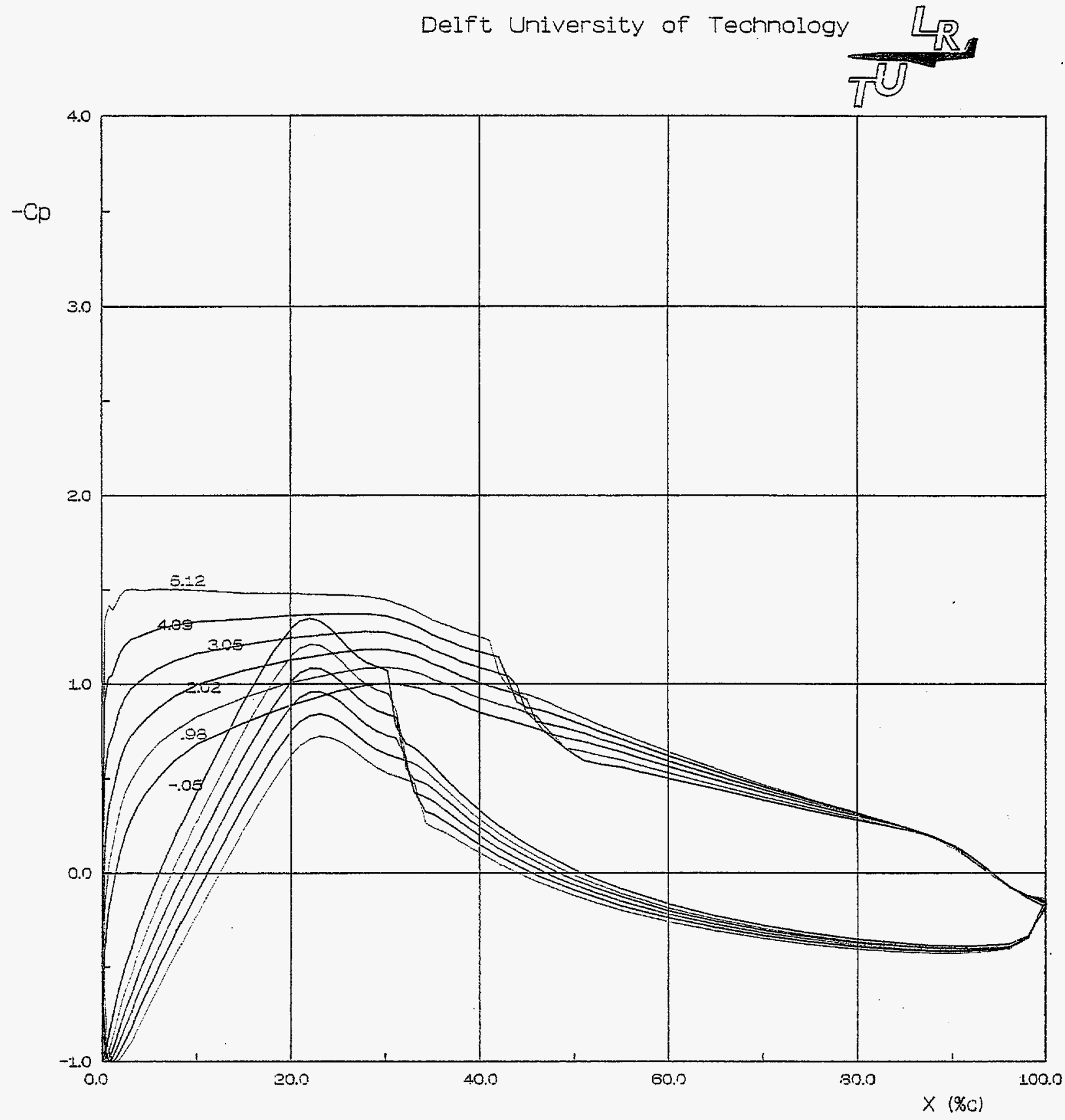

(a) $\alpha=-0.05^{\circ}, 0.98^{\circ}, 2.02^{\circ}, 3.05^{\circ}, 4.09^{\circ}$, and $5.12^{\circ}$.

Figure 7.- Pressure distributions for $\mathrm{R}=1.5 \times 10^{6}$ and $\mathrm{M}=0.10$ with transition free. 



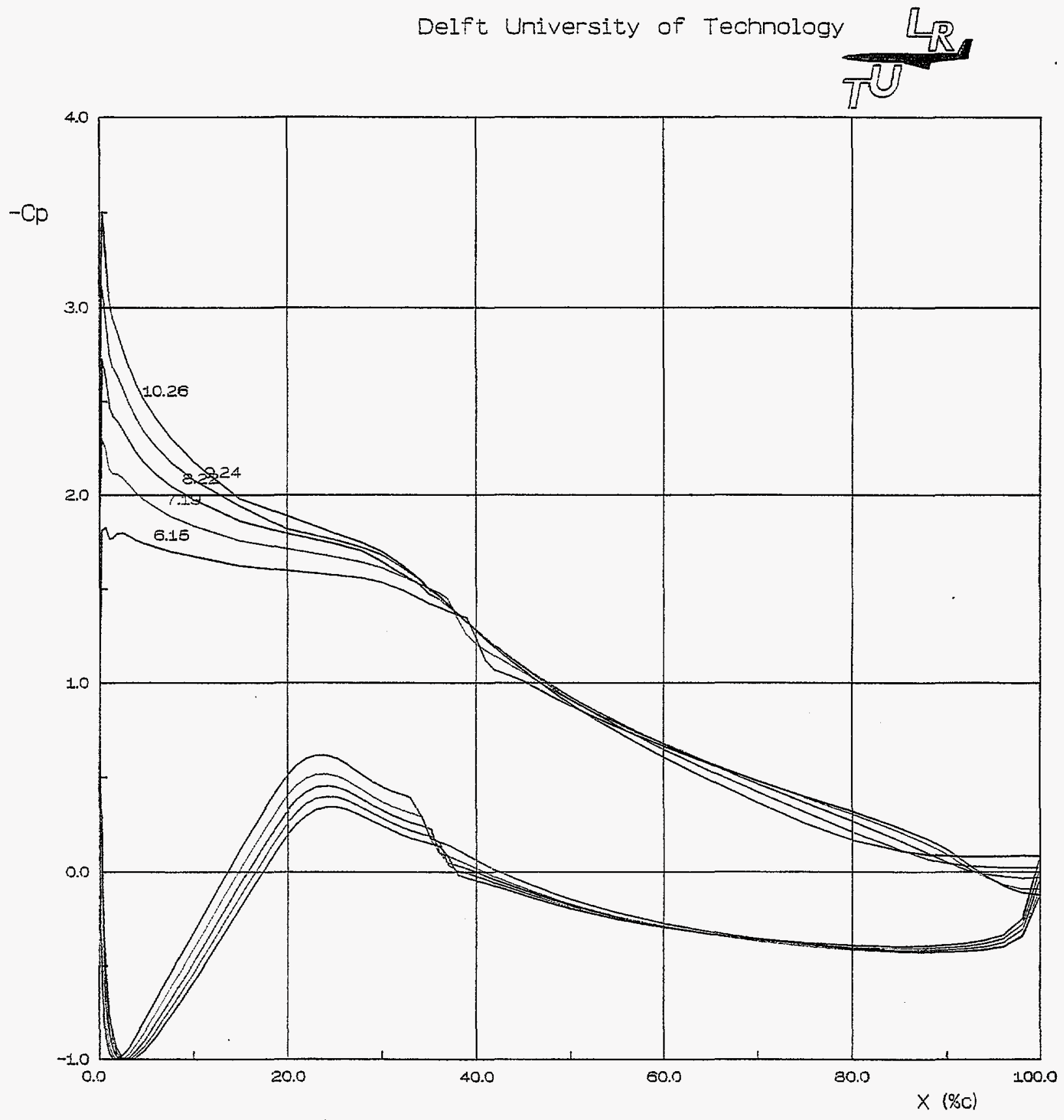

(b) $\alpha=6.15^{\circ}, 7.19^{\circ}, 8.22^{\circ}, 9.24^{\circ}$, and $10.26^{\circ}$.

Figure 7.- Continued. 



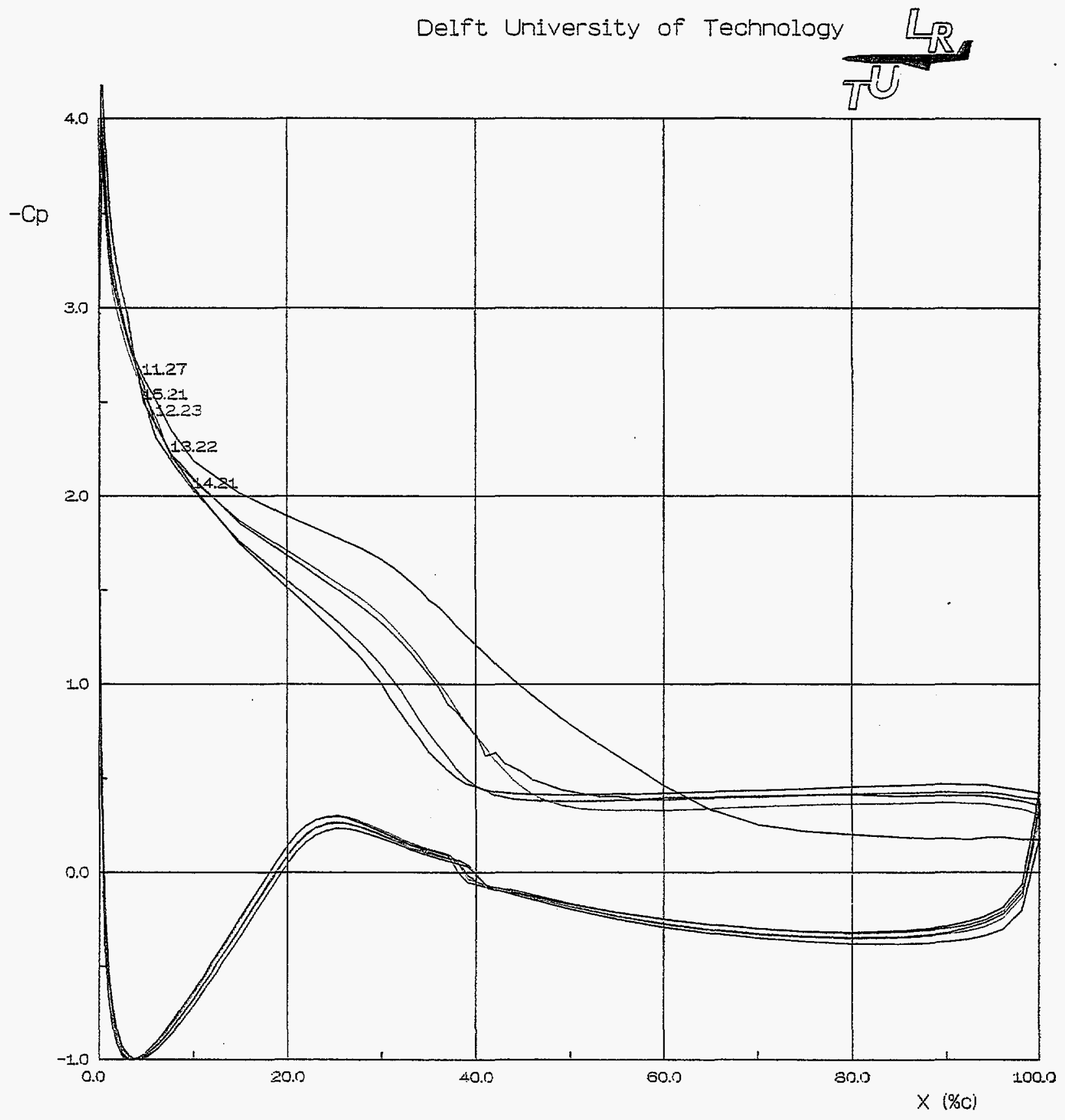

(c) $\alpha=11.27^{\circ}, 12.23^{\circ}, 13.22^{\circ}, 14.21^{\circ}$, and $15.21^{\circ}$.

Figure 7.- Continued. 


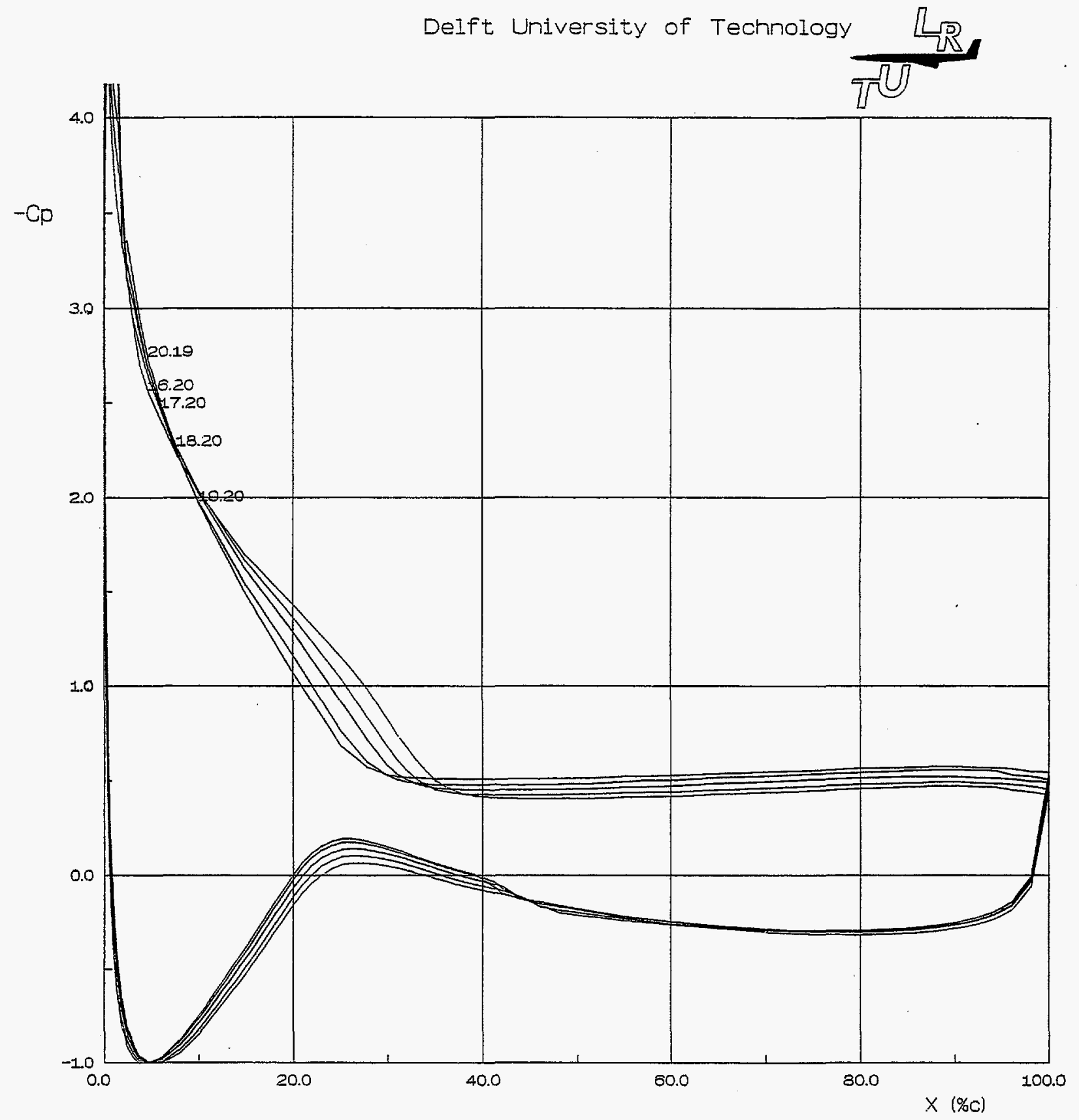

(d) $\alpha=16.20^{\circ}, 17.20^{\circ}, 18.20^{\circ}, 19.20^{\circ}$, and $20.19^{\circ}$.

Figure 7.- Continued. 


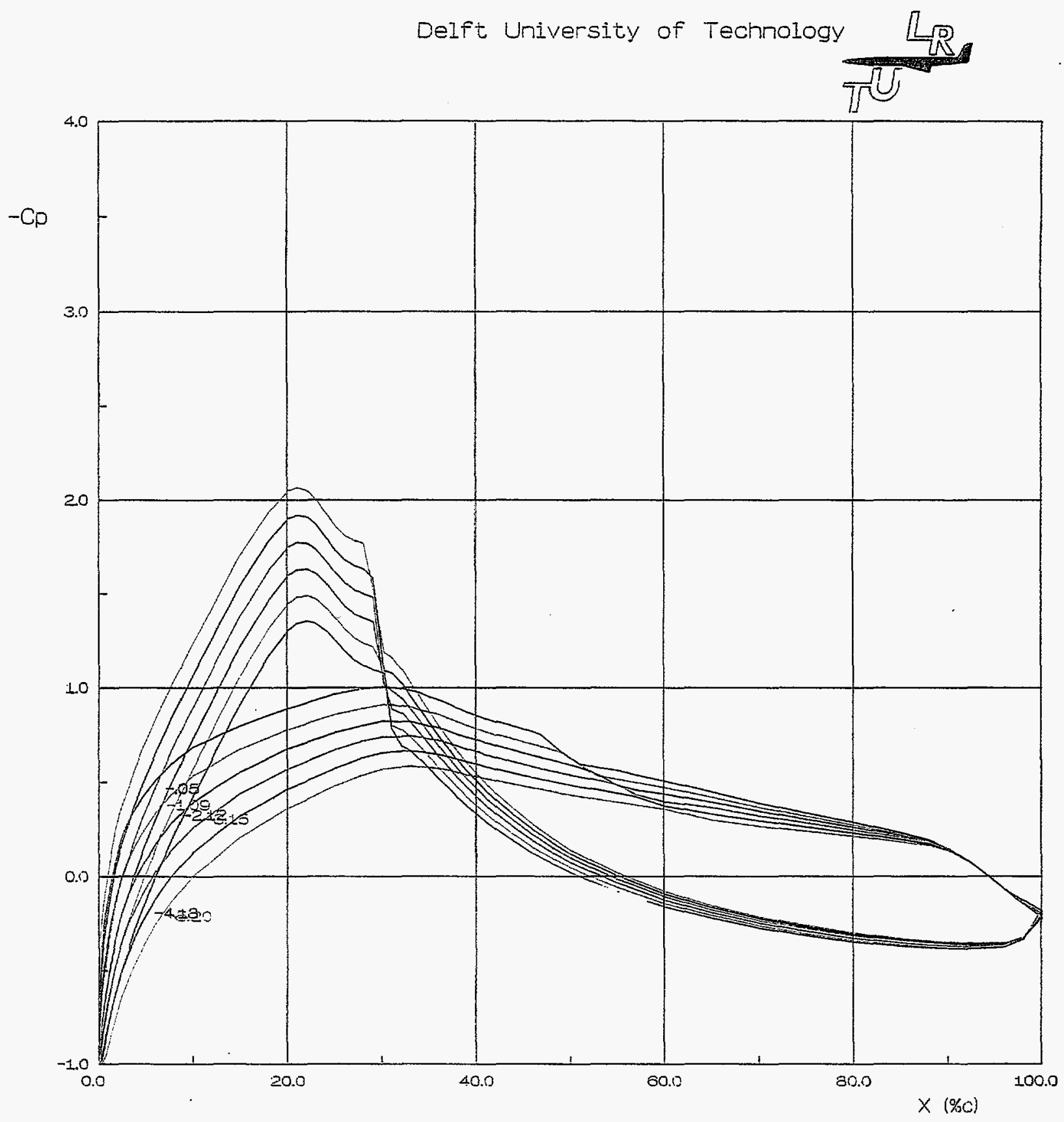

(e) $\alpha=-0.05^{\circ},-1.09^{\circ},-2.12^{\circ},-3.15^{\circ},-4.18^{\circ}$, and $-5.20^{\circ}$.

Figure 7.- Continued. 


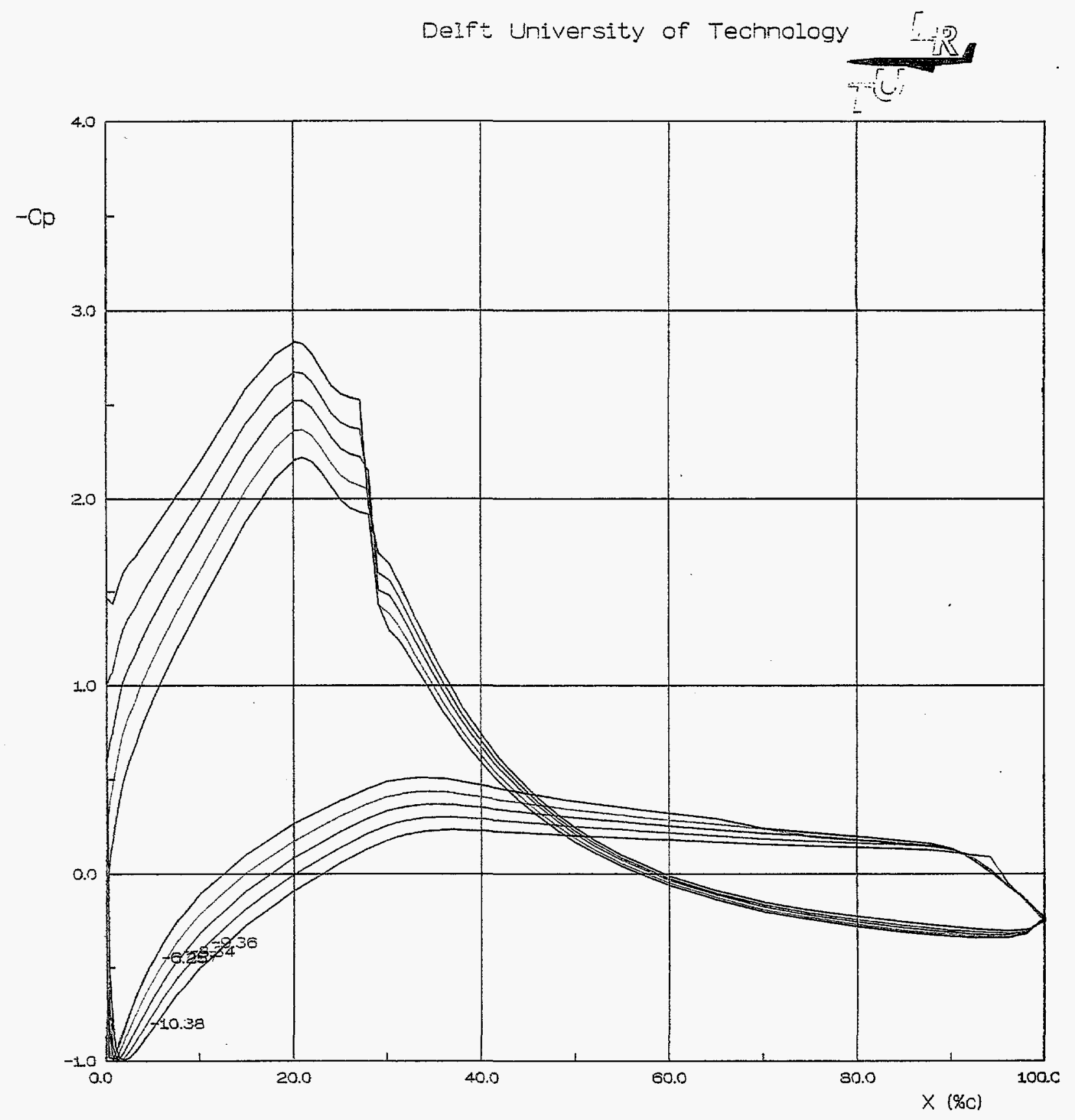

(f) $\alpha=-6.25^{\circ},-7.27^{\circ},-8.34^{\circ},-9.36^{\circ}$, and $-10.38^{\circ}$.

Figure 7.- Continued. 


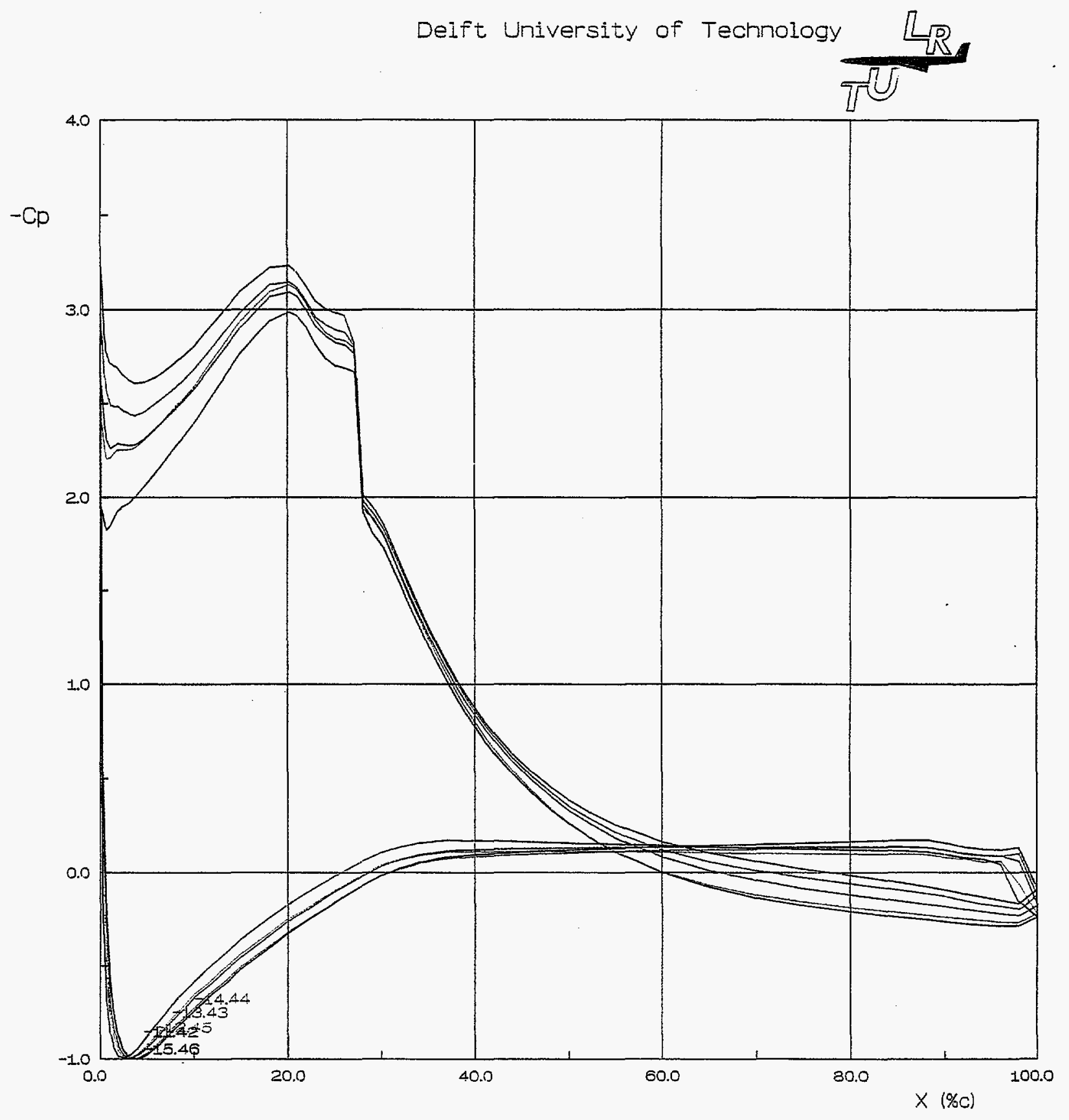

(g) $\alpha=-11.42^{\circ},-12.45^{\circ},-13.43^{\circ},-14.44^{\circ}$, and $-15.46^{\circ}$.

Figure 7.- Continued. 


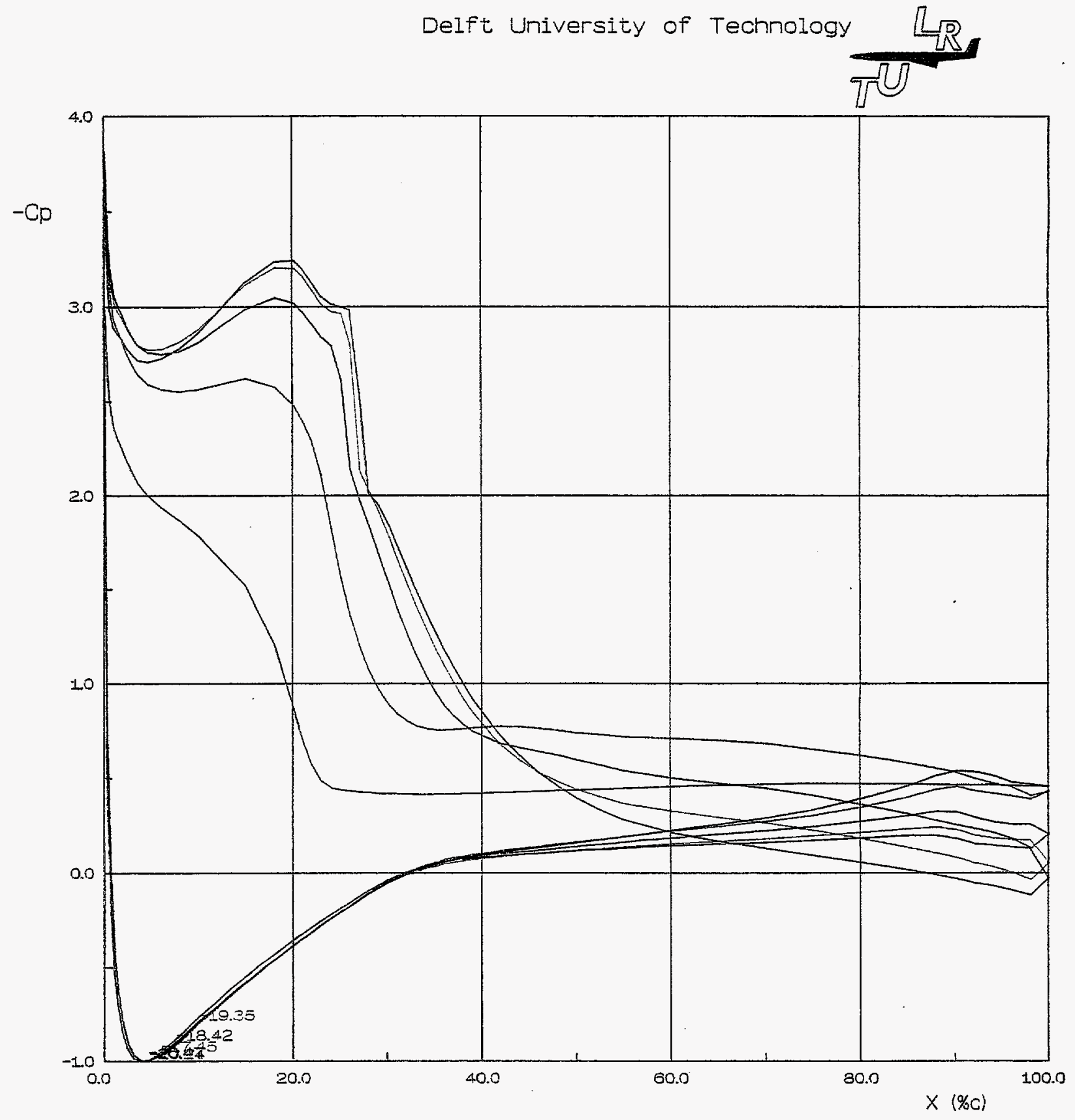

(h) $\alpha=-16.47^{\circ},-17.45^{\circ},-18.42^{\circ},-19.35^{\circ}$, and $-20.24^{\circ}$.

Figure 7.- Continued. 


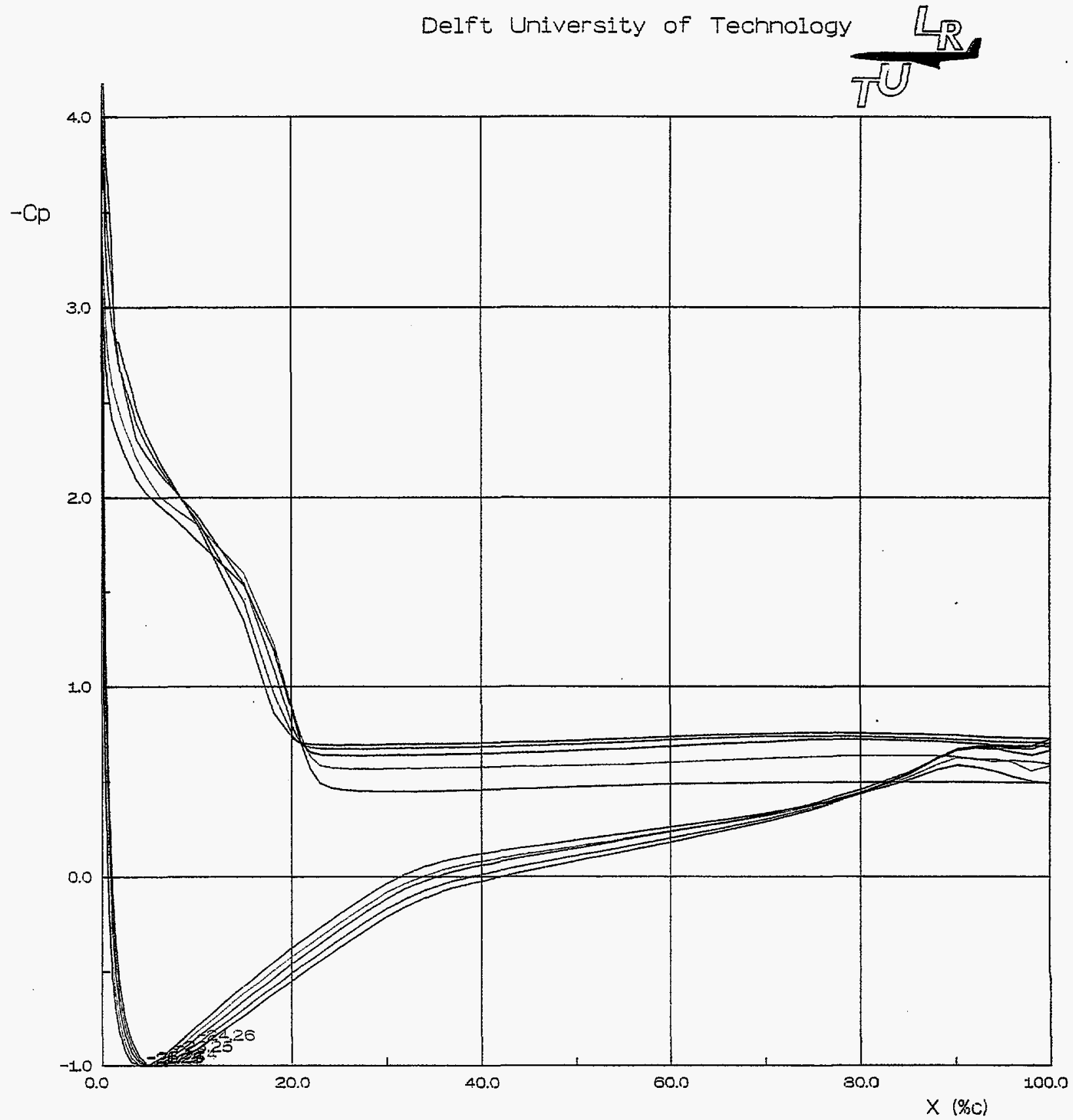

(i) $\alpha=-21.25^{\circ},-22.24^{\circ},-23.25^{\circ},-24.26^{\circ}$, and $-25.25^{\circ}$.

Figure 7.- Continued. 


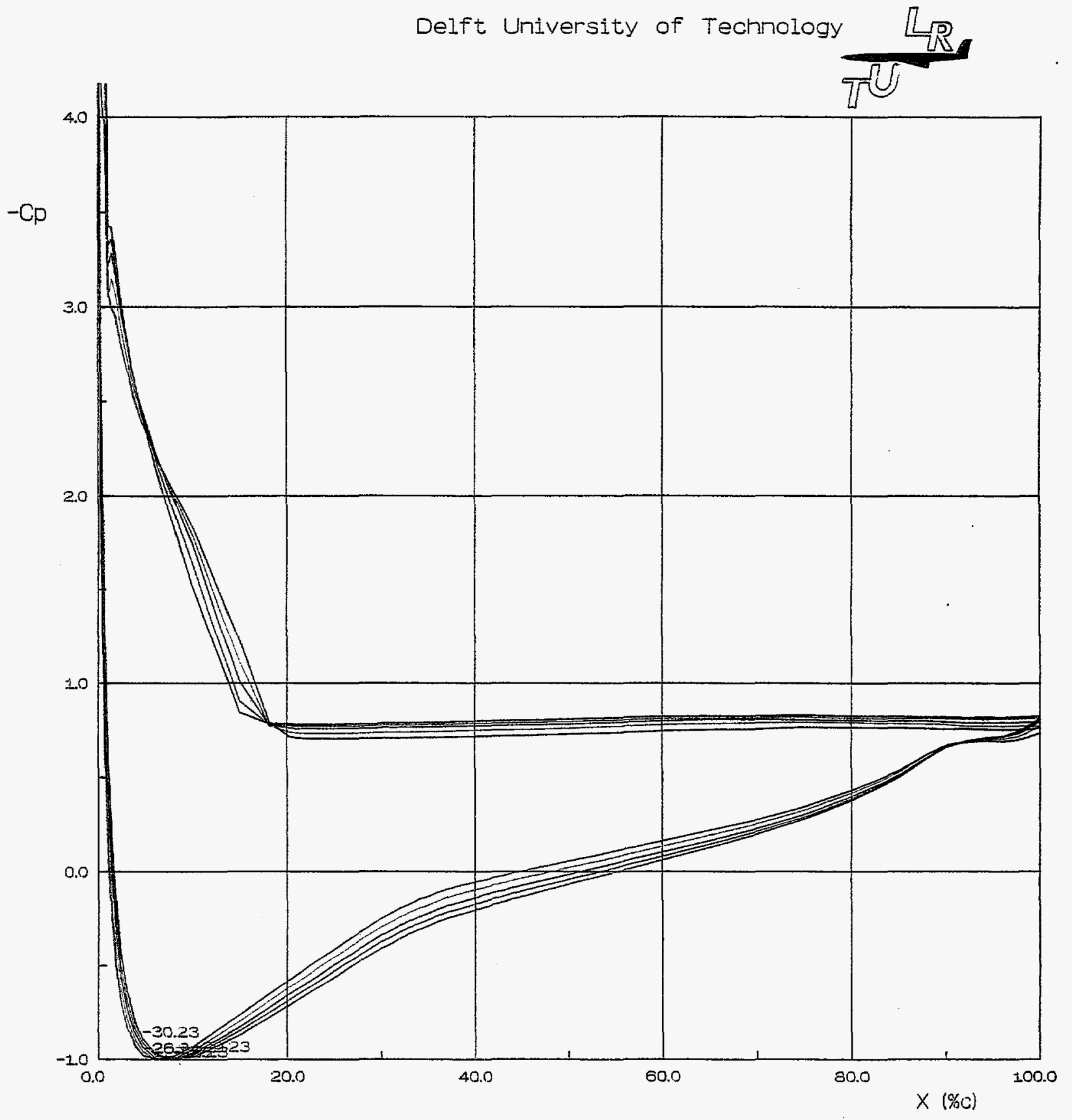

(j) $\alpha=-26.24^{\circ},-27.25^{\circ},-28.23^{\circ},-29.23^{\circ}$, and $-30.23^{\circ}$.

Figure 7.- Concluded. 


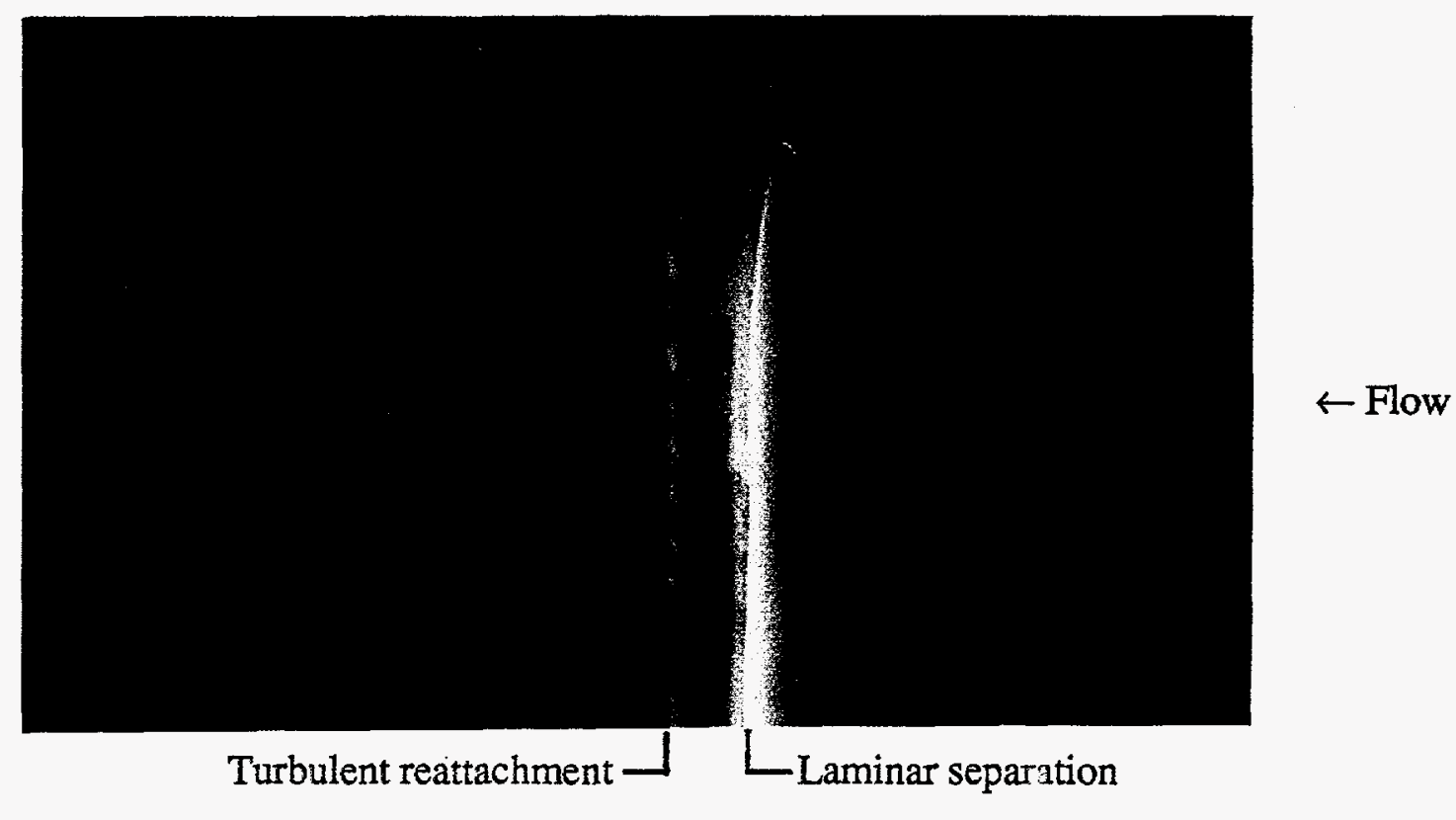

(a) Oil flow.

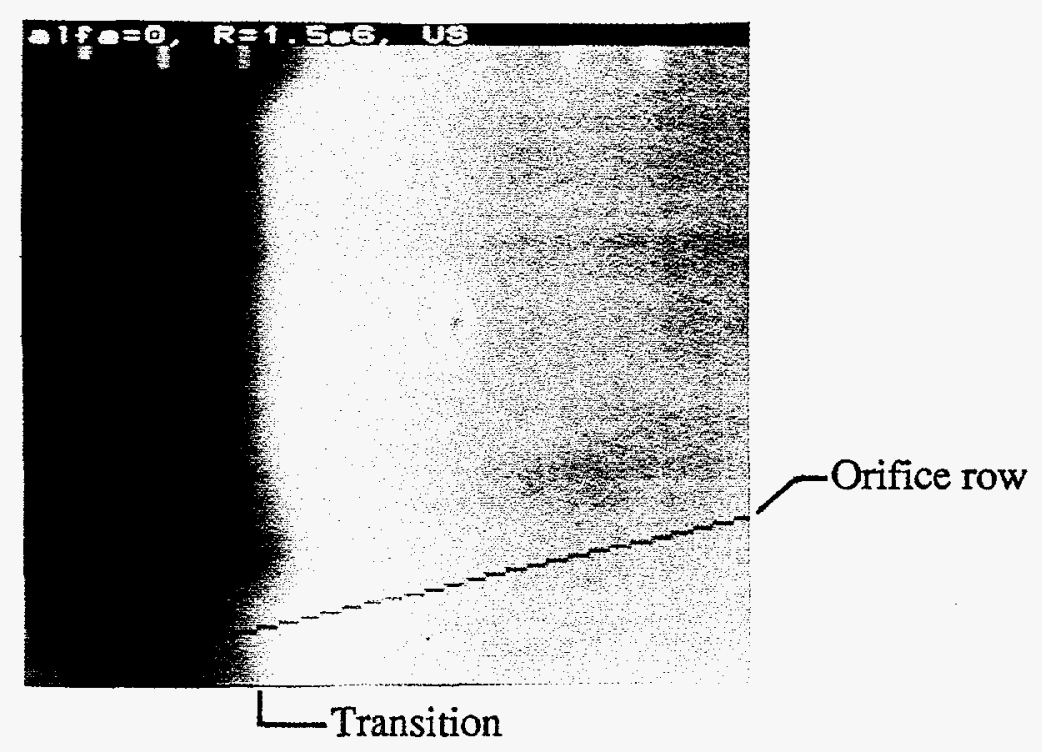

(b) Infrared.

Figure 8.- Upper-surface flow visualization at $c_{l}=0.4$ for $R=1.5 \times 10^{6}$ and $M=0.10$. 


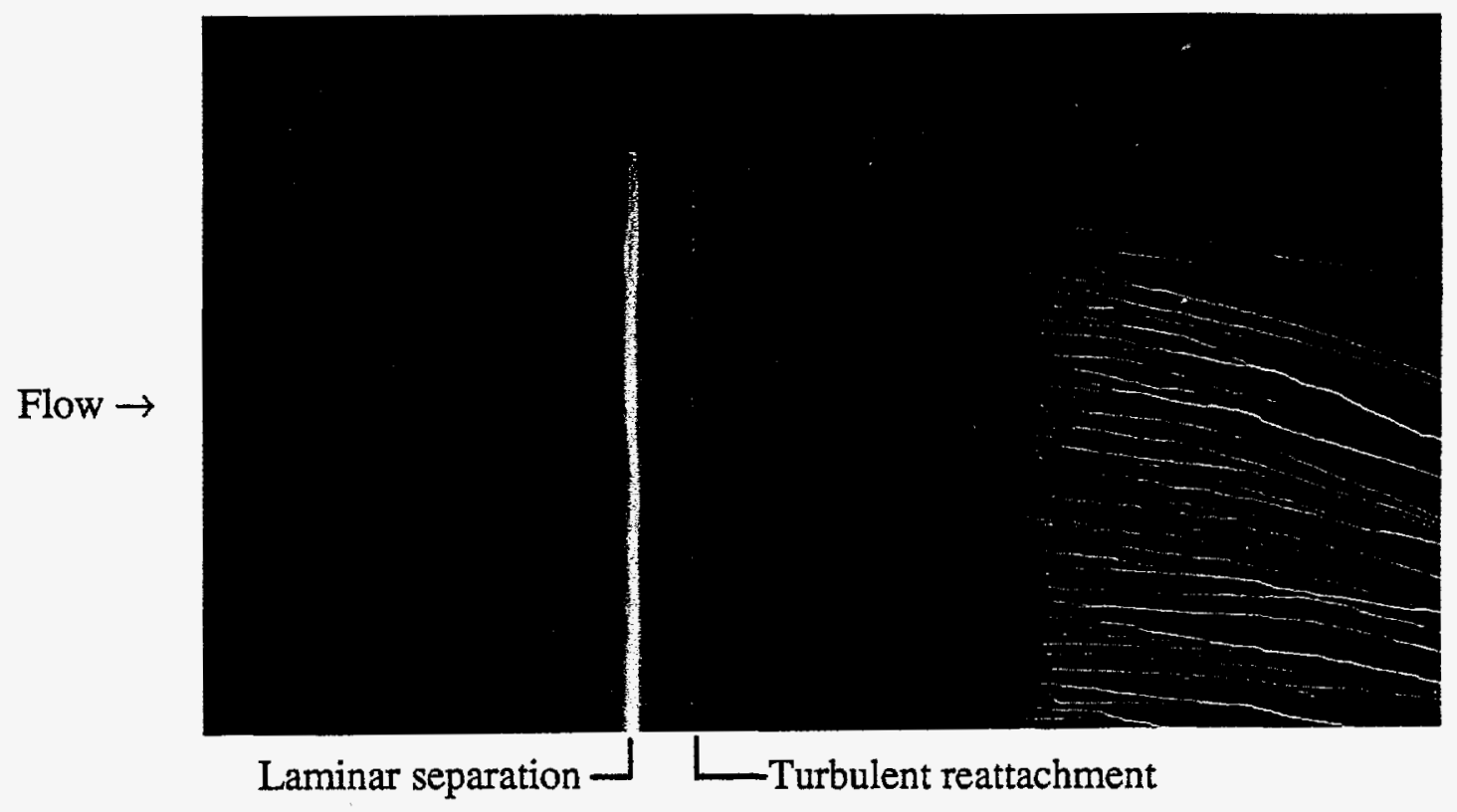

(a) Oil flow.

Flow $\rightarrow$

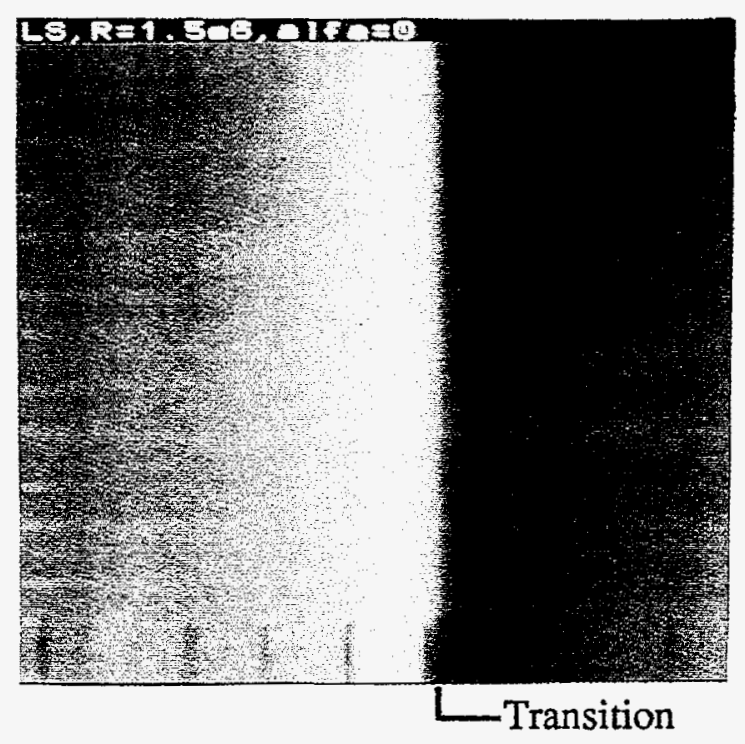

(b) Infrared.

Figure 9.- Lower-surface flow visualization at $c_{l}=0.4$ for $R=1.5 \times 10^{6}$ and $\mathrm{M}=0.10$. 


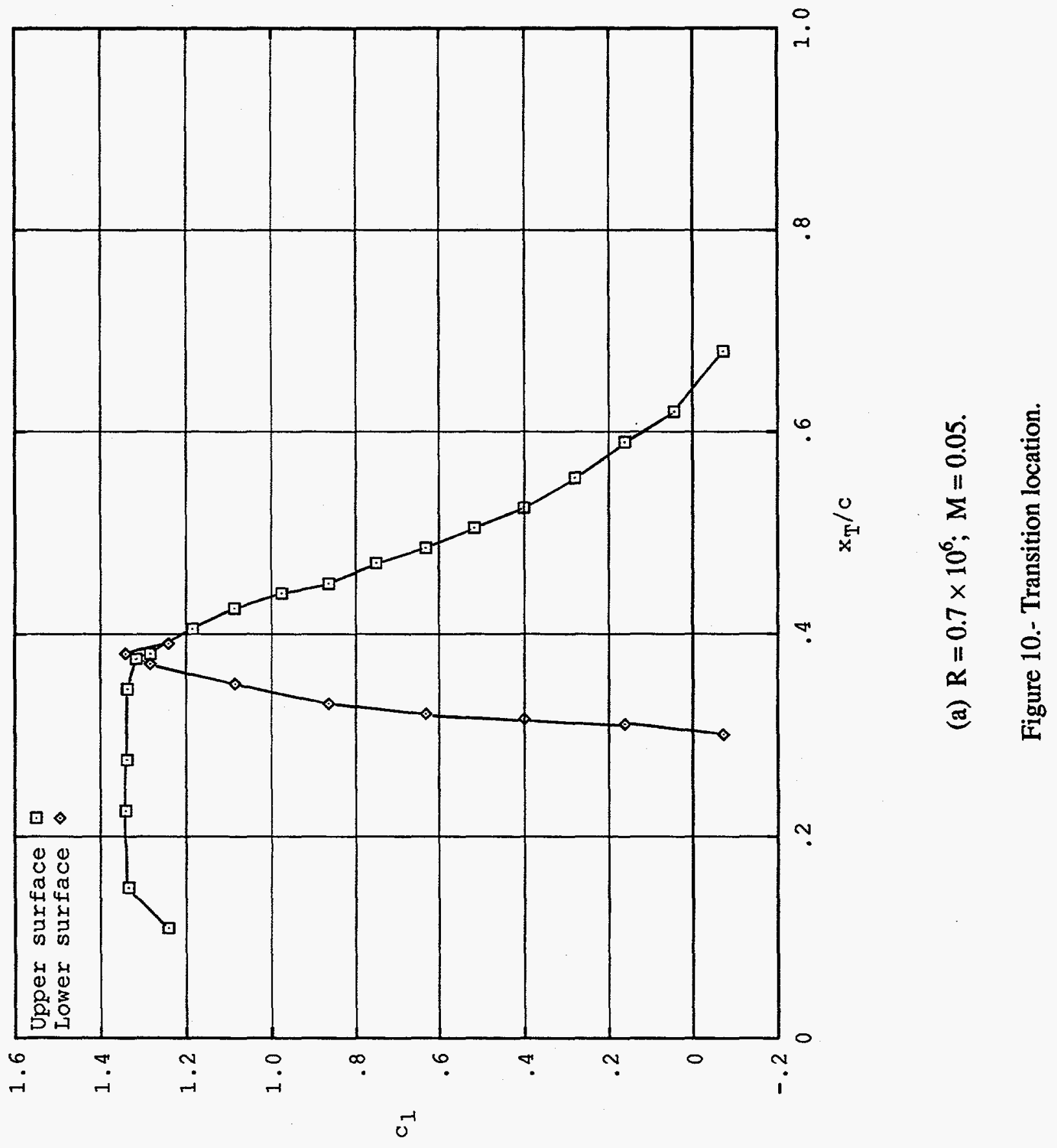




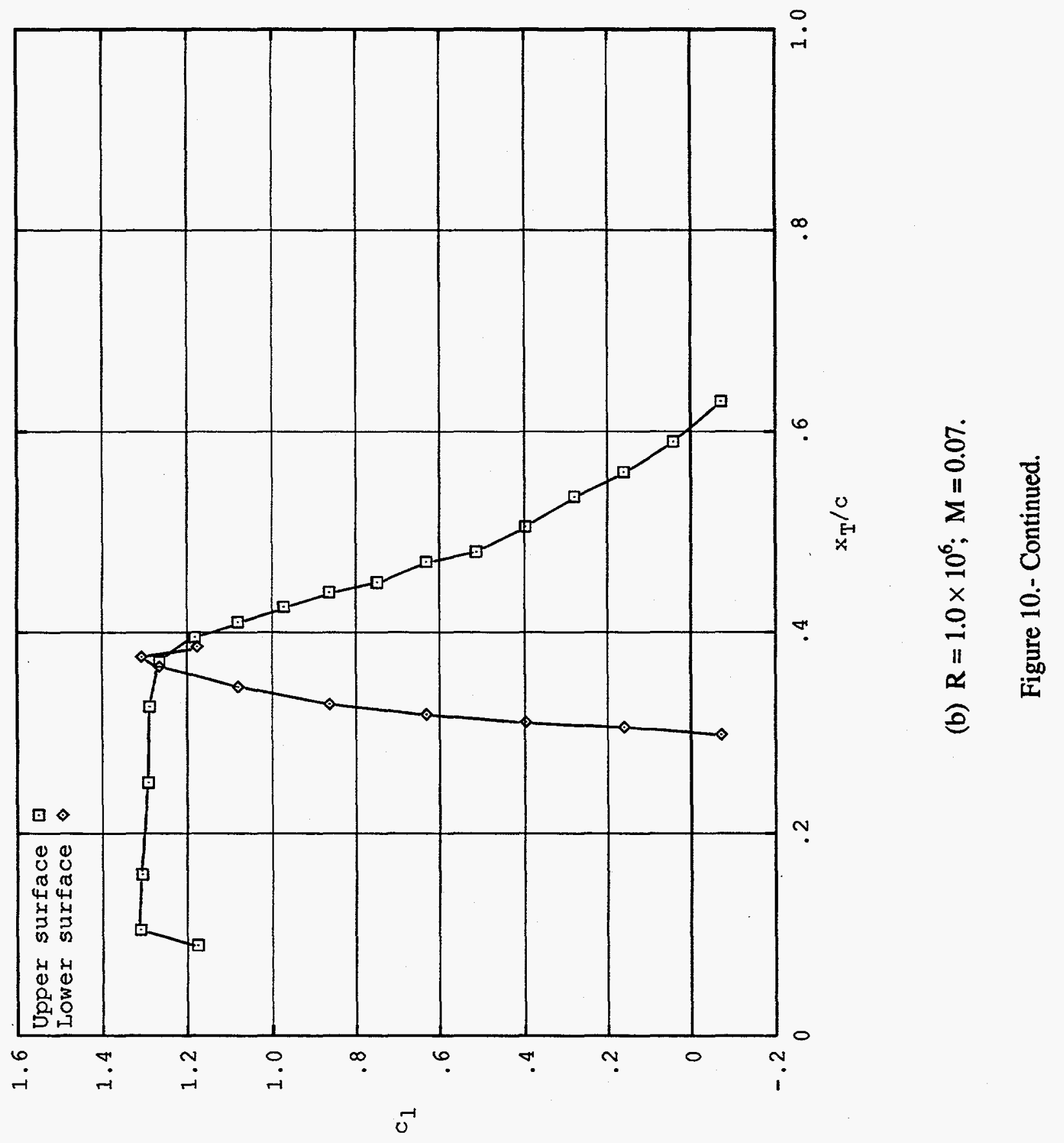




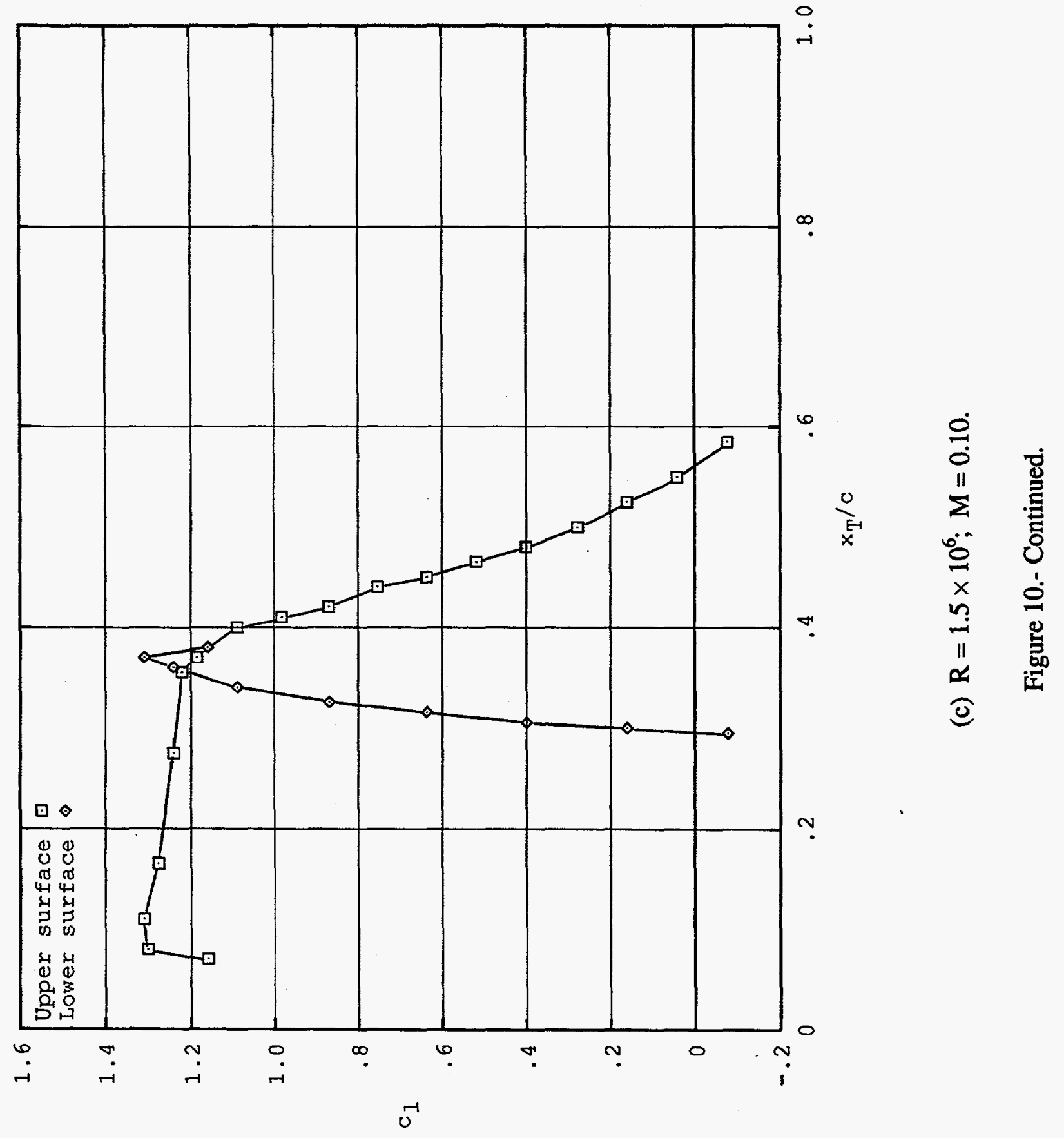




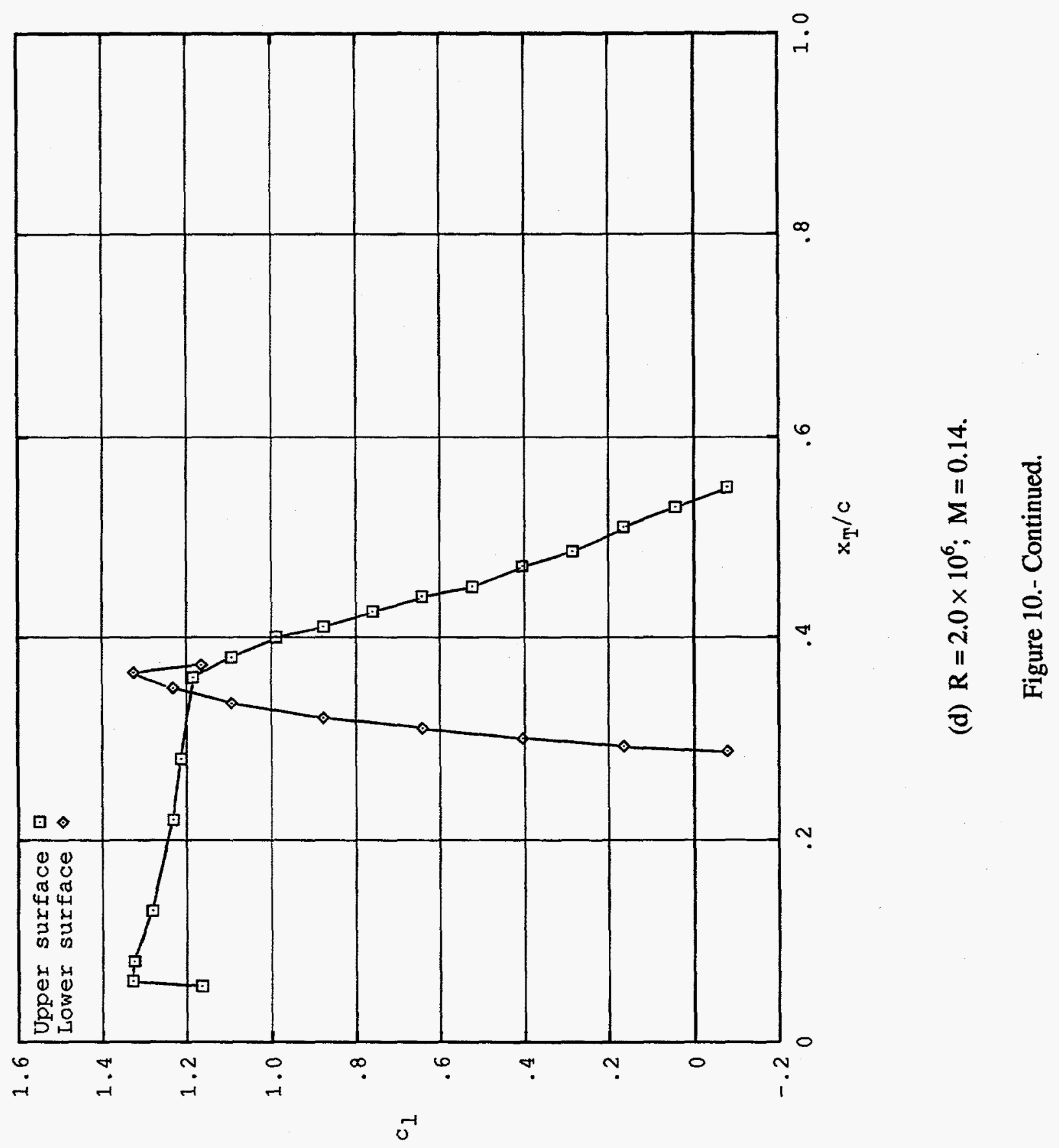




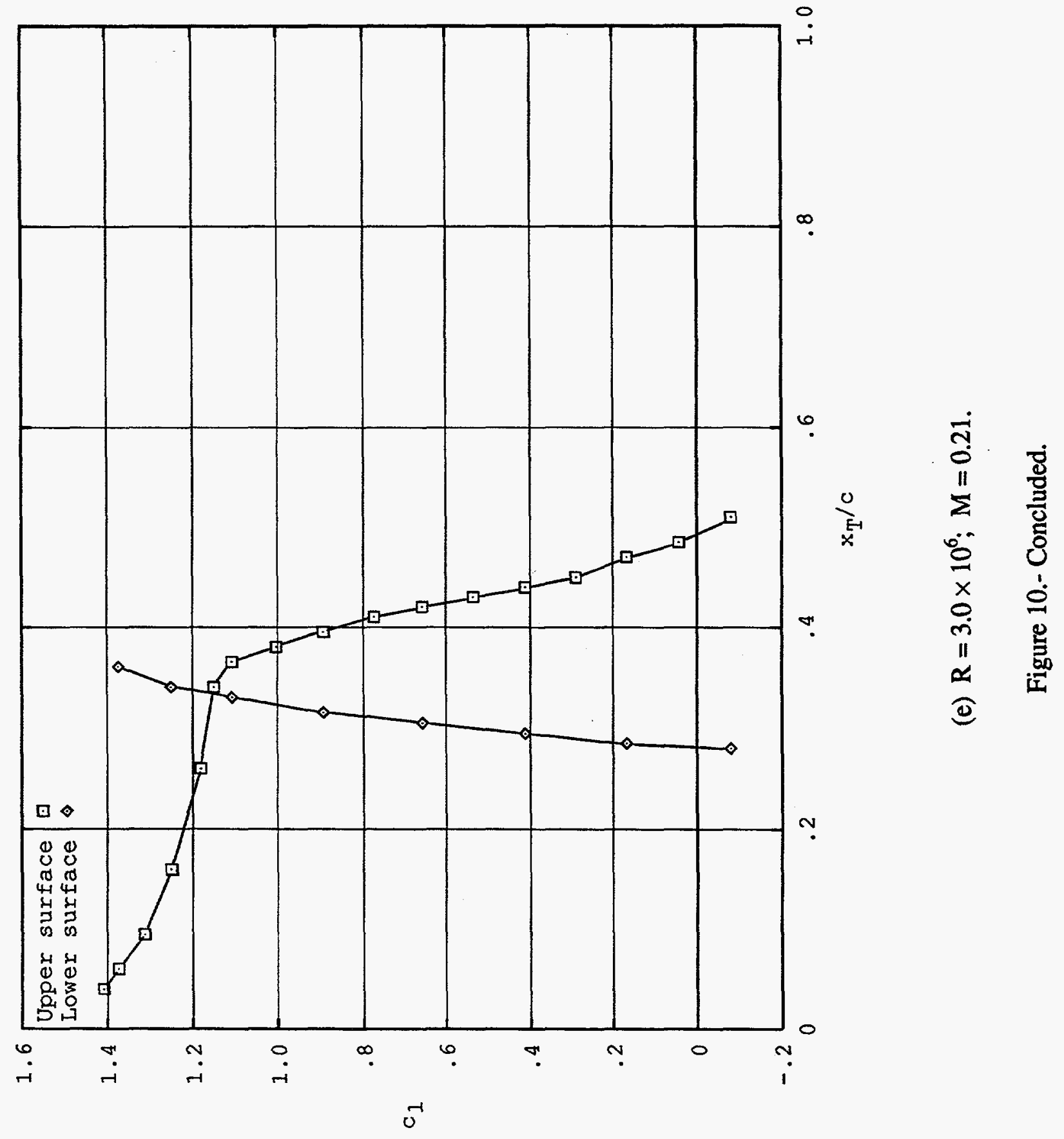




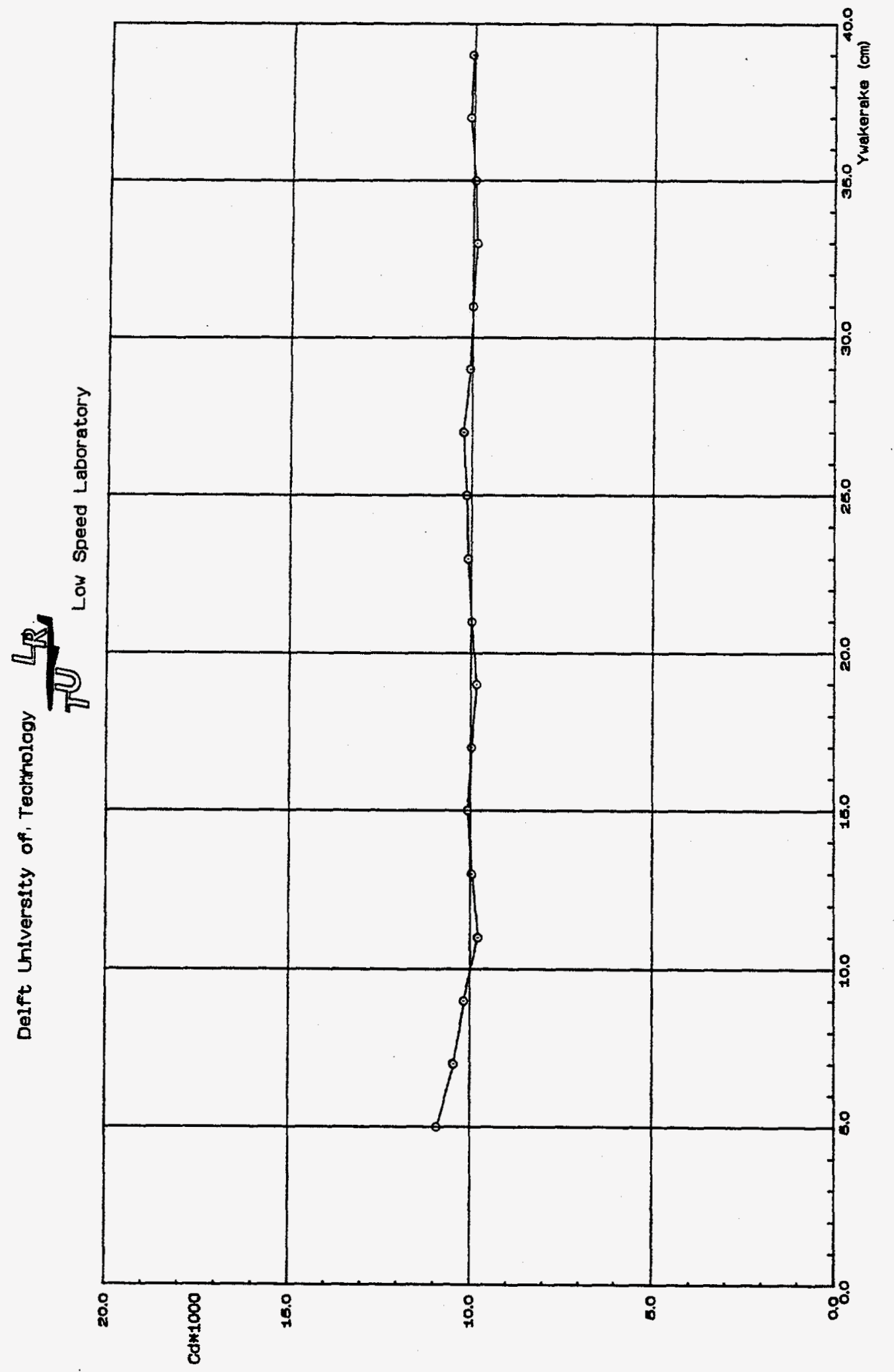

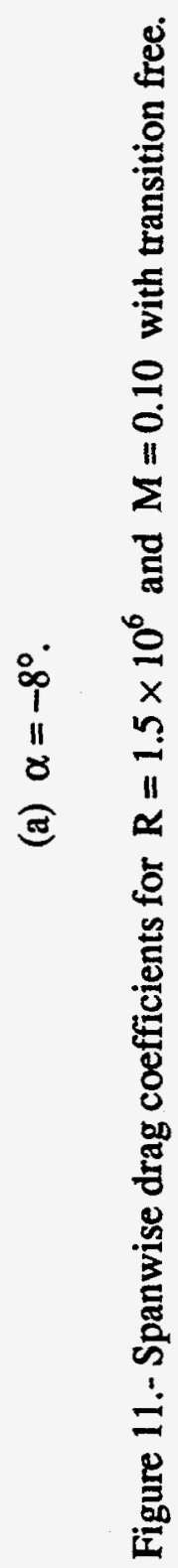




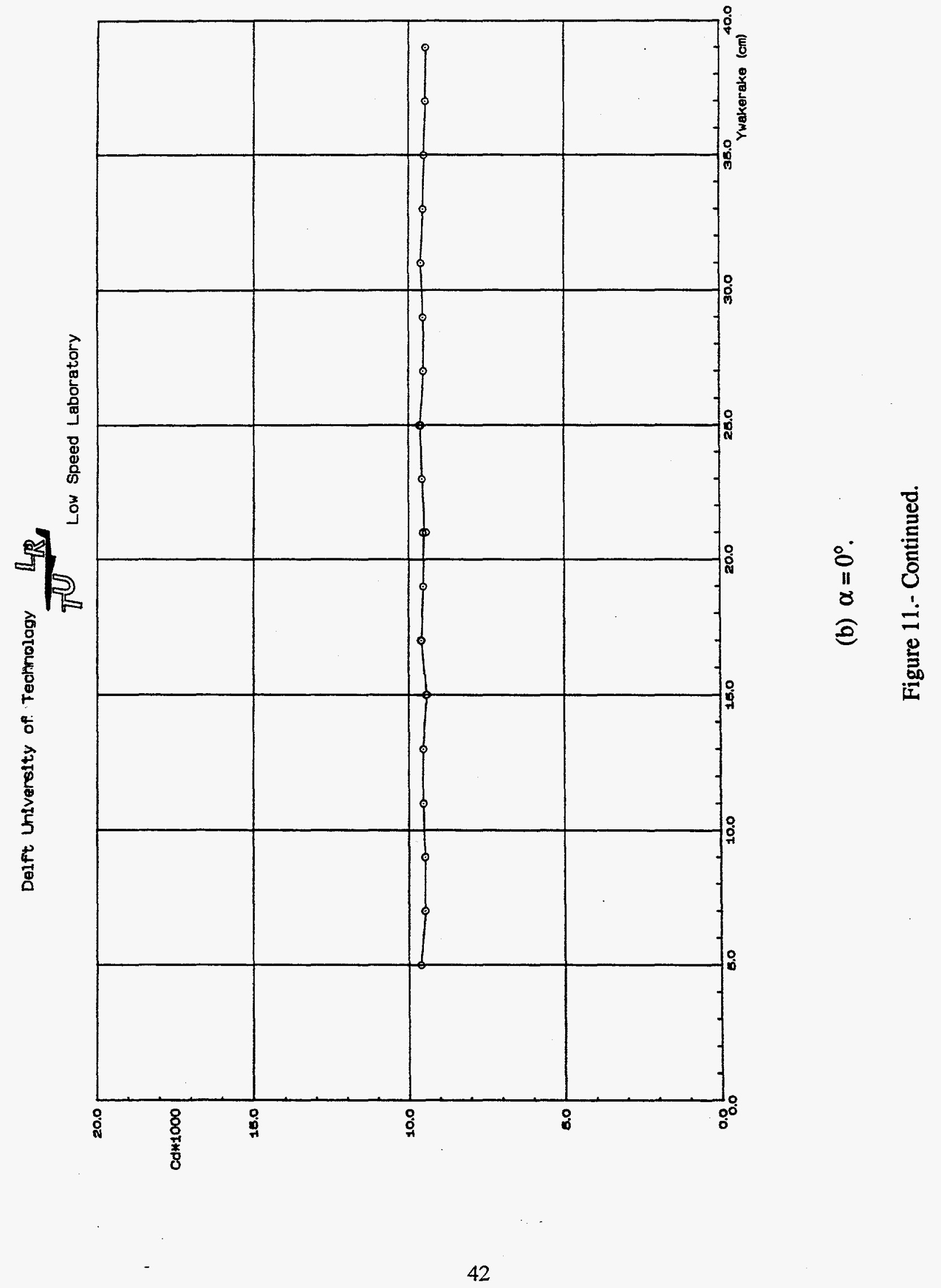




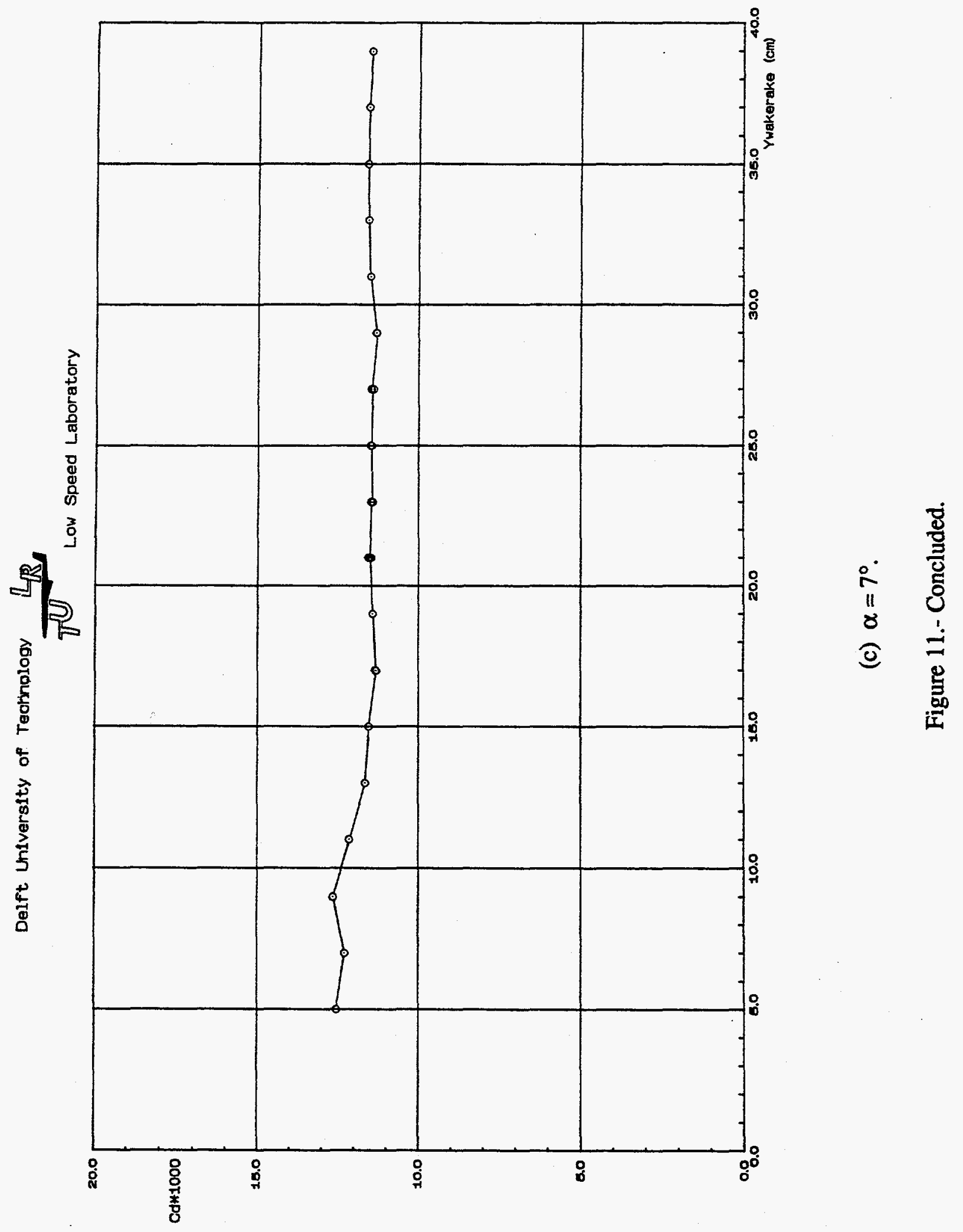




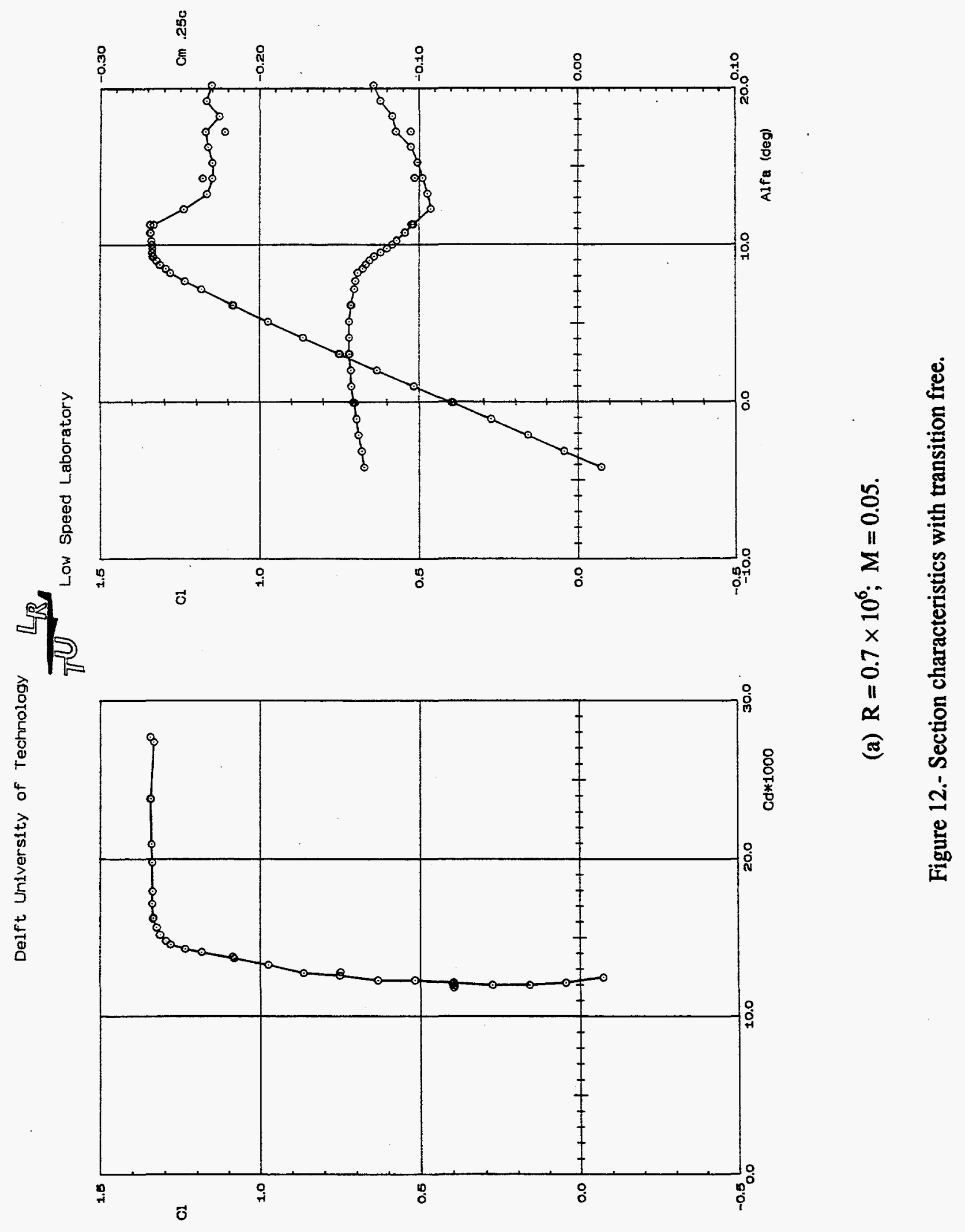




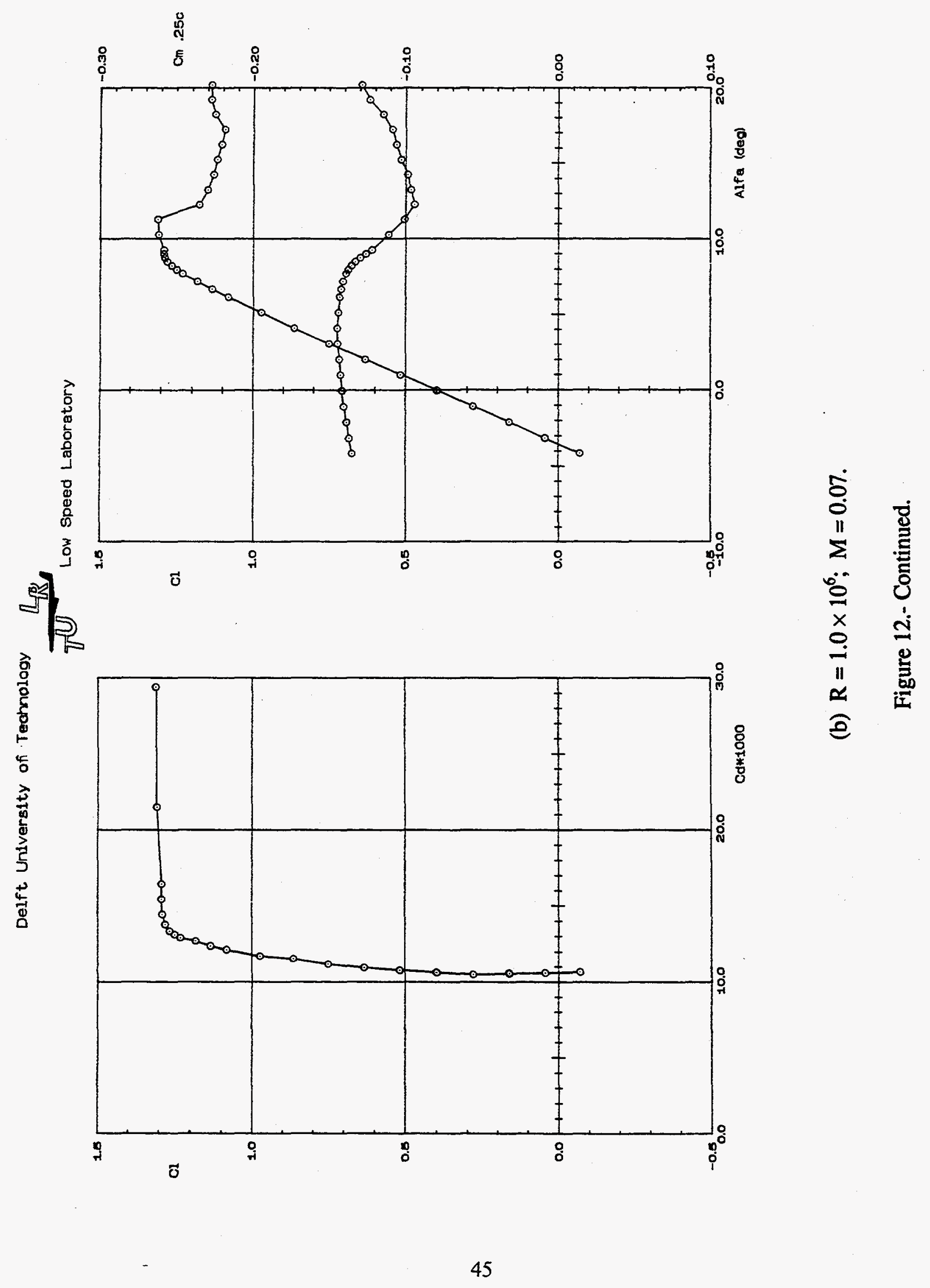




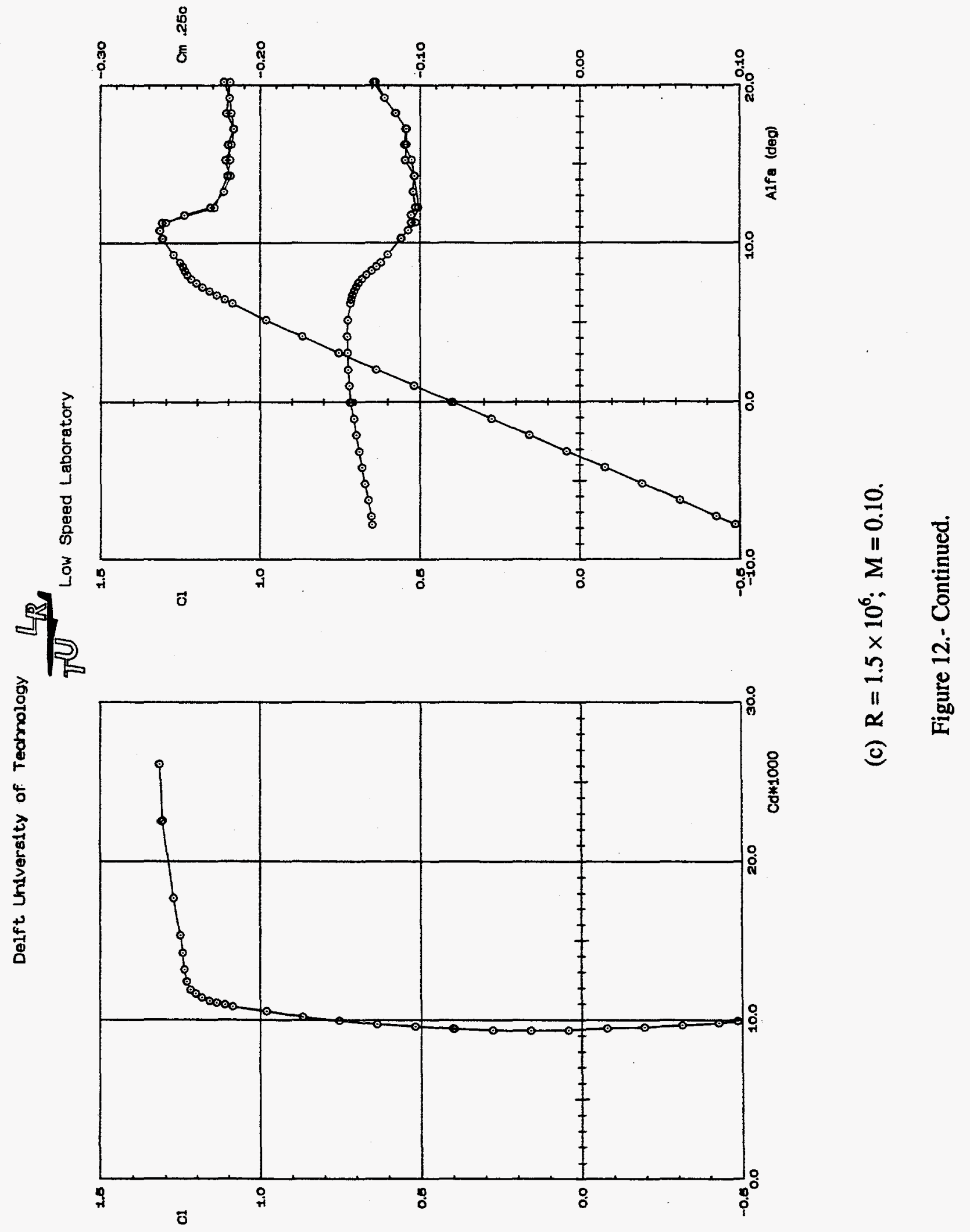




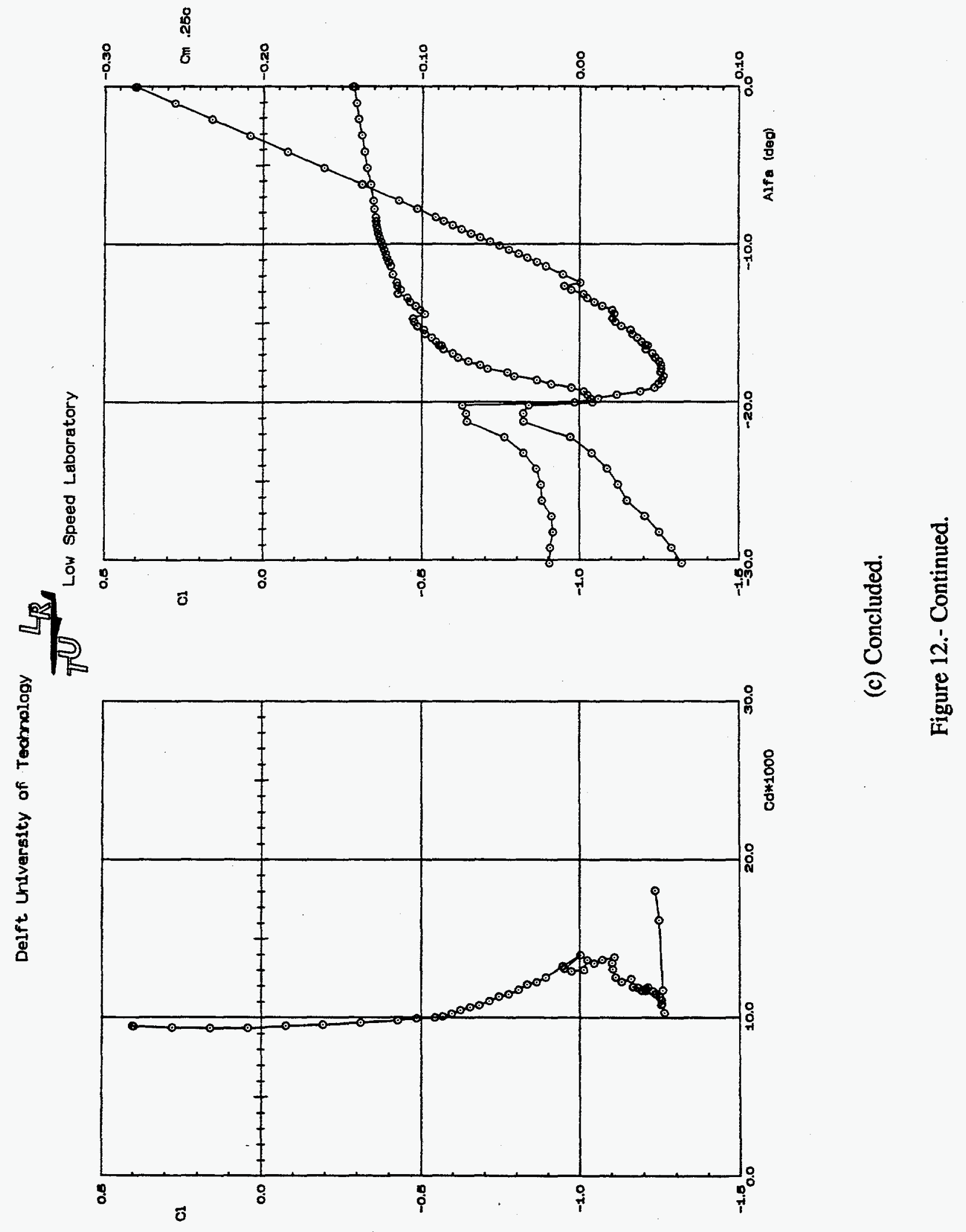




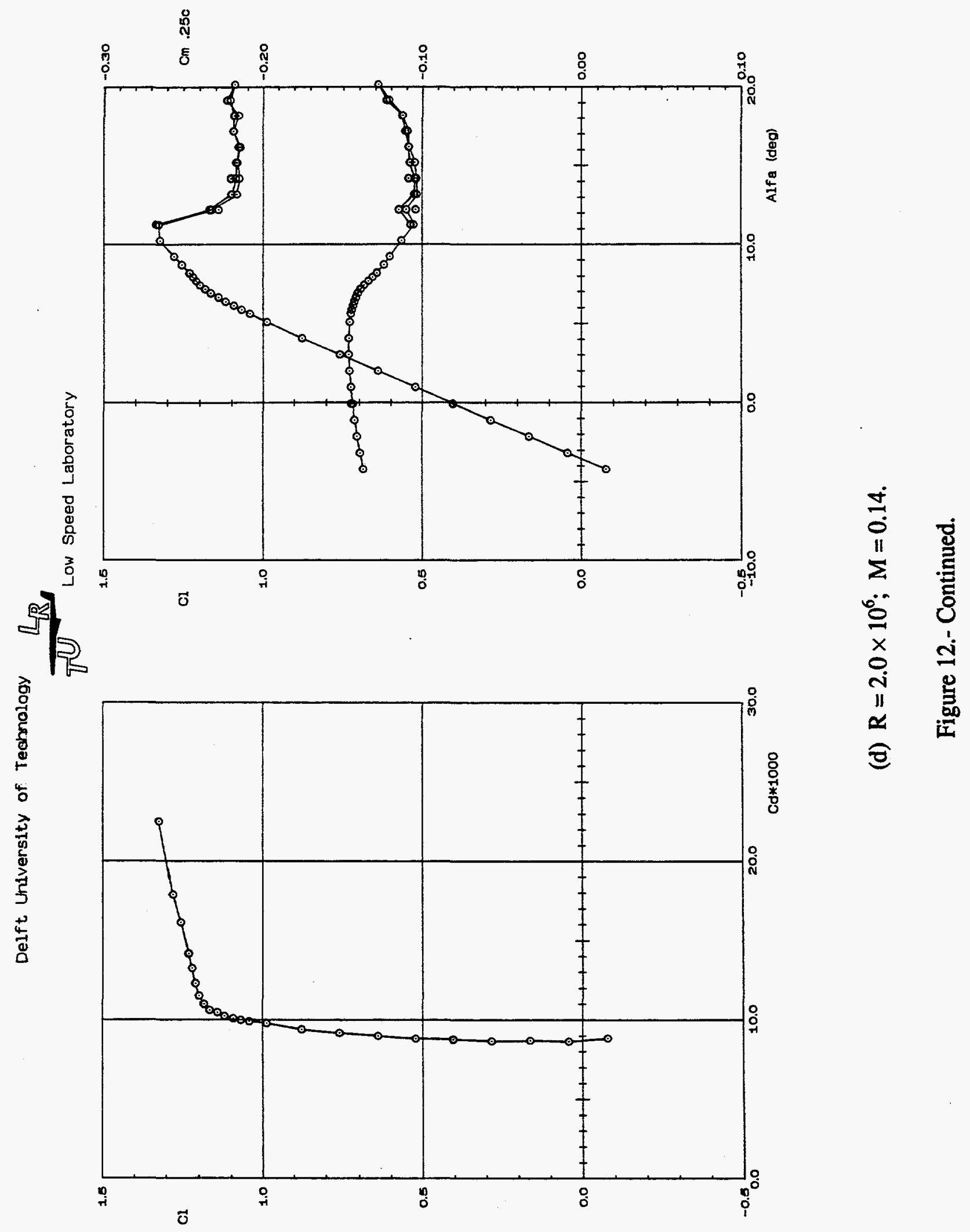




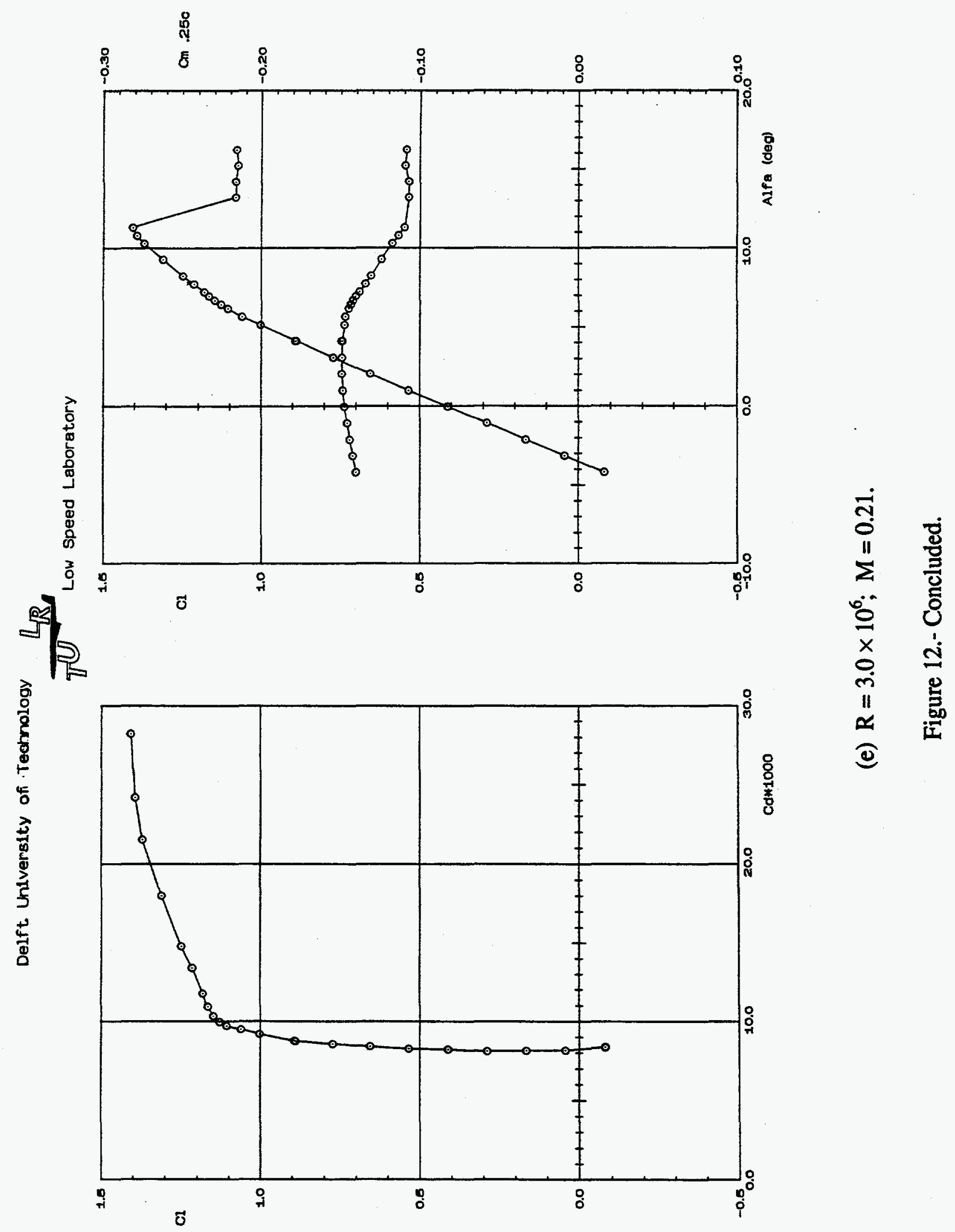




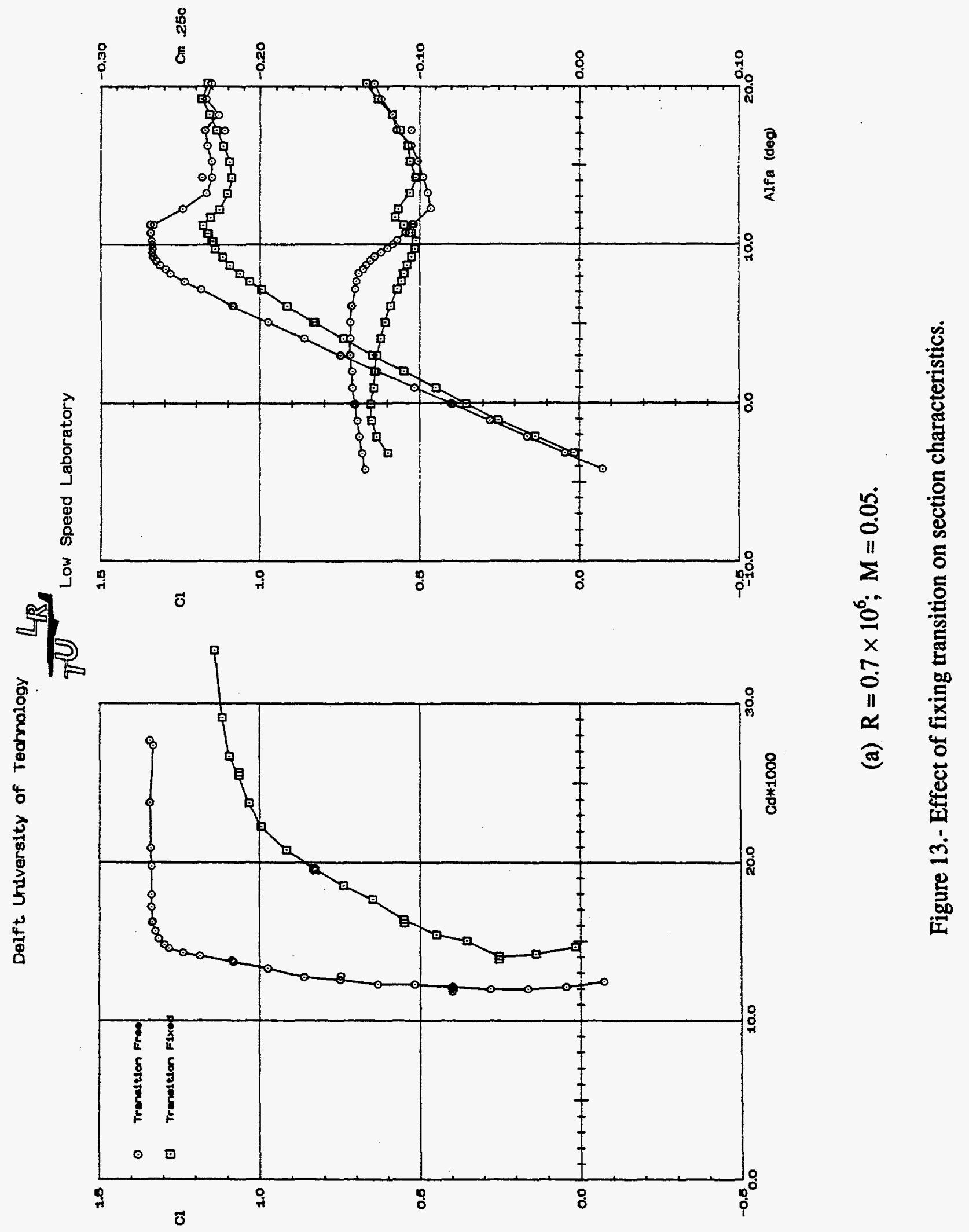




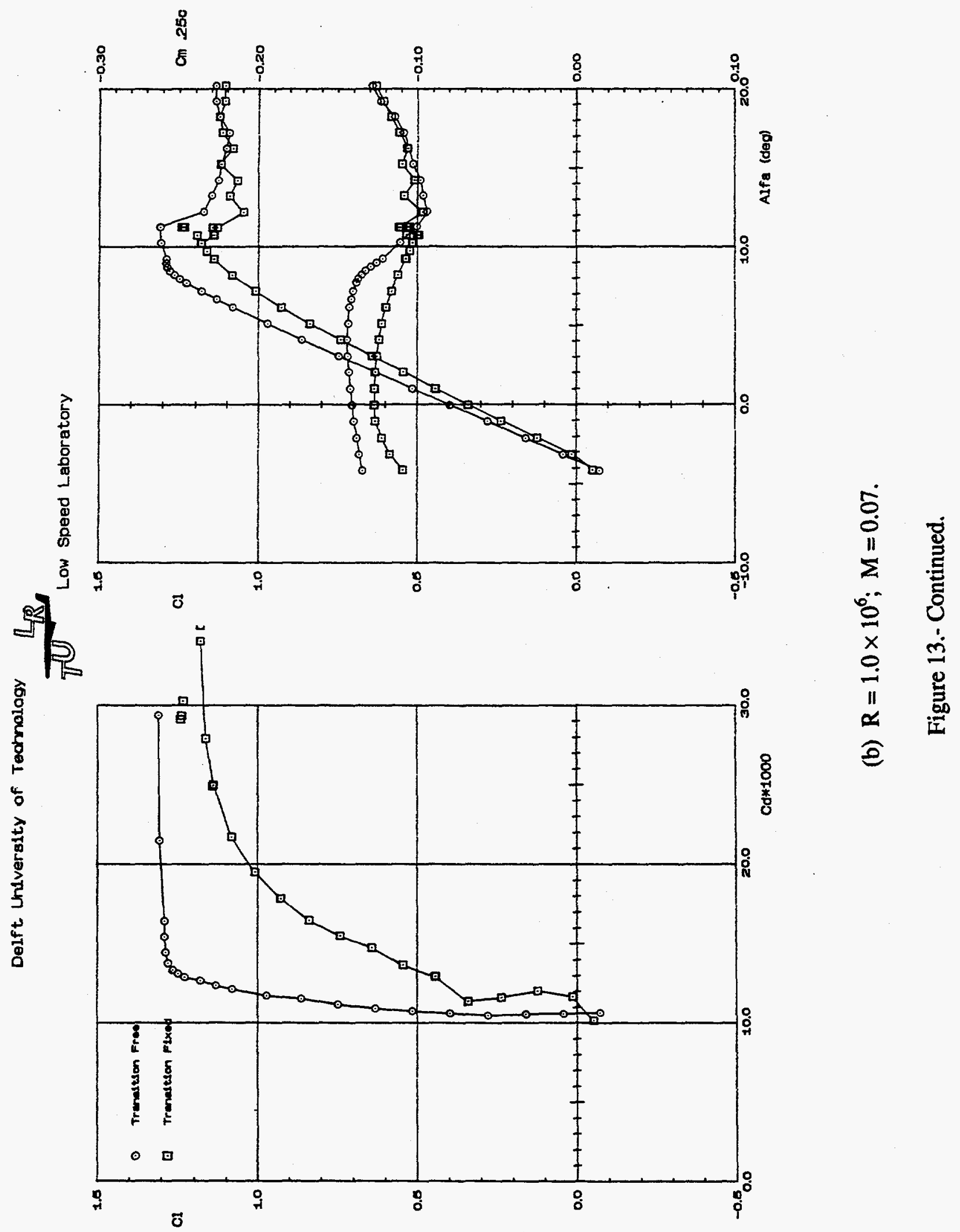




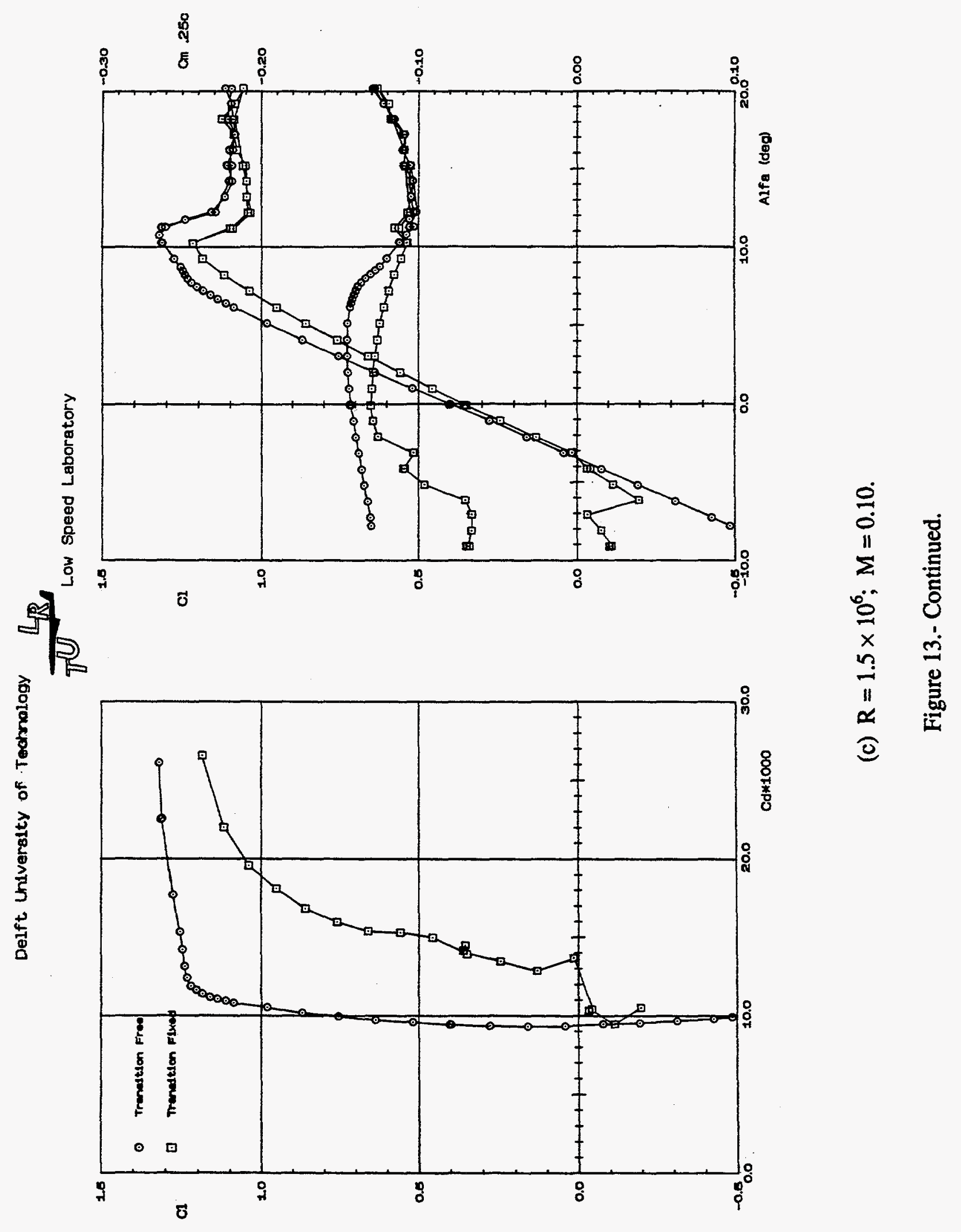




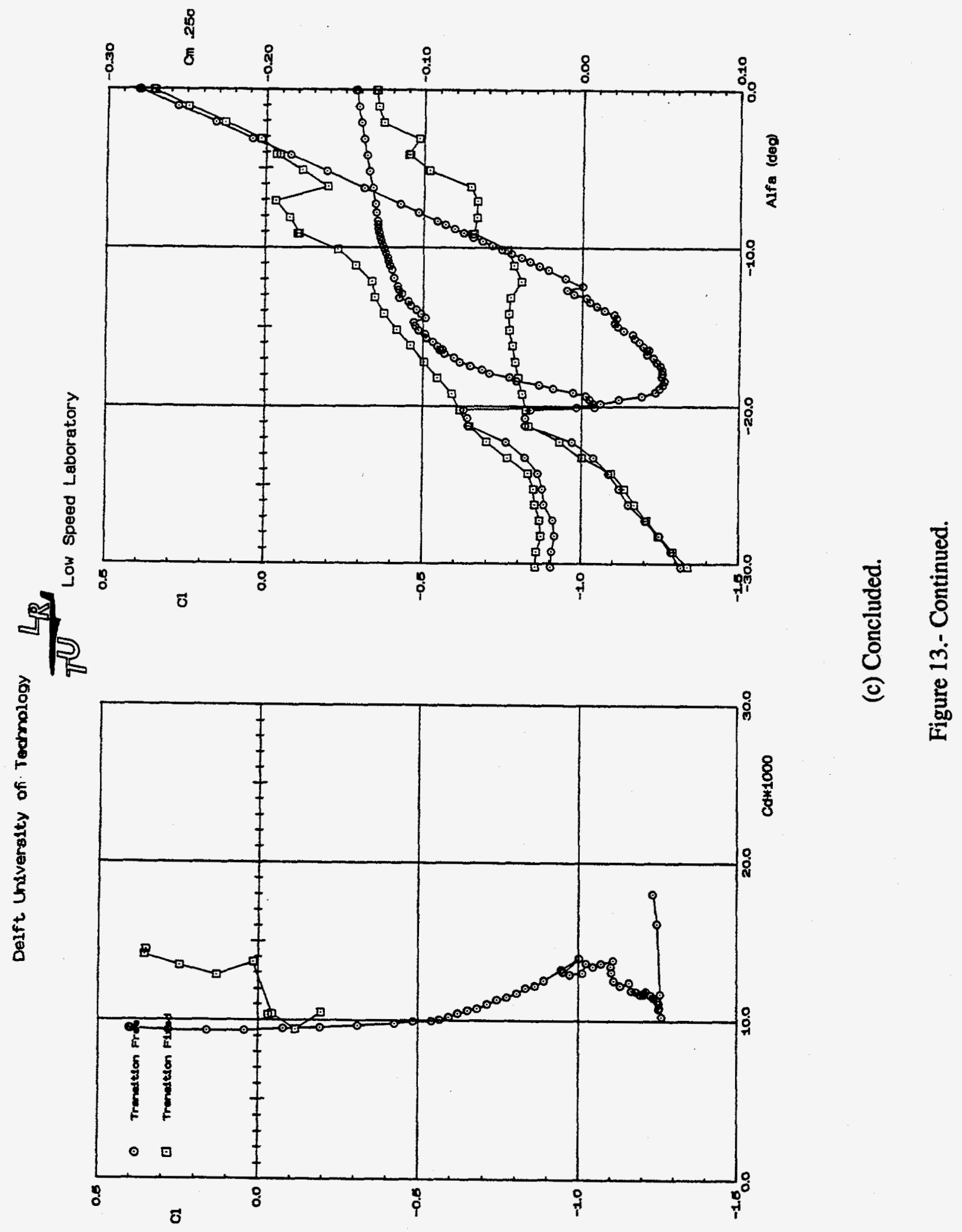




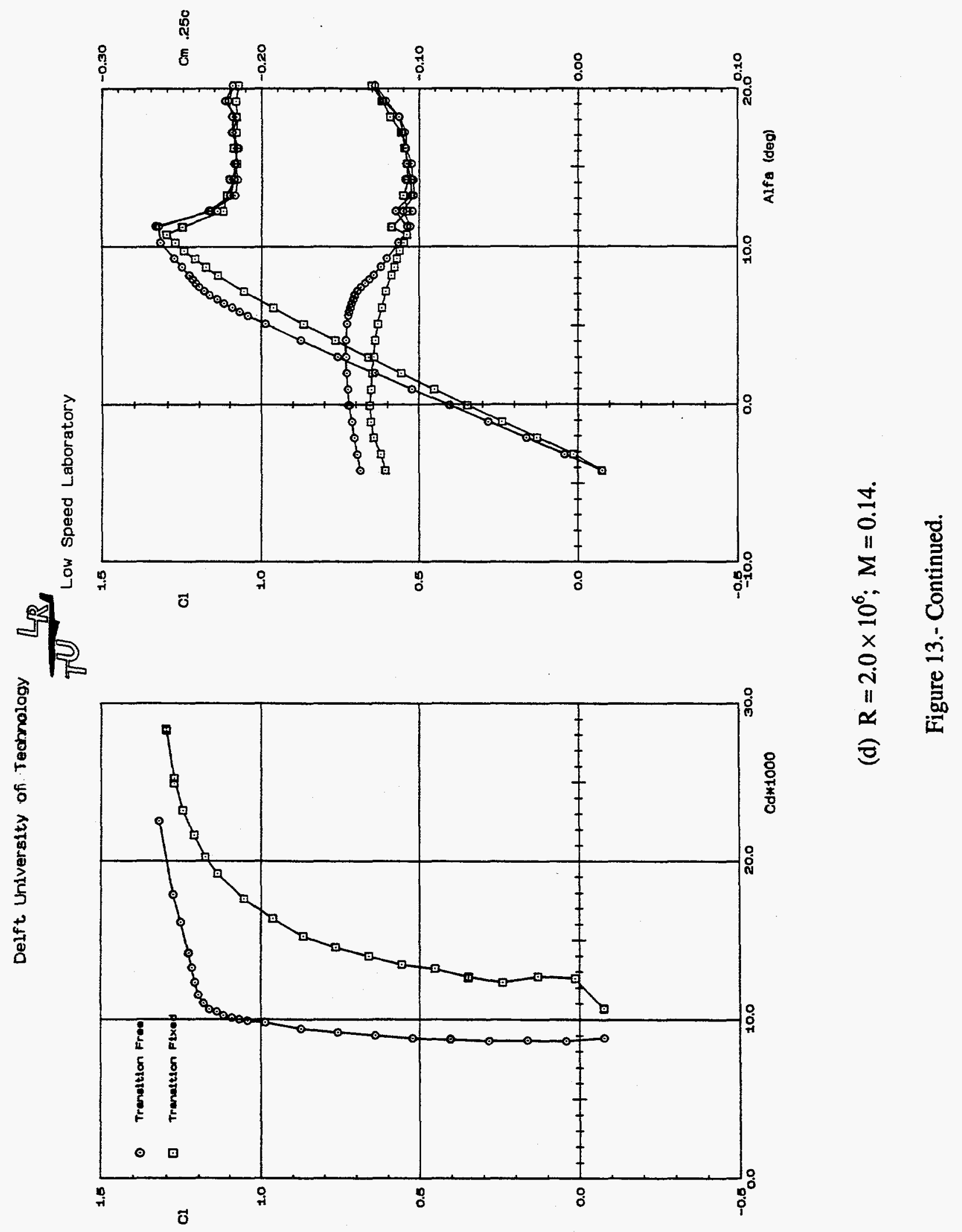




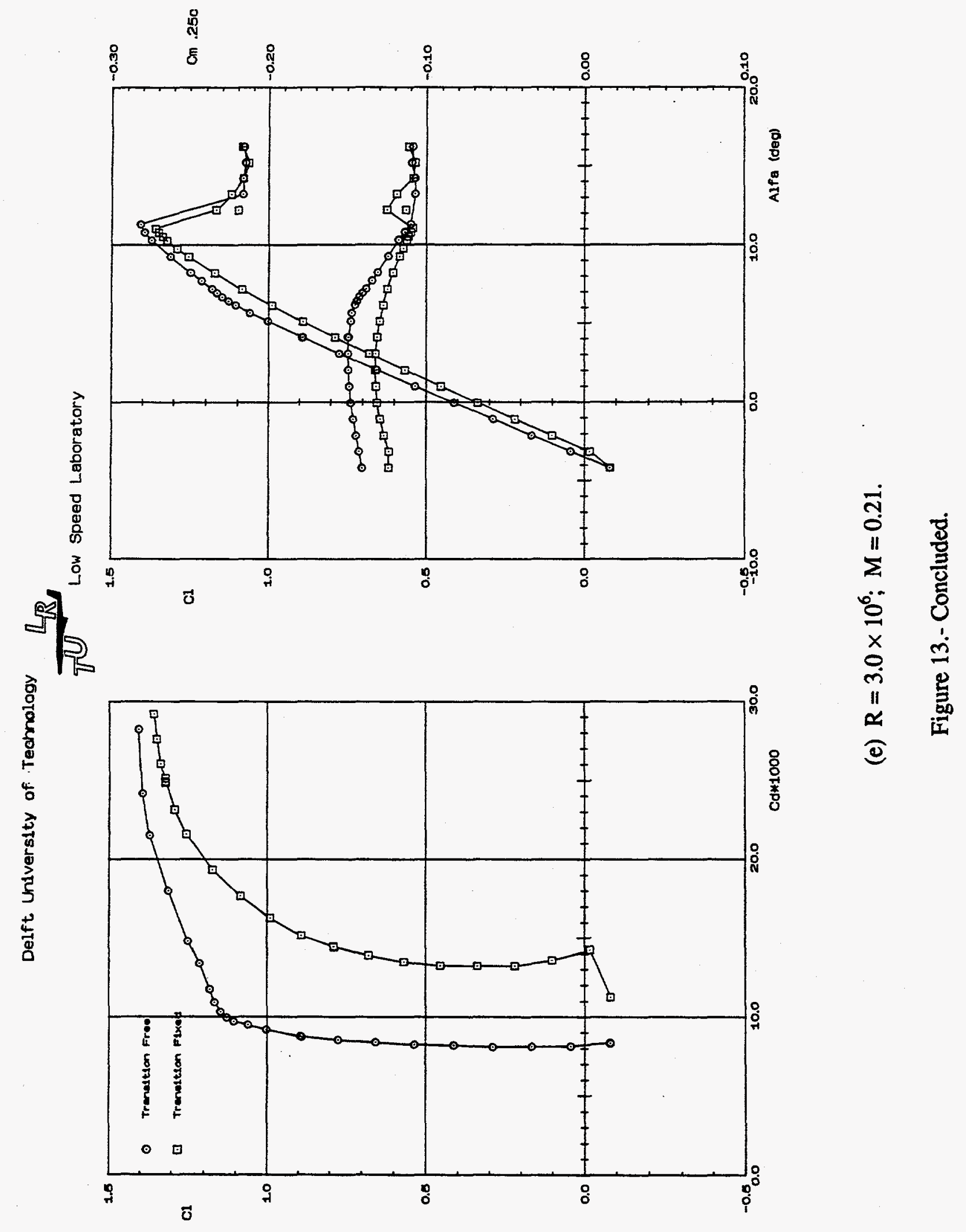




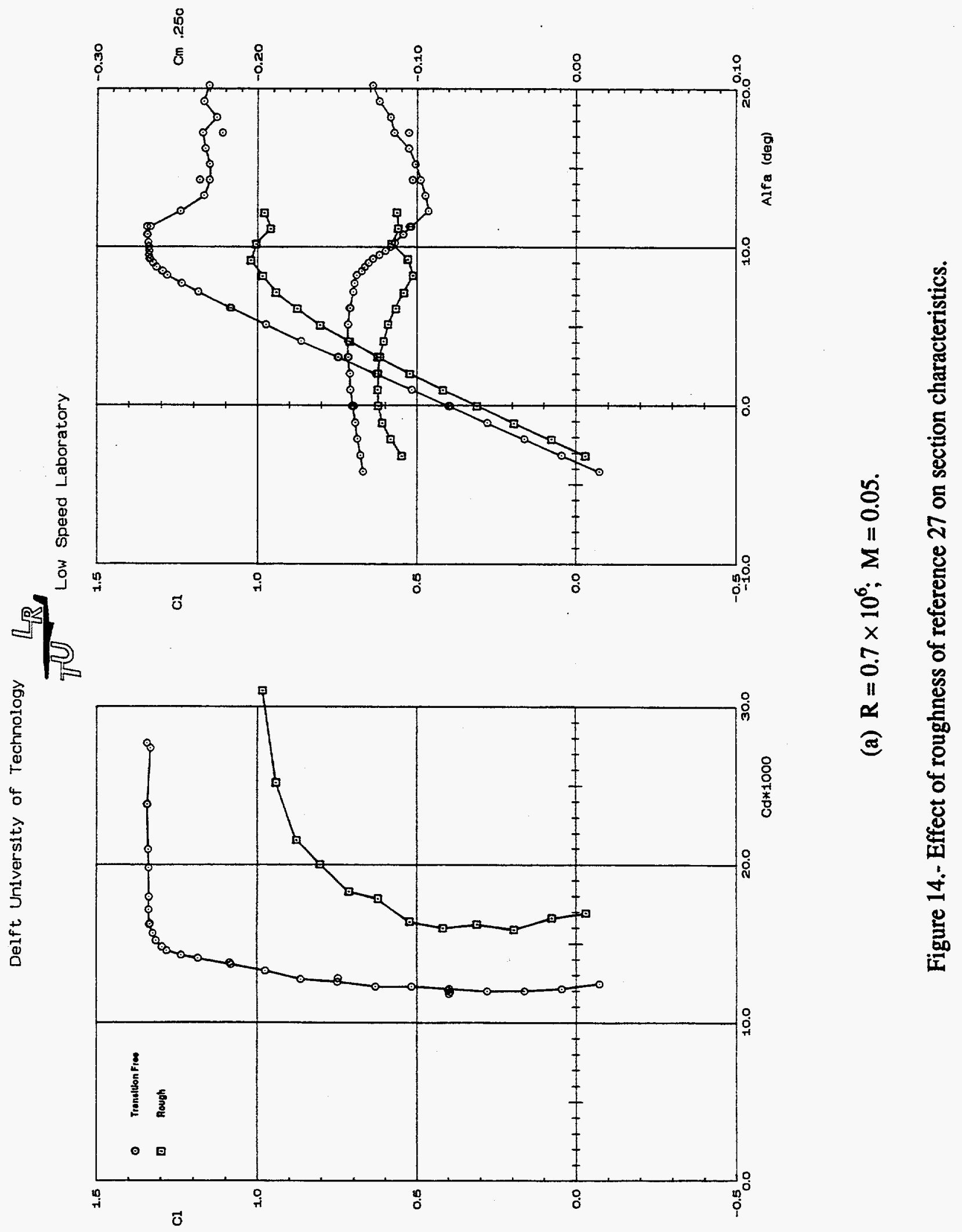




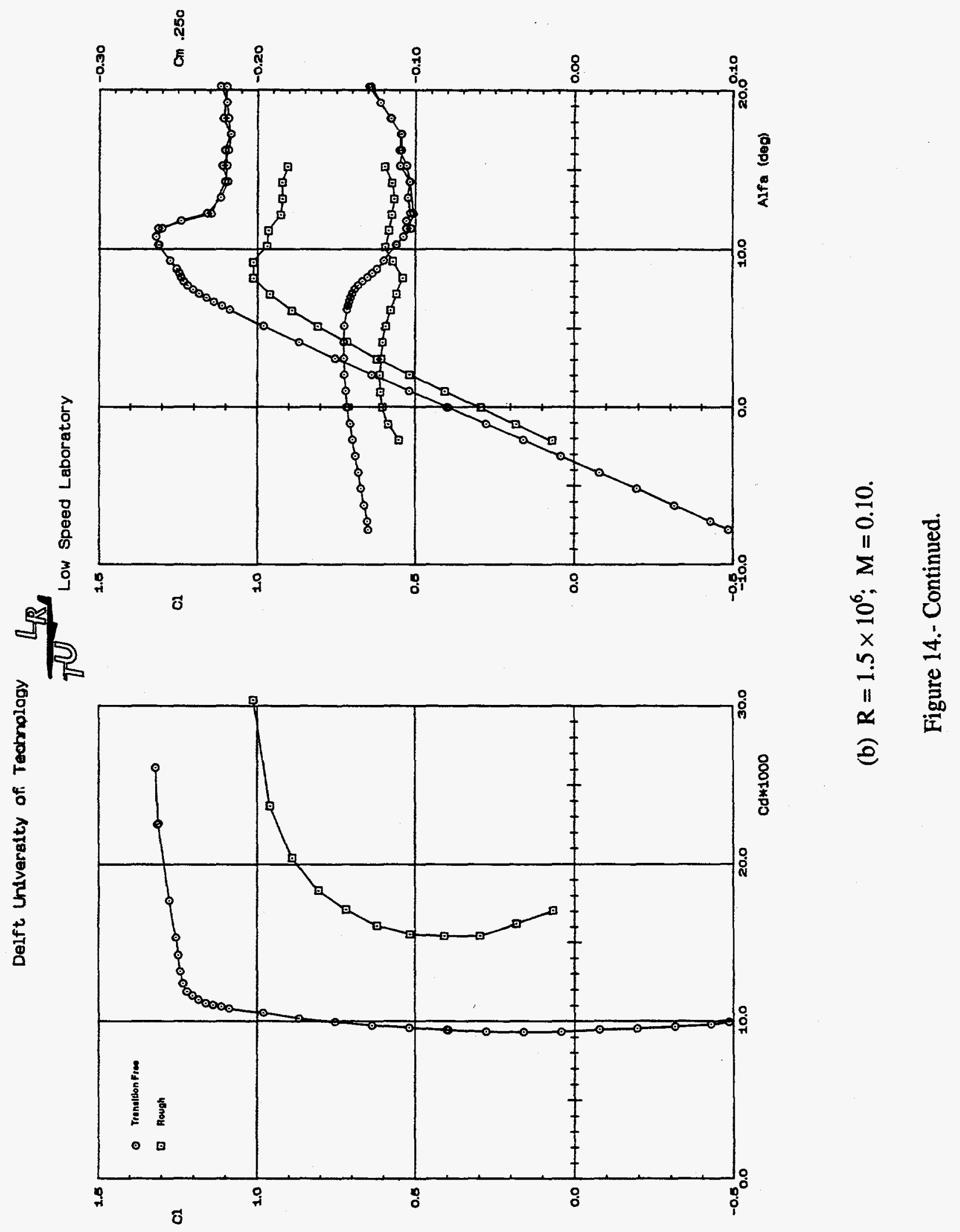




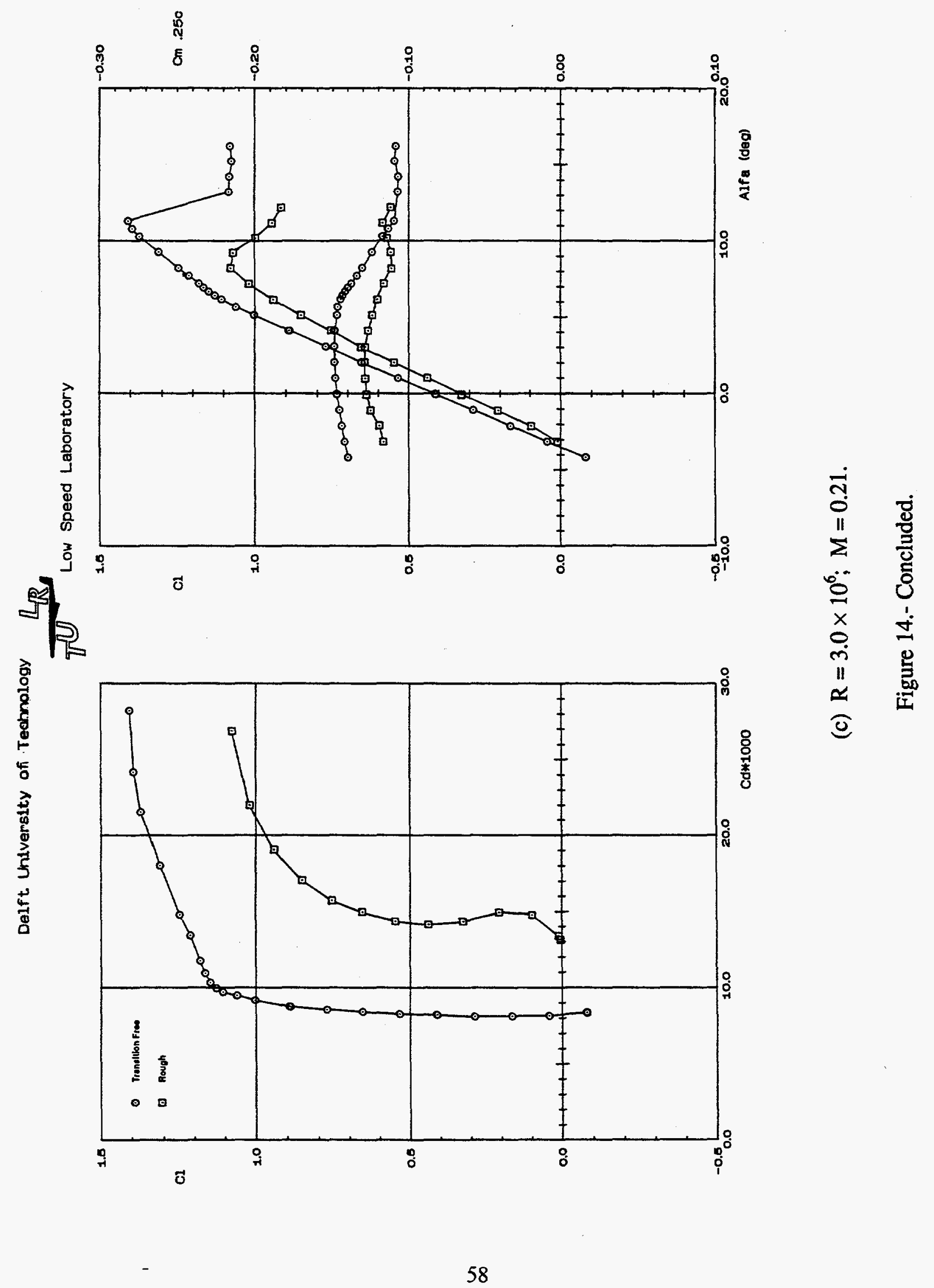




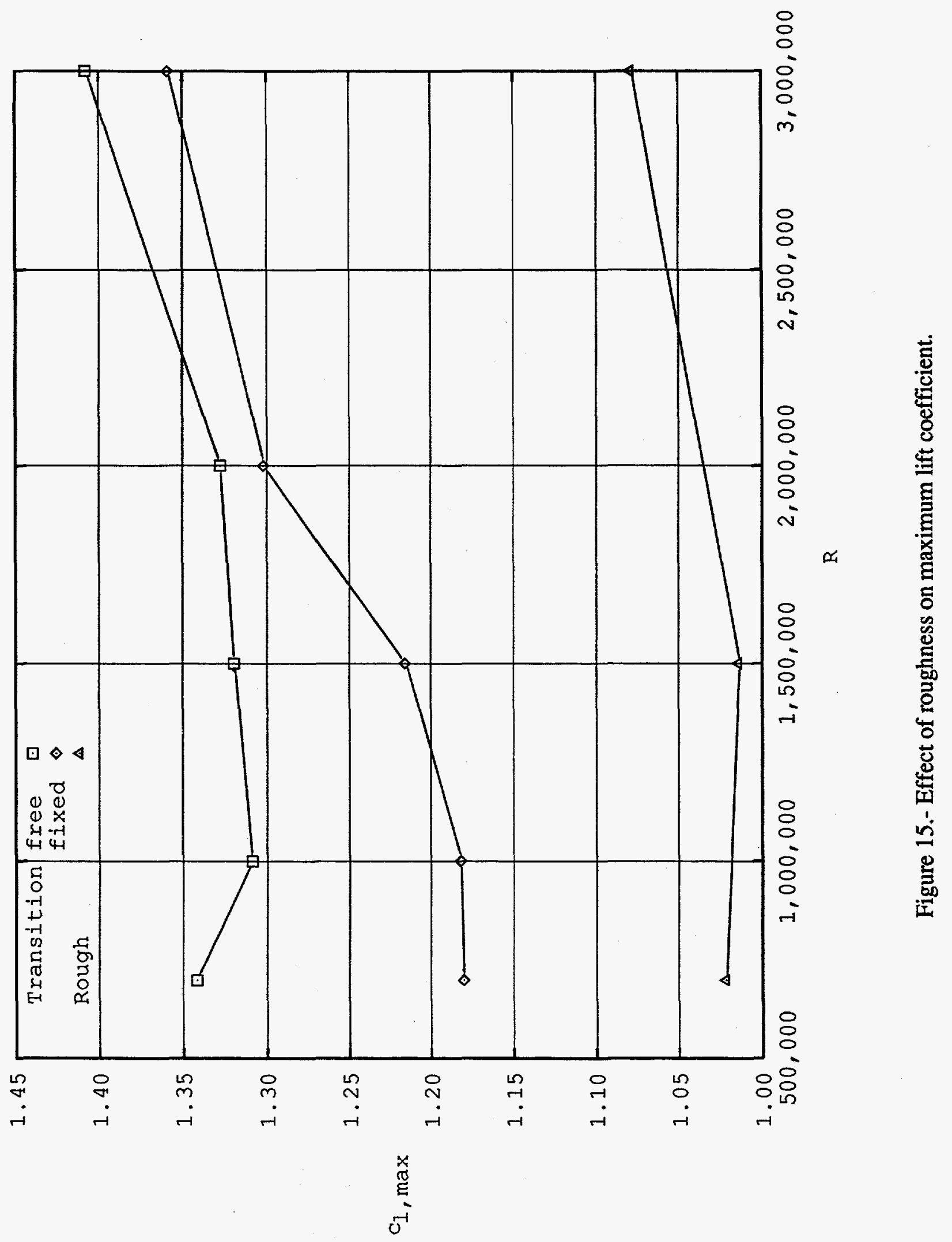




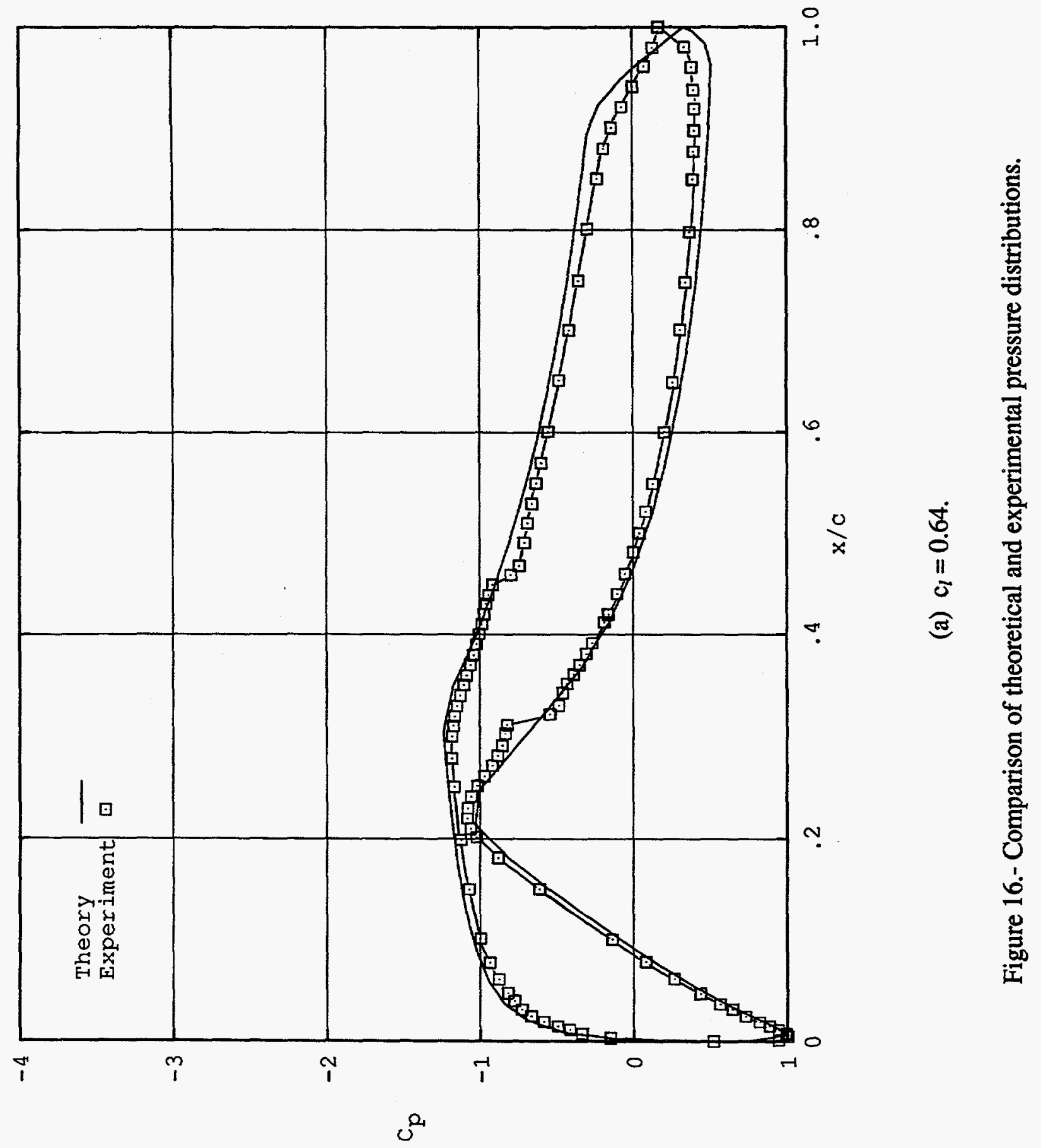




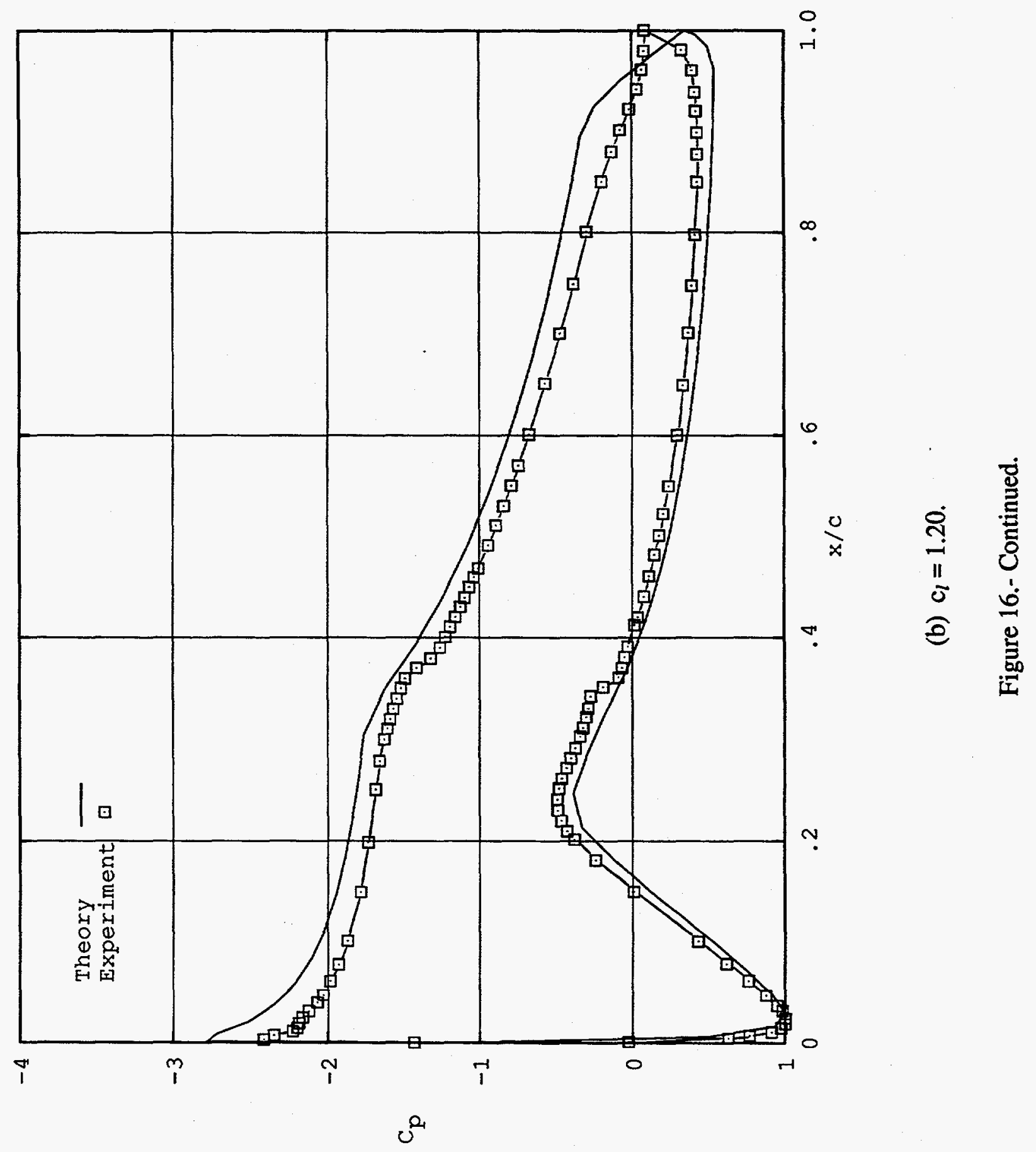




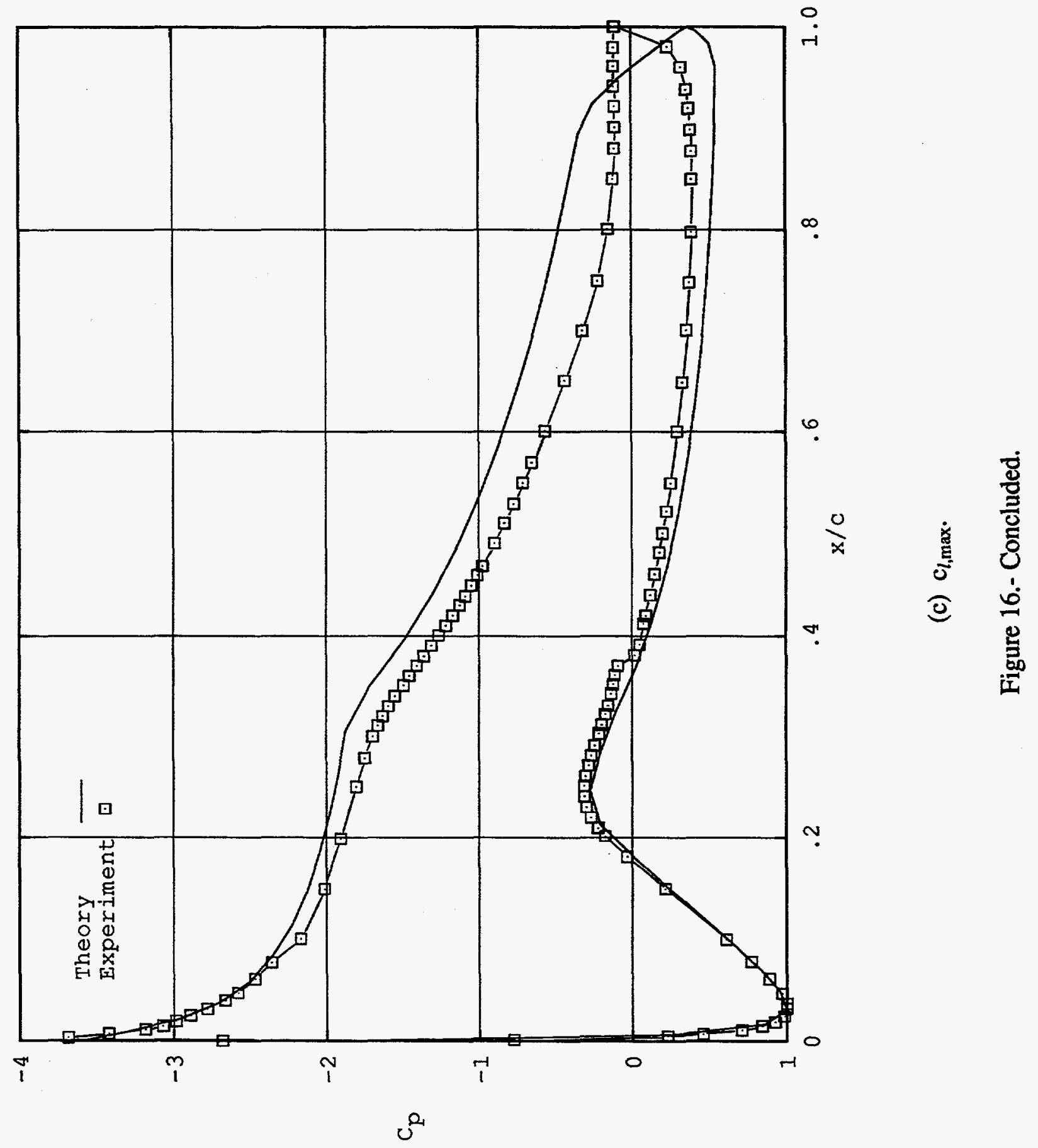


1

요

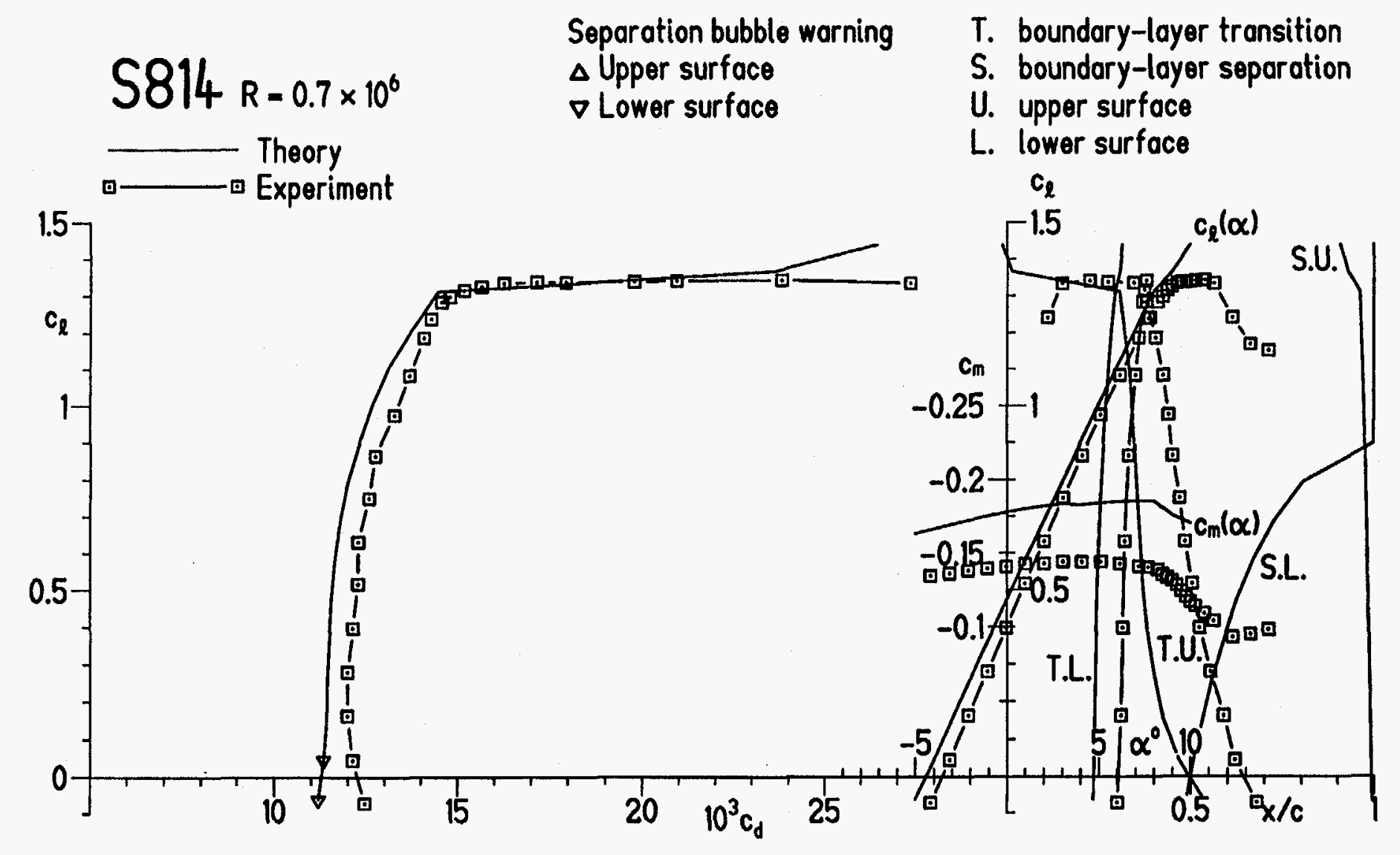

(a) $\mathrm{R}=0.7 \times 10^{6}$.

Figure 17.- Comparison of theoretical and experimental section characteristics with transition free. 


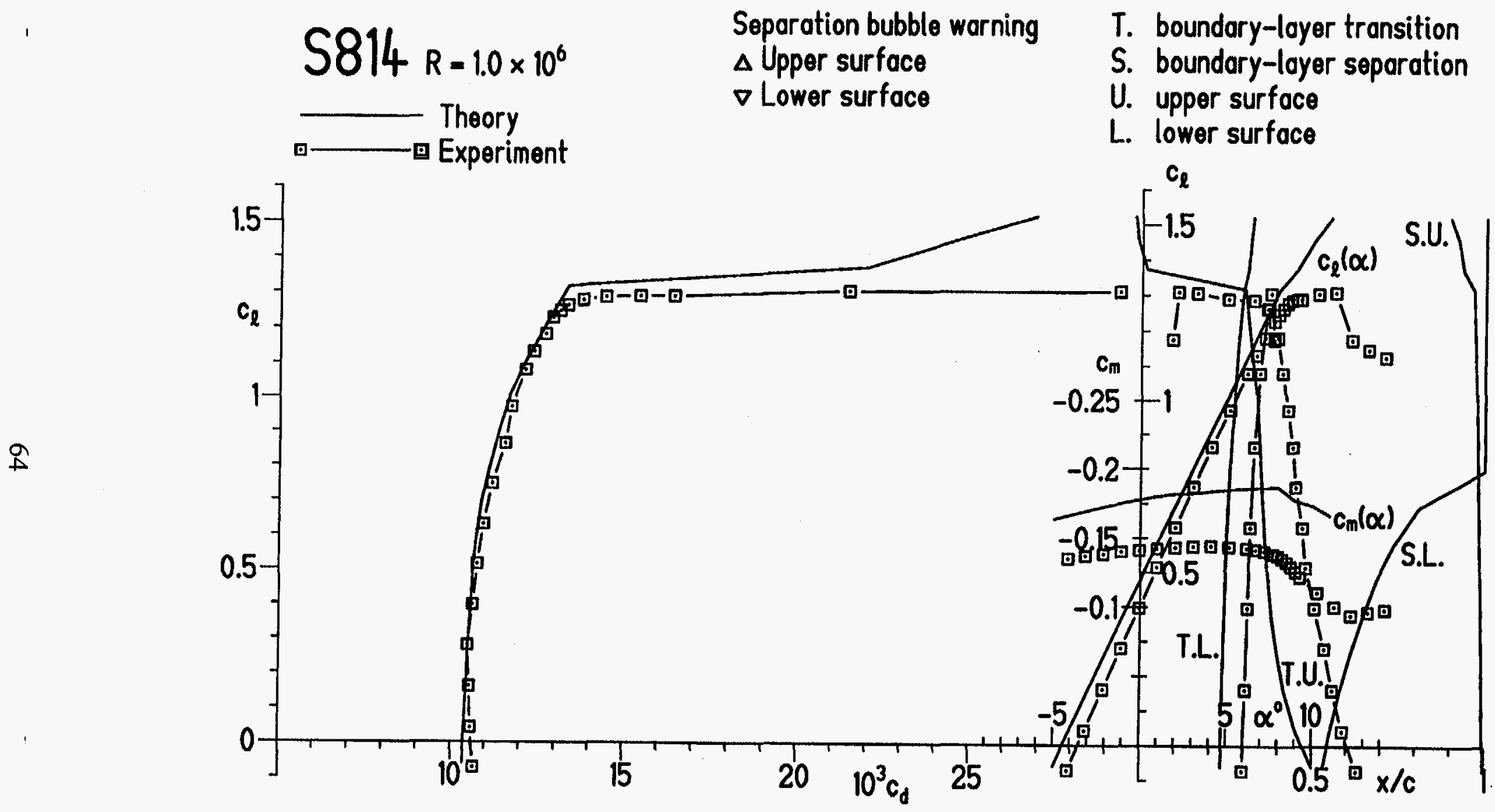

(b) $\mathrm{R}=1.0 \times 10^{6}$

Figure 17.- Continued. 


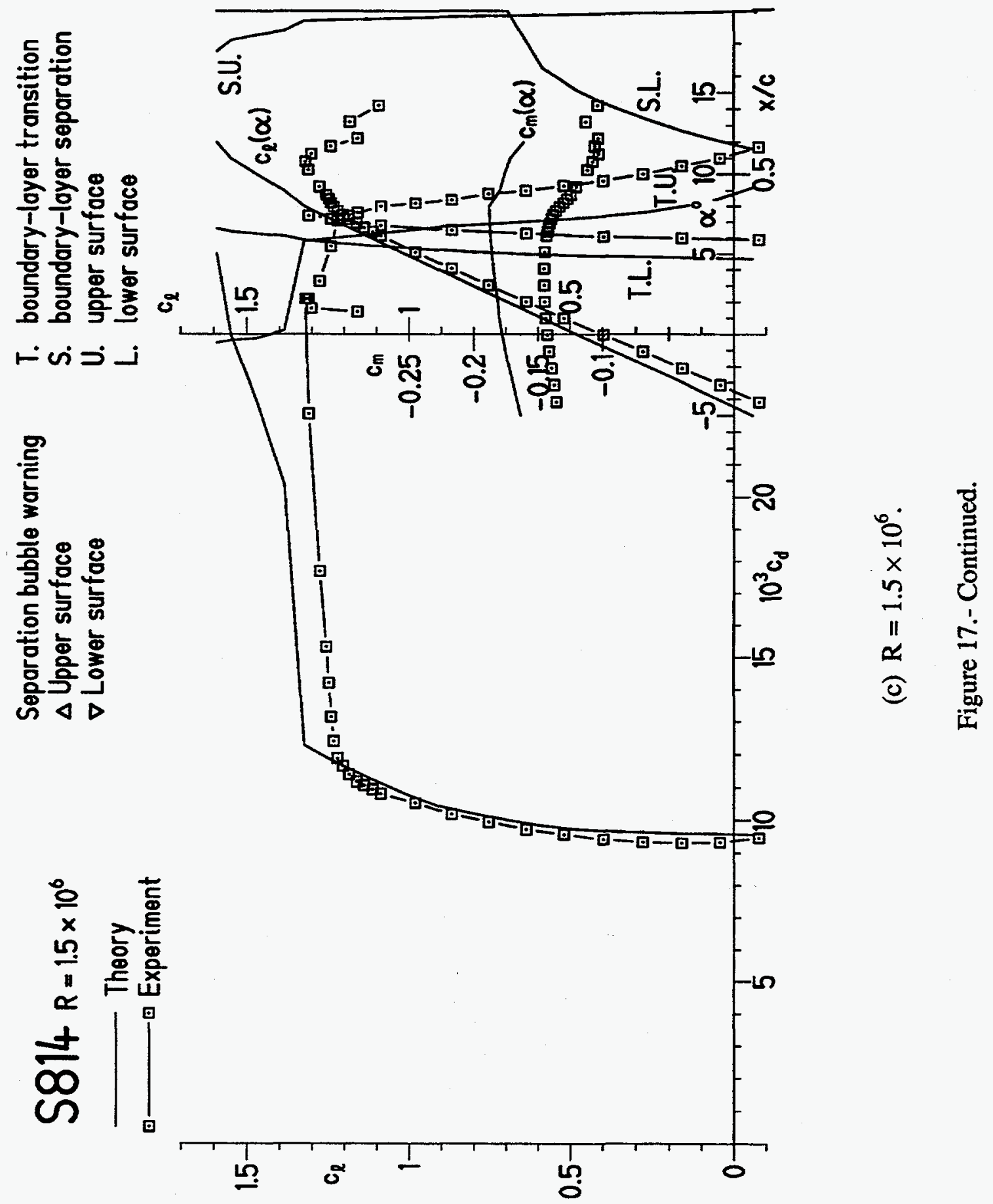




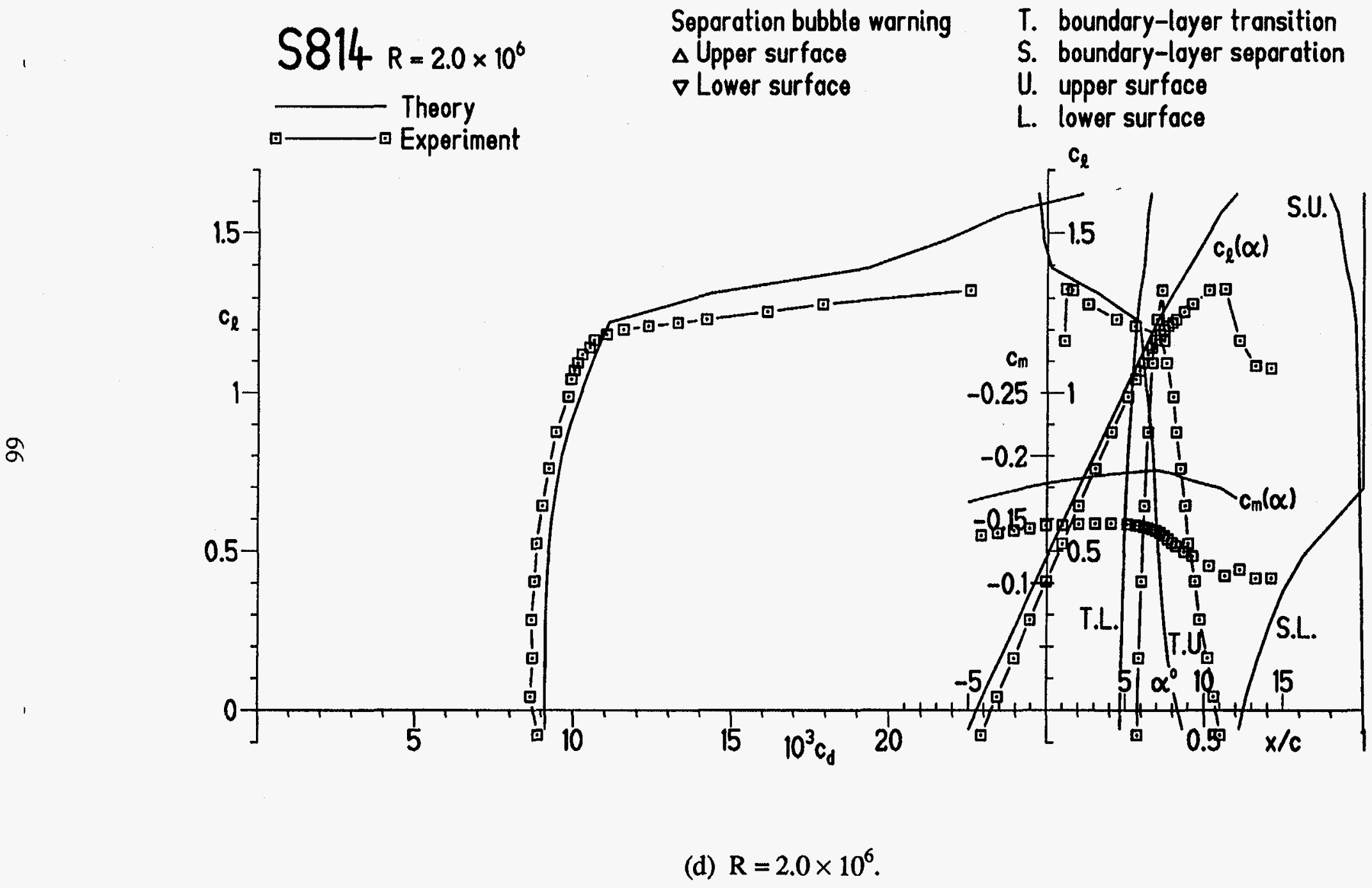

Figure 17.- Continued. 


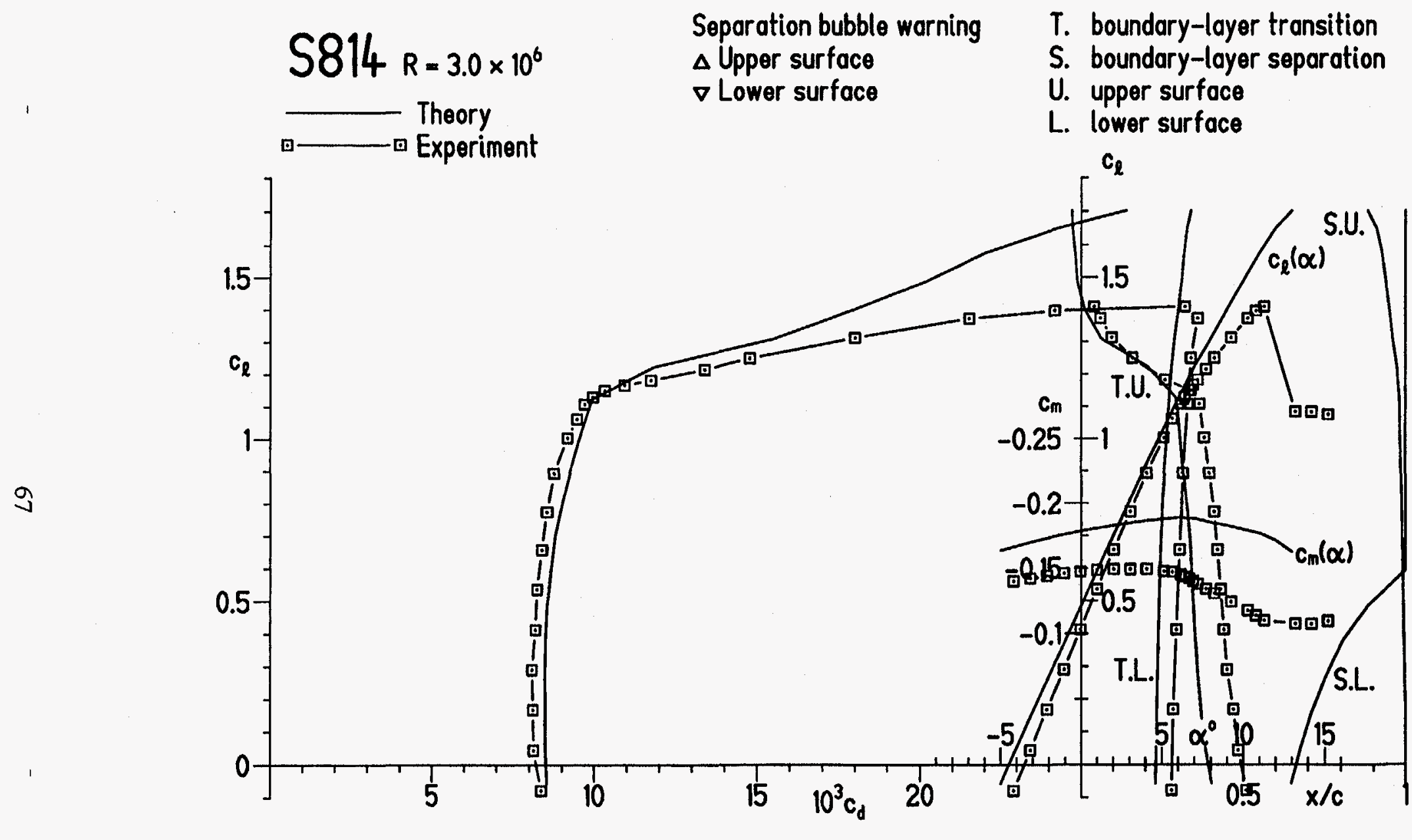

(e) $\mathrm{R}=3.0 \times 10^{6}$.

Figure 17.- Concluded. 


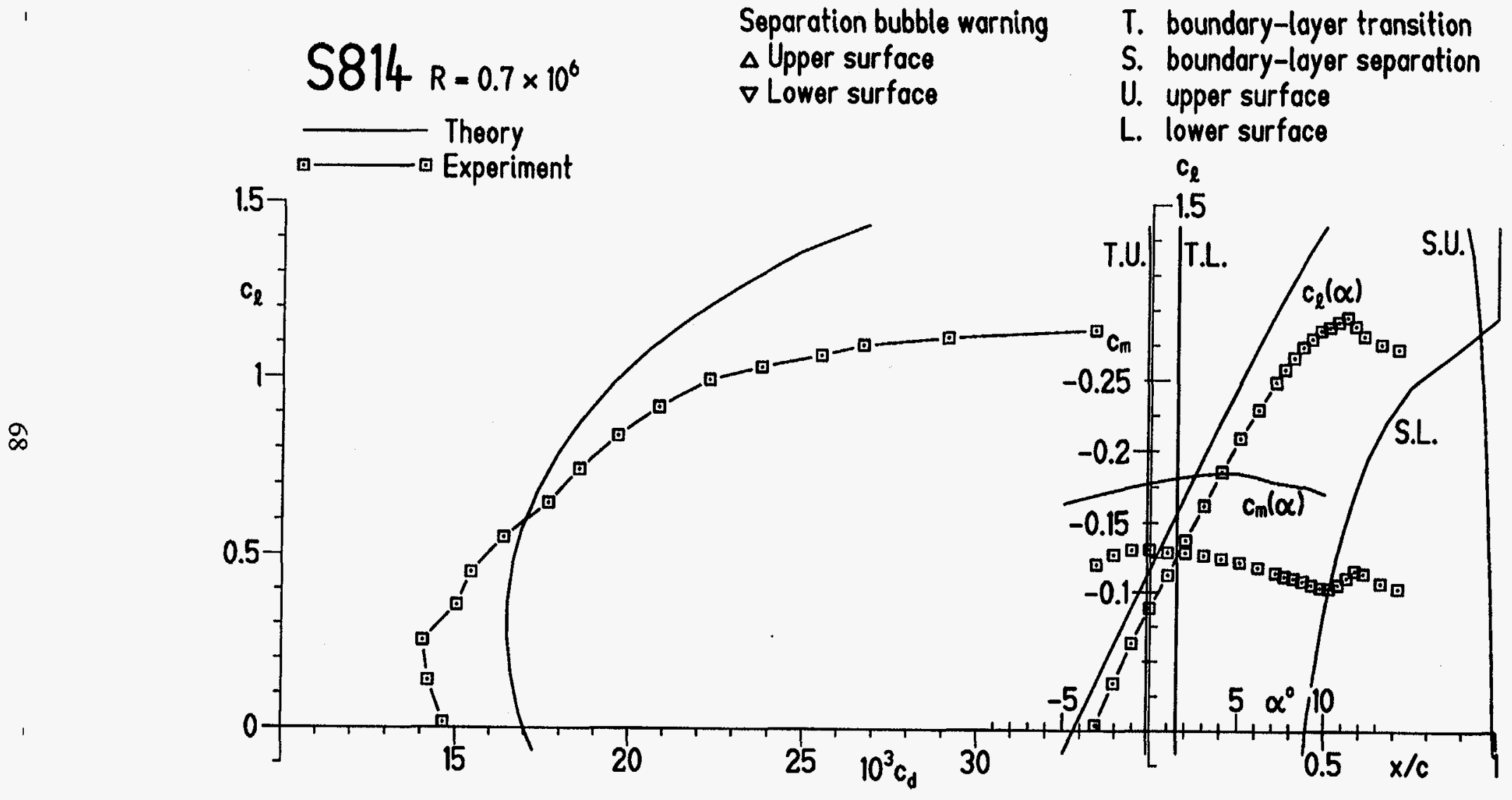

(a) $\mathrm{R}=0.7 \times 10^{6}$.

Figure 18.- Comparison of theoretical and experimental section characteristics with transition fixed. 


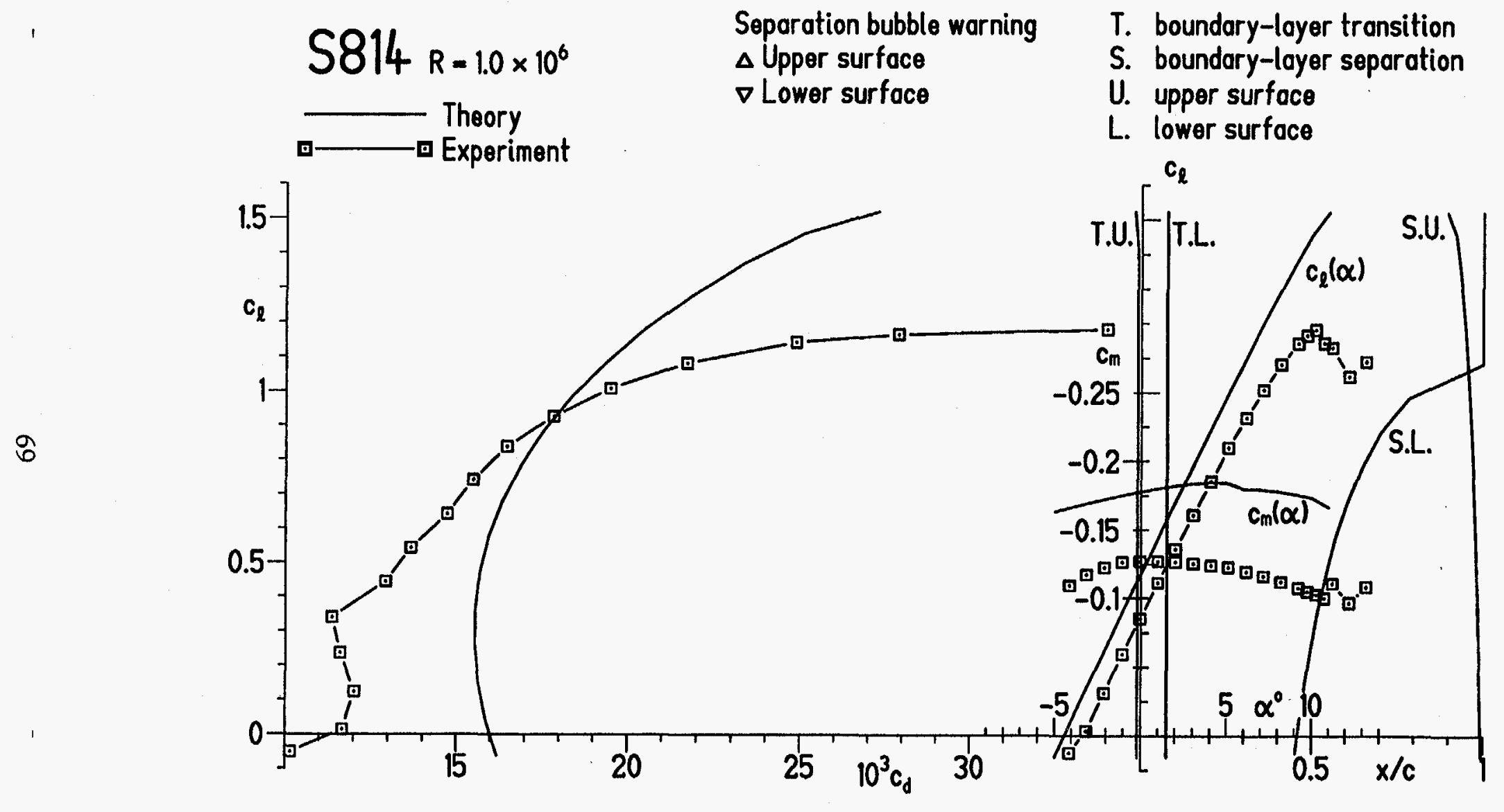

(b) $\mathrm{R}=1.0 \times 10^{6}$.

Figure 18.- Continued. 


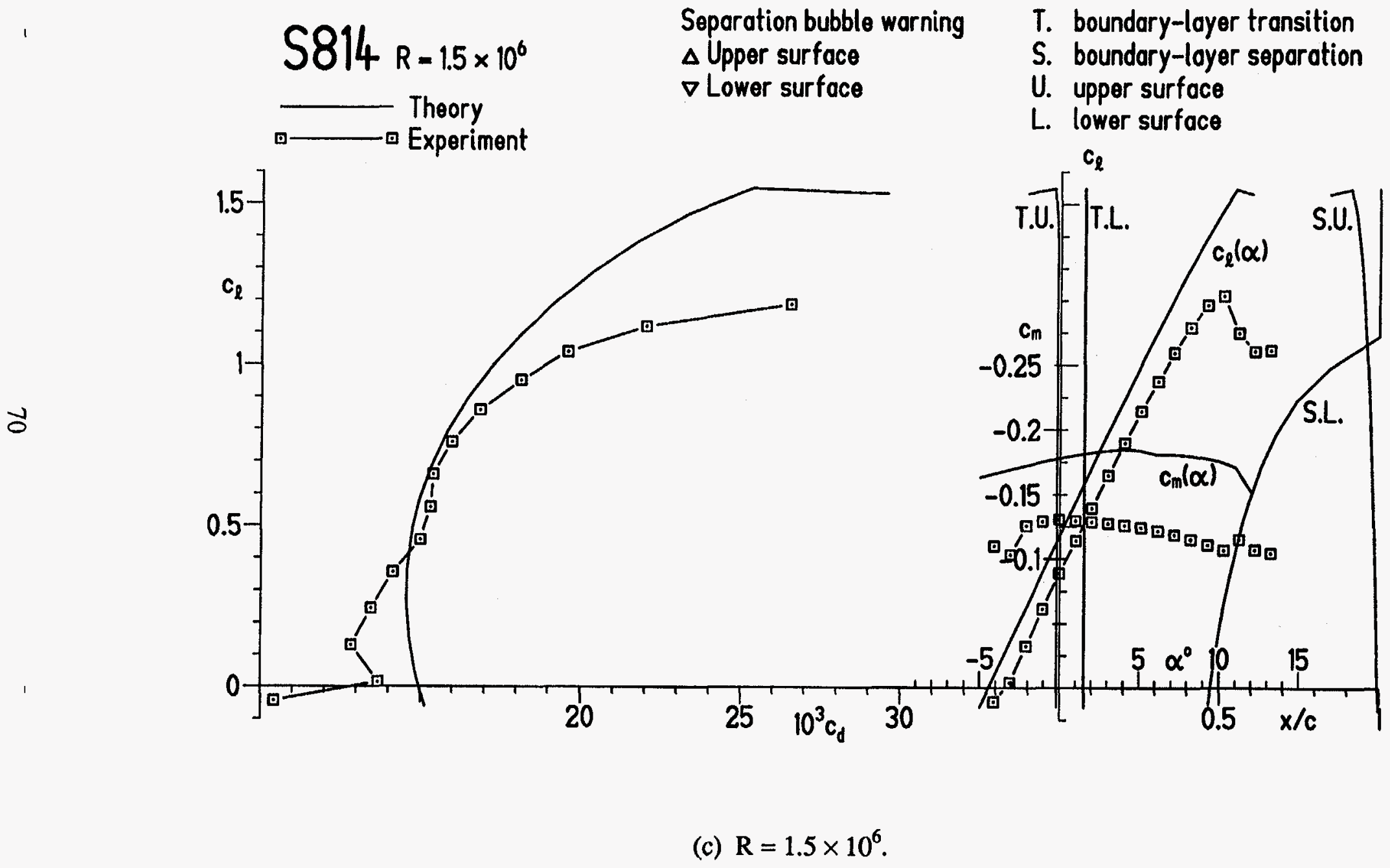

Figure 18.- Continued. 

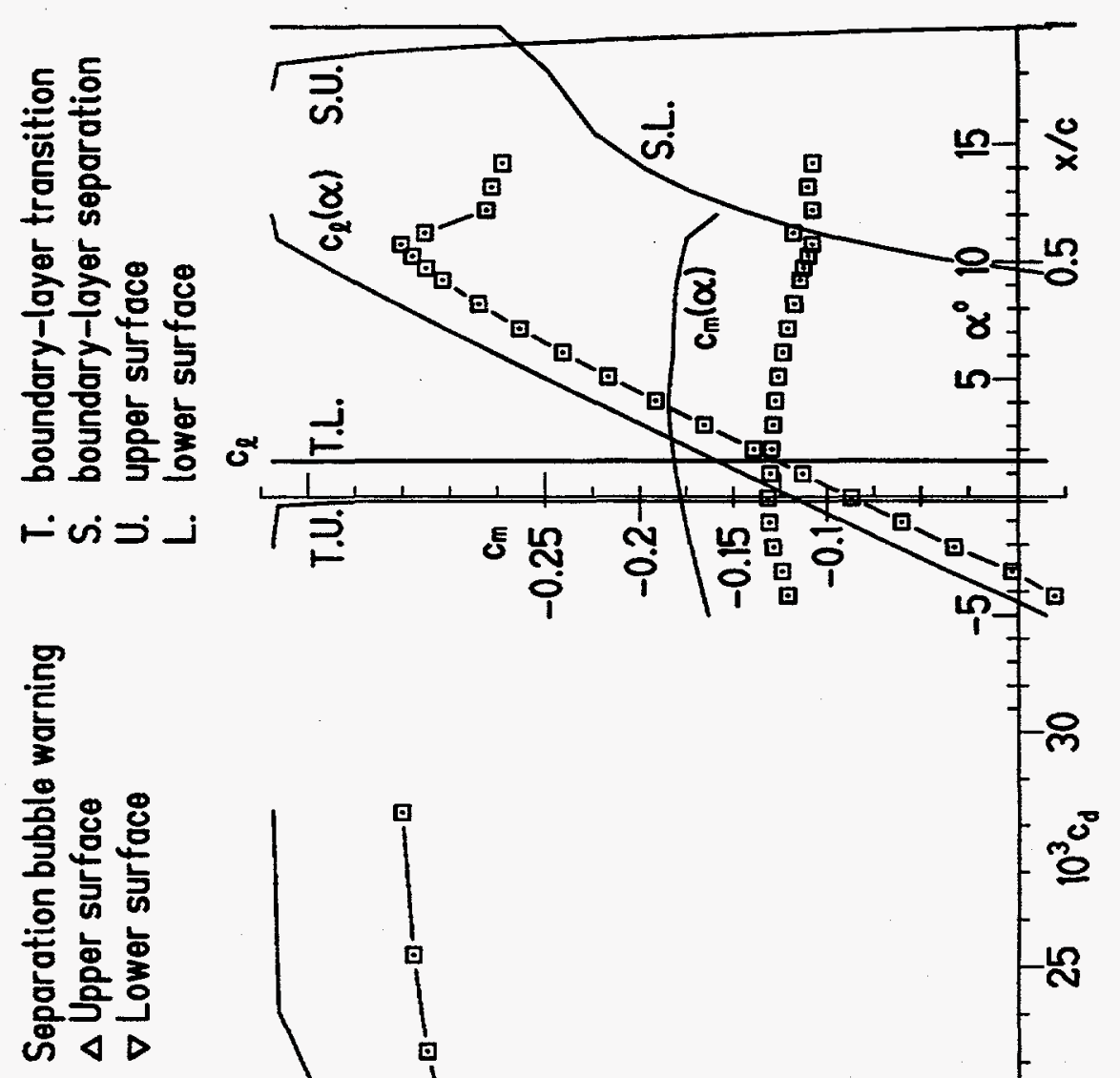
$S 814 R=3.0 \times 10^{6}$

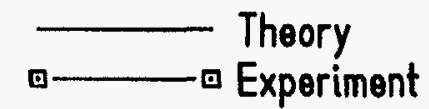

$\vec{N}$
Separation bubble warning

$\triangle$ Upper surface

$\nabla$ Lower surface
T. boundary-layer transition

S. boundary-layer separation

U. upper surface

L. lower surface

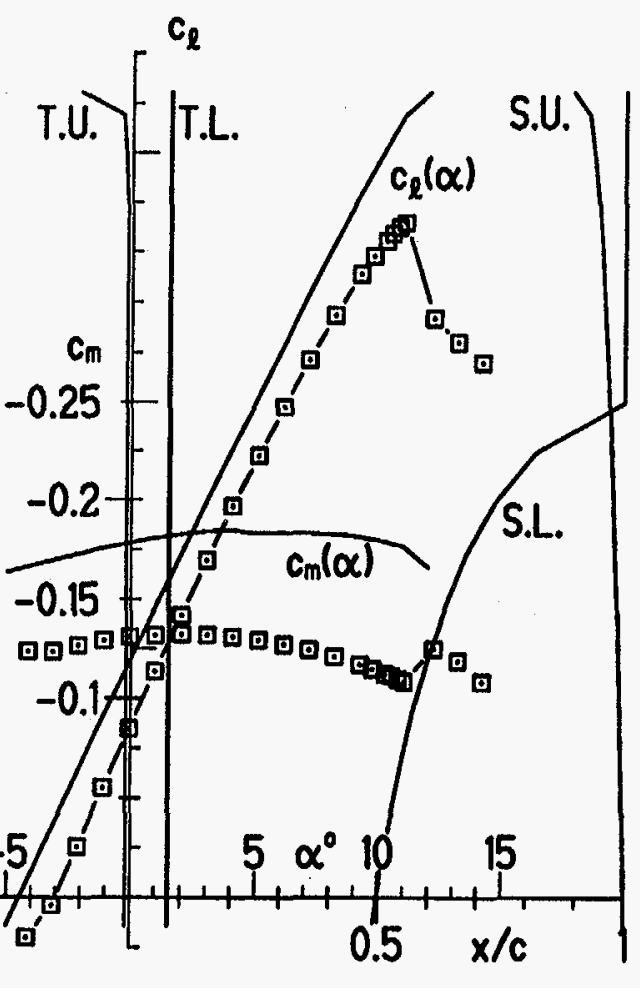

(e) $\mathrm{R}=3.0 \times 10^{6}$.

Figure 18.- Concluded. 


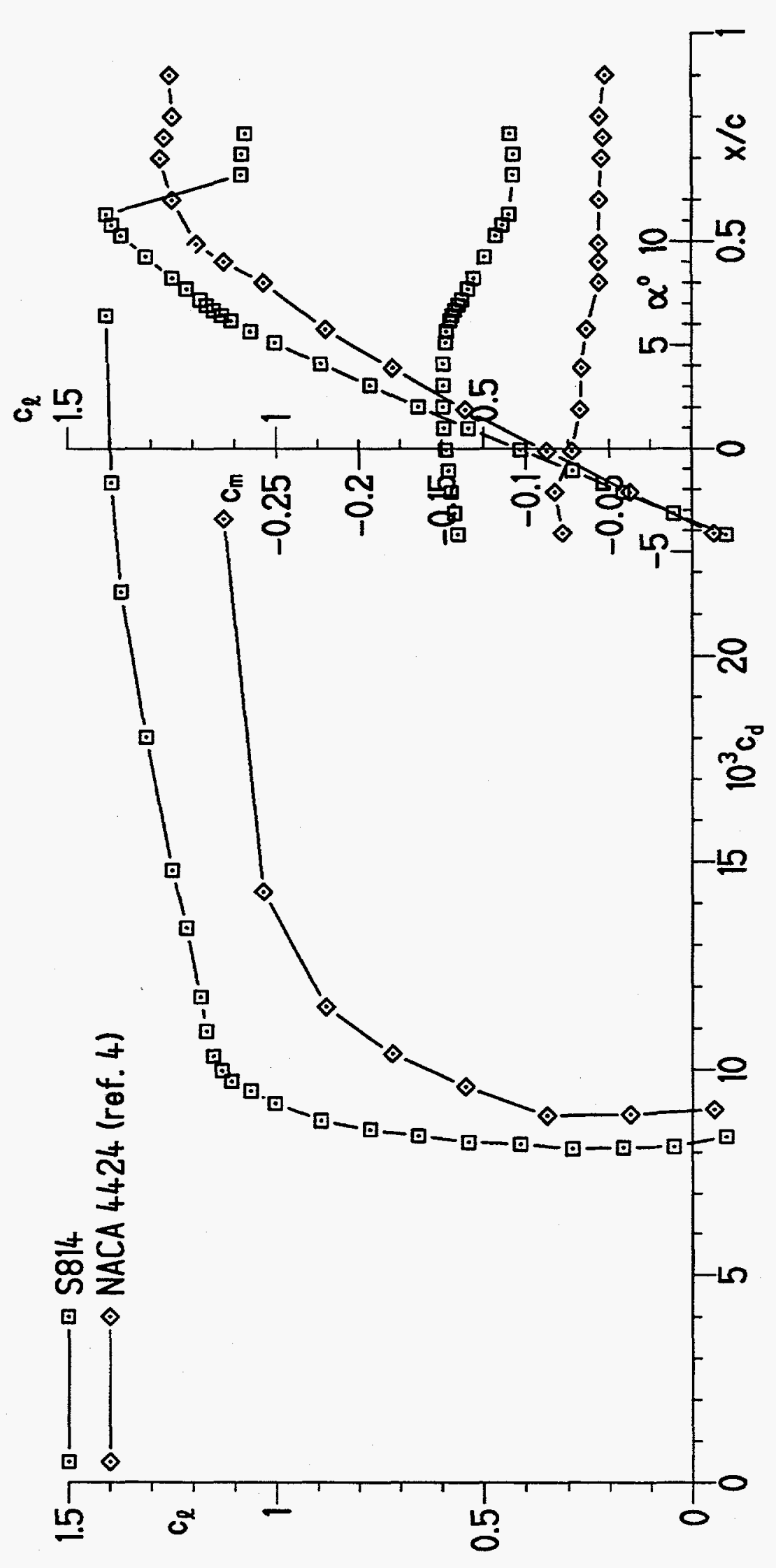

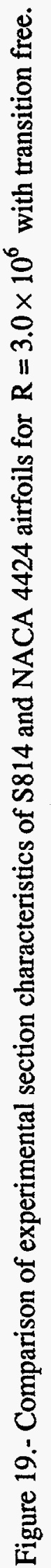




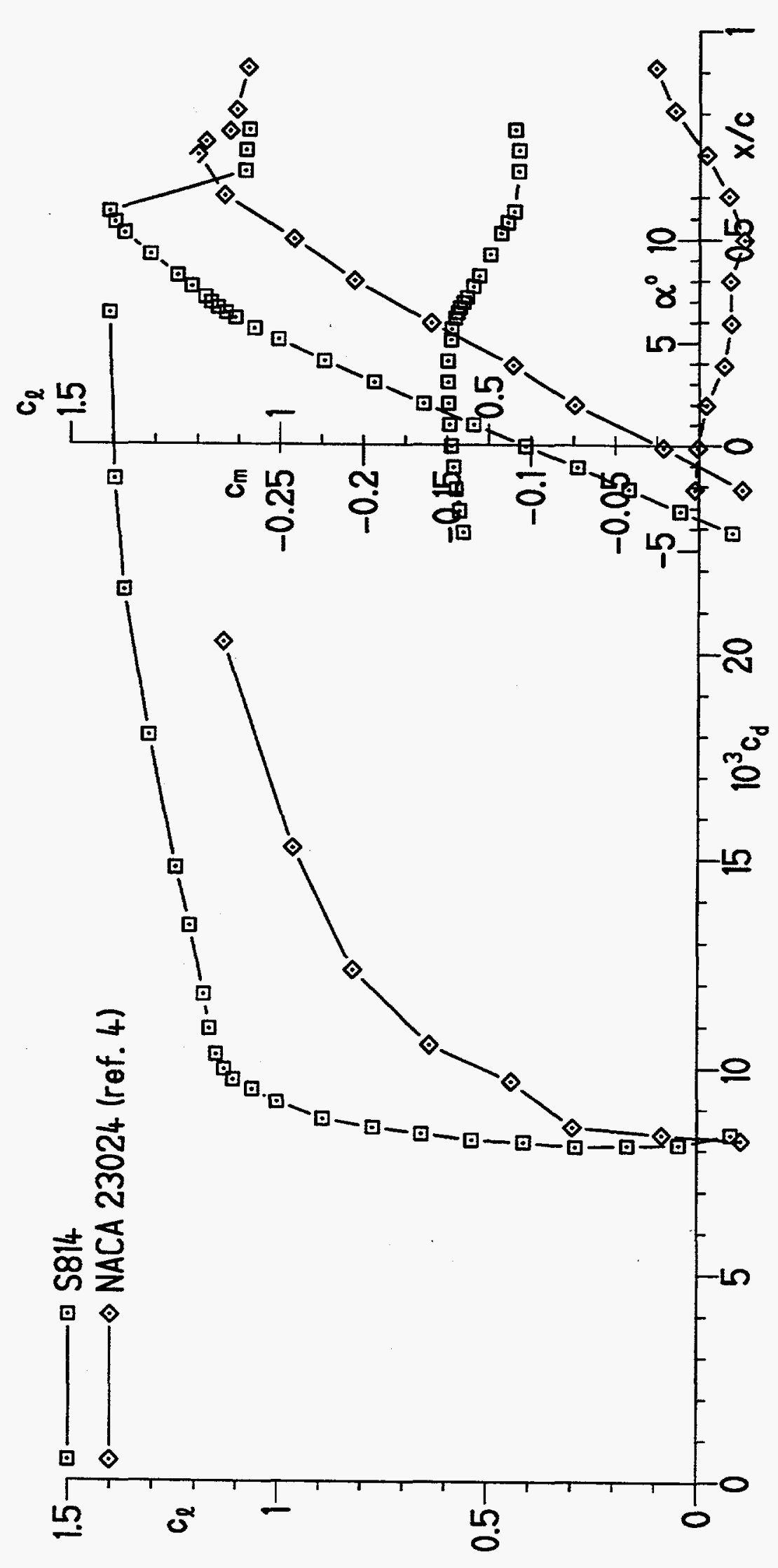

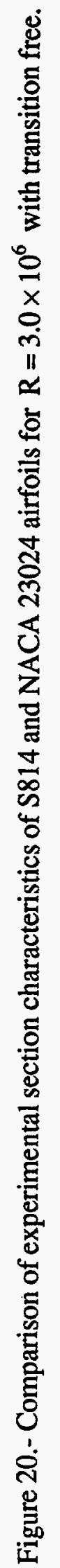




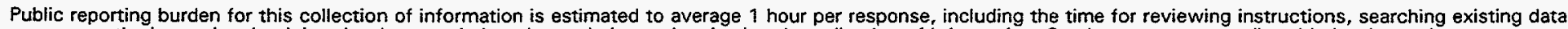

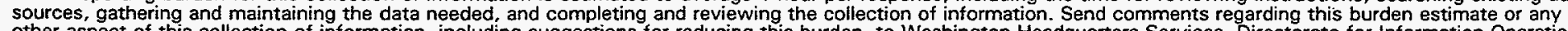

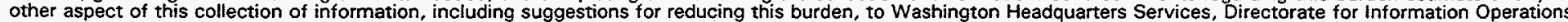

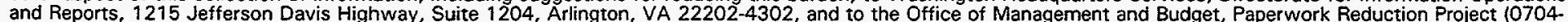
0188), Washington, DC 20503 .

(1)

2. REPORT DATE January 1997
3. REPORT TYPE AND DATES COVERED

Subcontract Report
4. TITLE AND SUBTITLE

Design and Experimental Results for the S814 Airfoil

6. AUTHOR(S)

Dan M. Somers

7. PERFORMING ORGANIZATION NAME(S) AND ADDRESS(ES)

Airfoils, Incorporated

State College, Pennsylvania
5. FUNDING NUMBERS

C: HK-4-04148-01

TA: WE711110

8. PERFORMING ORGANIZATION REPORT NUMBER

\section{SPONSORING/MONITORING AGENCY NAME(S) AND ADDRESS(ES)}

National Renewable Energy Laboratory

1617 Cole Blvd.

Golden, CO 80401-3393
10. SPONSORING/MONITORING AGENCY REPORT NUMBER

SR-440-6919

DE97000104

11. SUPPLEMENTARY NOTES

NREL Technical Monitor: James Tangler

12a. DISTRIBUTION/AVAILABILITY STATEMENT National Technical Information Service

U.S. Department of Commerce

5285 Port Royal Road

Springfield, VA 22161

12b. DISTRIBUTION CODE

UC-1213

\section{ABSTRACT (Maximum 200 words)}

An $24 \%$ thick, airfoil, the S814, for the root region of a horizontal-axis wind turbine blade, has been designed and analyzed theoretically and verified experimentally in the low-turbulence wind tunnel of the Delft University of Technology Low Speed Laboratory, The Netherlands. The two primary objectives of restrained maximum lift, insensitive to roughness, and low profile drag have been achieved. The constraints on the pitching moment and the airfoil thickness have been satisfied. Comparisons of the theoretical and experimental results show good agreement with the exception of maximum lift which is overpredicted. Comparisons with other airfoils illustrate the restrained maximum lift and lower profile-drag of the S814 airfoil, thus confirming the achievement of the objectives.

14. SUBJECT TERMS

horizontal-axis wind-turbine airfoil

15. NUMBER OF PAGES

16. PRICE CODE

18. SECURITY CLASSIFICATION OF THIS PAGE

Unclassified
19. SECURITY CLASSIFICATION OF ABSTRACT Unclassified
OF REPORT

Unclassified
20. LIMITATION OF ABSTRACT

UL

Standard Form 298 (Rev. 2-89) Prescribed by ANSI Std. Z39-18

NSN 7540-01-280-5500 